NUREG/CR-6144

BNL-NUREG-52399

Vol. 6, Part 1

Evaluation of Potential

Severe Accidents During

Low Power and Shutdown

Operations at Surry, Unit 1

Evaluation of Severe Accident Risk During

Mid-Loop Operations

\title{
Main Report
}

Manuscript Completed: October 1994

Date Published: May 1995

Prepared by

J. Jo, C. C. Lin, L. Neymotin, V. Mubayi

Brookhaven National Laboratory

Upton, NY 11973

Prepared for

Division of Systems Technology

Office of Nuclear Regulatory Research

U.S. Nuclear Regulatory Commission

Washington, DC 20555-0001

NRC Job Code L1680 



\section{DISCLAIMER}

This report was prepared as an account of work sponsored by an agency of the United States Government. Neither the United States Government nor any agency thereof, nor any of their employees, make any warranty, express or implied, or assumes any legal liability or responsibility for the accuracy, completeness, or usefuiness of any information, apparatus, product, or process disclosed, or represents that its use would not infringe privately owned rights. Reference herein to any specific commercial product, process, or service by trade name, trademark, manufacturer, or otherwise does not necessarily constitute or imply its endorsement, recommendation, or favoring by the United States Government or any agency thereof. The views and opinions of authors expressed herein do not necessarily state or reflect those of the United States Government or any agency thereof. 


\section{DISCLAIMER}

Portions of this document may be illegible in electronic image products. Images are produced from the best available original document. 


\begin{abstract}
Traditionally, probabilistic risk assessments (PRA) of severe accidents in nuclear power plants have considered initiating events potentially occurring only during full power operation. Some previous screening analysis that were performed for other modes of operation suggested that risks during those modes were small relative to full power operation. However, more recent studies and operational experience have implied that accidents during low power and shutdown could be significant contributors to risk.
\end{abstract}

During 1989, the Nuclear Regulatory Commission (NRC) initiated an extensive program to carefully examine the potential risks during low power and shutdown operations. The program includes two parallel projects being performed by Brookhaven National Laboratory (BNL) and Sandia National Laboratories (SNL). Two plants, Surry (pressurized water reactor) and Grand Gulf (boiling water reactor), were selected as the plants to be studied.

The objectives of the program are to assess the risks of severe accidents initiated during plant operational states other than full power operation and to compare the estimated core damage frequencies, important accident sequences and other qualitative and quantitative results with those accidents initiated during full power operation as assessed in NUREG-1150. The scope of the program includes that of a level-3 PRA.

A phased approach was used in the level-1 program. In phase 1 which was completed in Fall 1991, a coarse screening analysis including internal fire and flood was performed for all plant operational states (POSs). The objective of the phase 1 study was to identify potential vulnerable plant configurations, to characterize (on a high, medium, or low basis) the potential core damage accident scenarios, and to provide a foundation for a detailed phase 2 analysis.

In phase 2, mid-loop operation was selected as the plant configuration to be analyzed based on the results of the phase 1 study. The objective of the phase 2 study is to perform a detailed analysis of the potential accident scenarios that may occur during mid-loop operation, and compare the results with those of NUREG1150. Volume 1 summarizes the results of the study. The scope of the level-1 study includes plant damage state analyses, and uncertainty analysis. The internal event analysis is documented in Volume 2. The internal fire and internal flood analysis are documented in Volumes 3 and 4, respectively. A separate study on seismic analysis, documented in Volume 5, was performed for the NRC by Future Resources Associated, Inc.

A phased approach was also used in the level $2 / 3$ program however both phases addressed the risk from only mid-loop operation. The first phase of the level 2/3 PRA was initiated in late 1991 and consisted of an Abridged Risk Study. This study was completed in May 1992 and was focused on accident progression and consequences, conditional on core damage. Phase 2 is a more detailed study in which an evaluation of risk during mid-loop operation was performed. The results of the phase 2 level $2 / 3$ study are the subject of this volume of NUREG/CR-6144, Volume 6.

The offsite risk estimates for latent health effects of accidents during mid-loop operation were similar to the risk estimates for full power operation. The early health consequences are much lower than the full power results primarily due to the long time after shutdown when the accidents occur in mid-loop operation (i.e., because of the natural decay of the short-lived isotopes of iodine and tellurium, which are primarily associated with early health effects). The uncertainties in risk for accidents during mid-loop operating are largely due to uncertainties associated with isolating the containment and achieving a pressure retaining capability.

Vol. 6, Part 1

- iii -

NUREG/CR-6144 



\section{CONTENTS}

Section

Page

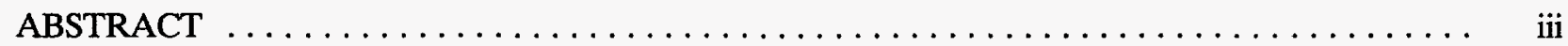

EXECUTIVE SUMMARY $\ldots \ldots \ldots \ldots \ldots \ldots \ldots \ldots \ldots \ldots \ldots \ldots \ldots \ldots \ldots \ldots \ldots \ldots \ldots$

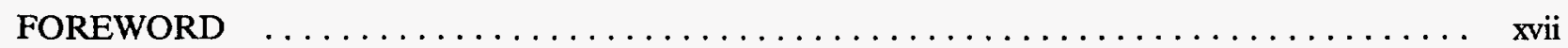

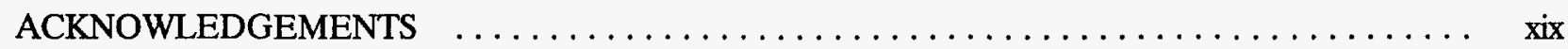

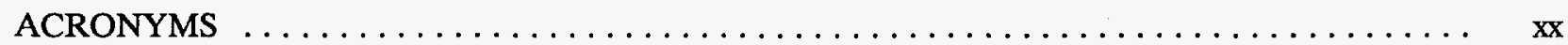

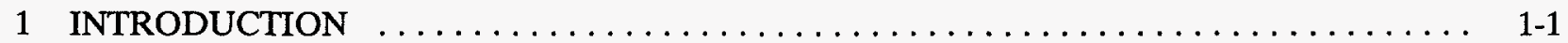

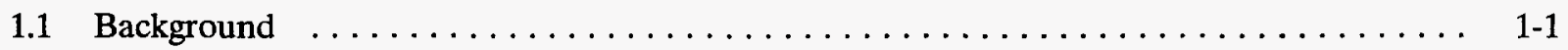

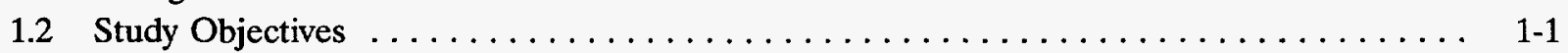

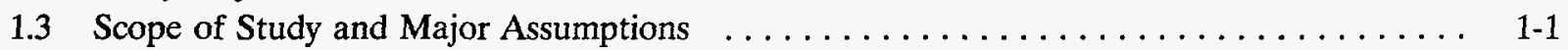

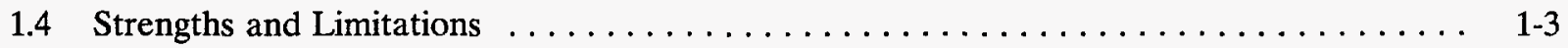

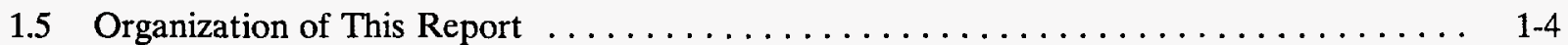

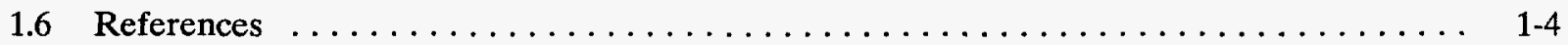

2 SUMMARY OF ABRIDGED STUDY ON RISK DURING MID-LOOP OPERATION . . . . $2-1$

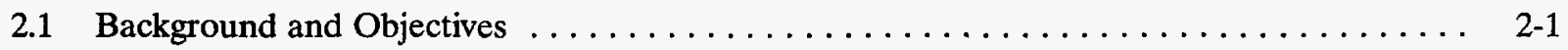

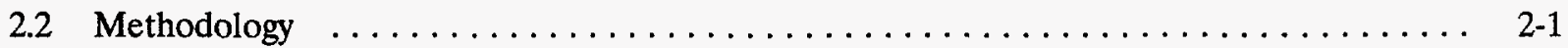

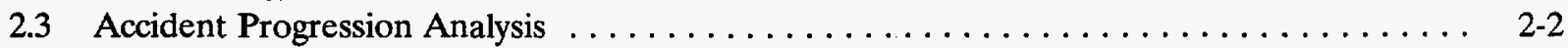

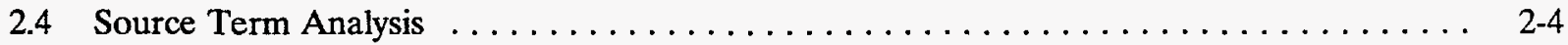

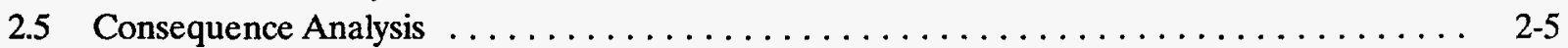

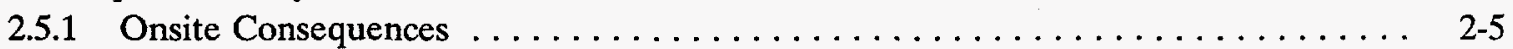

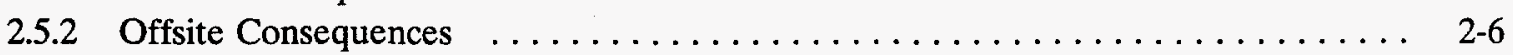

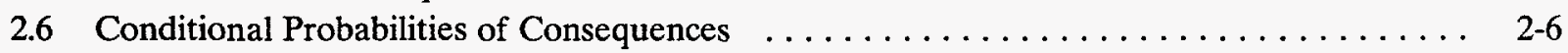

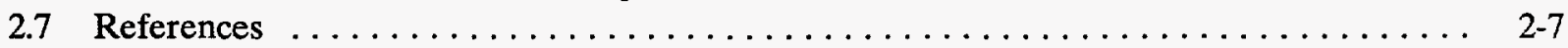

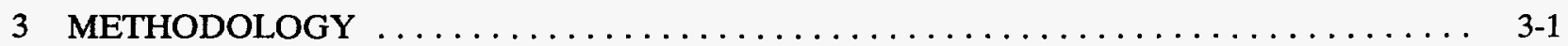

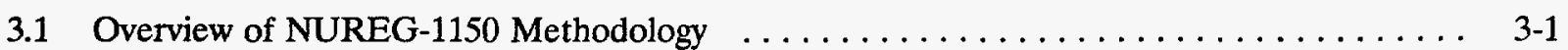

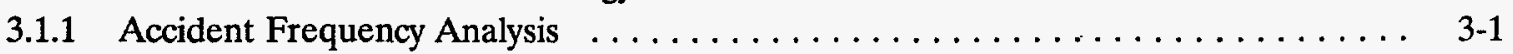

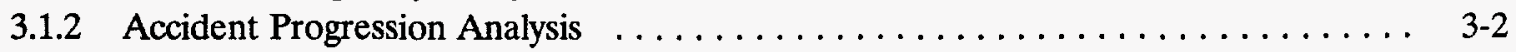

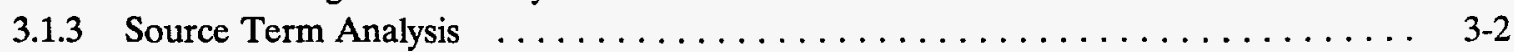

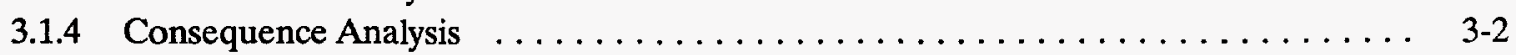

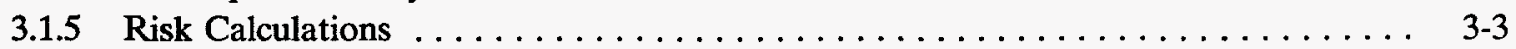

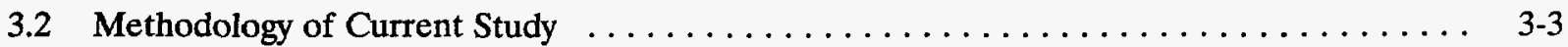

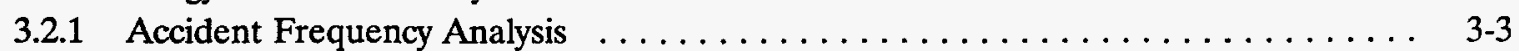

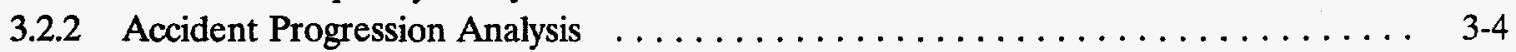

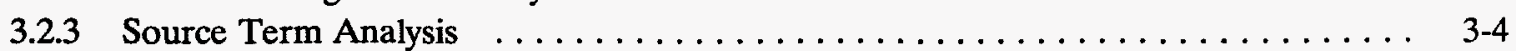

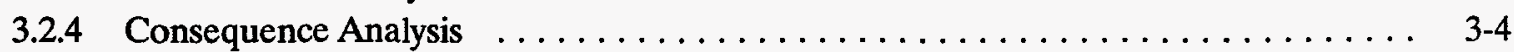

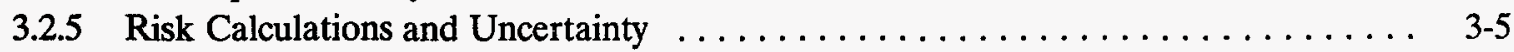

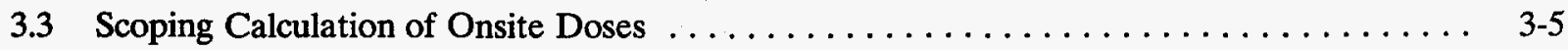

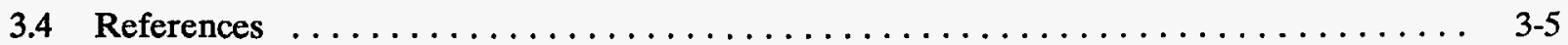




\section{CONTENTS (continued)}

Section

Page

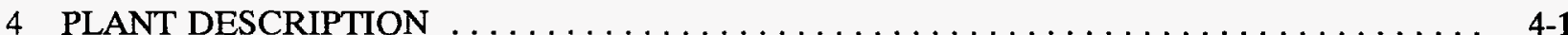

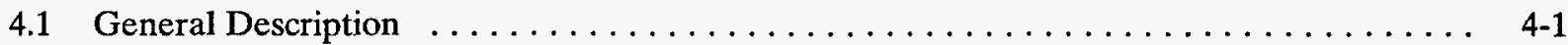

4.2 Plant and System Configuration During Mid-Loop Operation $\ldots \ldots \ldots \ldots \ldots \ldots \ldots \ldots$ 4-2

4.2.1 Status of the Reactor Coolant System $\ldots \ldots \ldots \ldots \ldots \ldots \ldots \ldots \ldots \ldots . \ldots \ldots$. $\ldots \ldots \ldots$

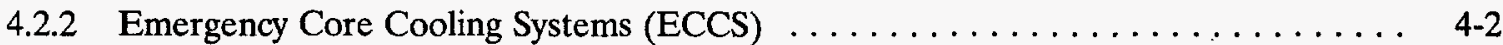

4.2.2.1 High Pressure Injection/Recirculation System $\ldots \ldots \ldots \ldots \ldots \ldots \ldots$. . . . . . . .

4.2.2.2 Low Pressure Injection//Recirculation System $\ldots \ldots \ldots \ldots \ldots \ldots$. . . . . . . .

4.2.3 Containment Configuration During Mid-Loop Operation $\ldots \ldots \ldots \ldots \ldots \ldots \ldots$ 4-4

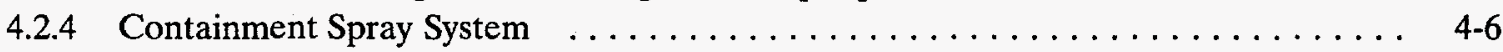

4.2.4.1 Containment Spray Injection System $\ldots \ldots \ldots \ldots \ldots \ldots \ldots \ldots$ 4-6

4.2.4.2 CSS Configuration During Mid-Loop Operation $\ldots \ldots \ldots \ldots \ldots \ldots .4 .6 \ldots$

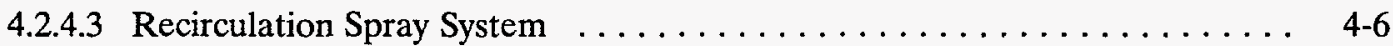

4.2.4.4 Recirculation Spray System Configuration During Mid-Loop Operation . . . 4-7

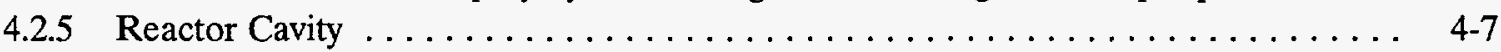

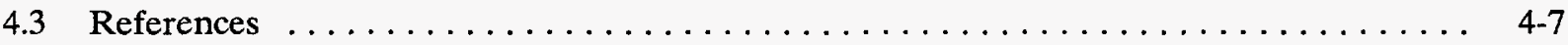

5 ACCIDENT FREQUENCY ANALYSIS INTERFACE $\ldots \ldots \ldots \ldots \ldots \ldots \ldots \ldots \ldots \ldots$

5.1 Summary of Level 1 Core Damage Accidents $\ldots \ldots \ldots \ldots \ldots \ldots \ldots \ldots \ldots \ldots \ldots . \ldots \ldots \ldots$

5.1.1 Definition of Plant Outage Types and Operational States $\ldots \ldots \ldots \ldots \ldots \ldots \ldots$ 5-1

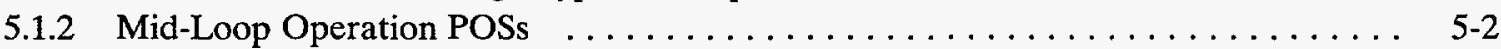

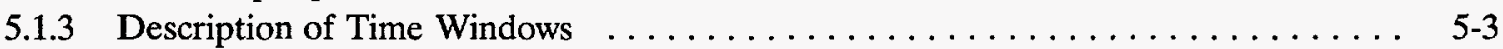

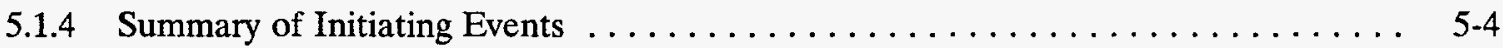

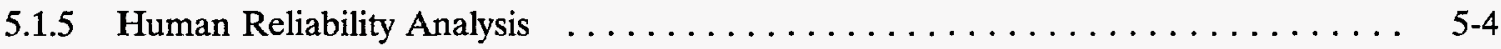

5.1.6 Accident Sequence Quantification and Results $\ldots \ldots \ldots \ldots \ldots \ldots \ldots \ldots \ldots \ldots$

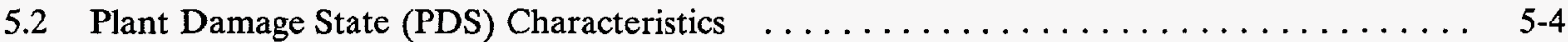

5.3 Plant Damage State (PDS) Results $\ldots \ldots \ldots \ldots \ldots \ldots \ldots \ldots \ldots \ldots \ldots \ldots \ldots \ldots$

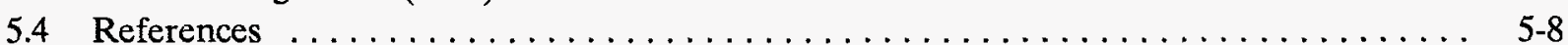

6 ANALYSIS OF THE ACCIDENT PROGRESSION $\ldots \ldots \ldots \ldots \ldots \ldots \ldots \ldots \ldots \ldots \ldots$

6.1 Description of the Accident Progression Event Tree $\ldots \ldots \ldots \ldots \ldots \ldots \ldots \ldots \ldots \ldots$. $\ldots \ldots \ldots$

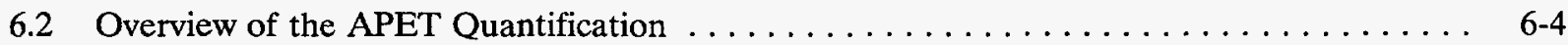

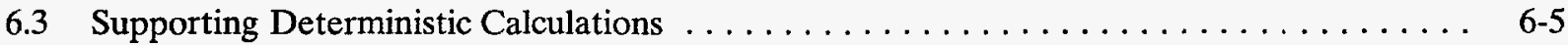

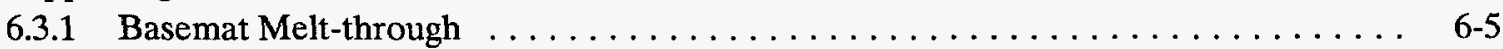

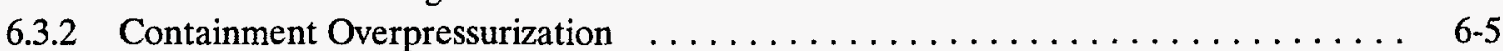

6.4 Description of the Accident Progression Bins $\ldots \ldots \ldots \ldots \ldots \ldots \ldots \ldots \ldots \ldots \ldots \ldots$

6.5 Results of the Accident Progression Analysis $\ldots \ldots \ldots \ldots \ldots \ldots \ldots \ldots \ldots \ldots \ldots$ 6.7

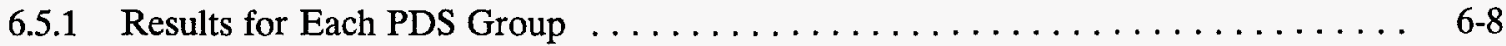

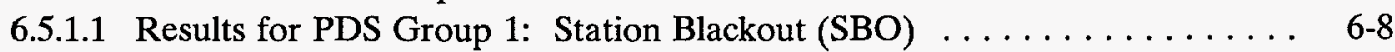

6.5.1.2 Results for PDS Group 2: Human Errors (HX) . . . . . . . . . . 6 6-8

6.5.1.3 Results for PDS Group 3: Recirculation Failure $\ldots \ldots \ldots \ldots \ldots \ldots$. $6-9$

6.5.1.4 Results for PDS Group 4: Loss of $4 \mathrm{kV}$ Bus ............... 6-9 


\section{CONTENTS (continued)}

Section

Page

6.5.2 Core Damage Arrest and Avoidance of Vessel Breach . . . . . . . . . . . . . . 6-10

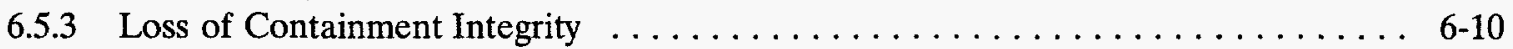

6.6 References $\ldots \ldots \ldots \ldots \ldots \ldots \ldots \ldots \ldots \ldots \ldots \ldots \ldots \ldots \ldots \ldots \ldots \ldots \ldots$

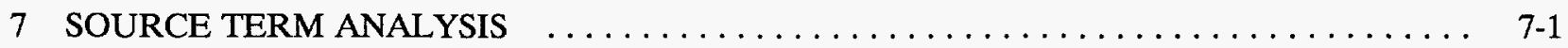

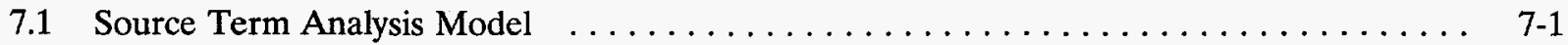

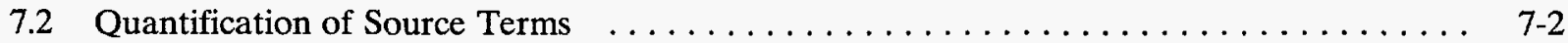

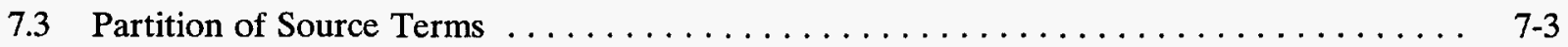

7.4 References $\ldots \ldots \ldots \ldots \ldots \ldots \ldots \ldots \ldots \ldots \ldots \ldots \ldots \ldots \ldots \ldots \ldots \ldots$

8 CONSEQUENCE ANALYSIS $\ldots \ldots \ldots \ldots \ldots \ldots \ldots \ldots \ldots \ldots \ldots \ldots \ldots \ldots \ldots \ldots$

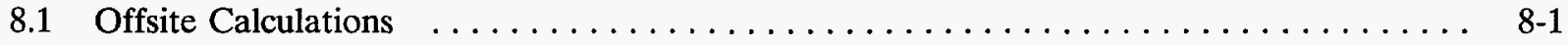

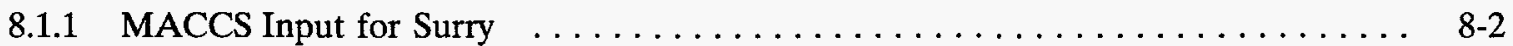

8.1.2 Results of Offsite Consequence Calculations $\ldots \ldots \ldots \ldots \ldots \ldots \ldots \ldots \ldots$. $8-2$

8.2 Onsite Consequences $\ldots \ldots \ldots \ldots \ldots \ldots \ldots \ldots \ldots \ldots \ldots \ldots \ldots \ldots \ldots$

8.2.1 Ramsdell Model ............................... $8-4$

8.2 .2 Wilson Model $\ldots \ldots \ldots \ldots \ldots \ldots \ldots \ldots \ldots \ldots \ldots \ldots \ldots \ldots \ldots \ldots$

8.2.3 NRC Regulatory Guide 1.145 Model $\ldots \ldots \ldots \ldots \ldots \ldots \ldots \ldots \ldots \ldots$. 8 .

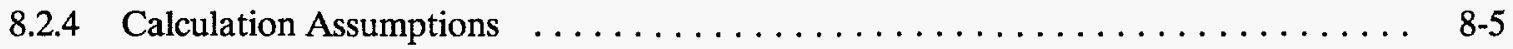

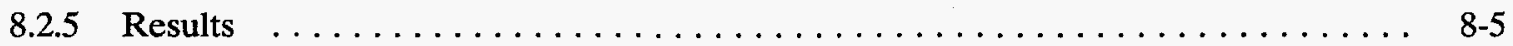

8.3 References $\ldots \ldots \ldots \ldots \ldots \ldots \ldots \ldots \ldots \ldots \ldots \ldots \ldots \ldots \ldots \ldots \ldots \ldots$

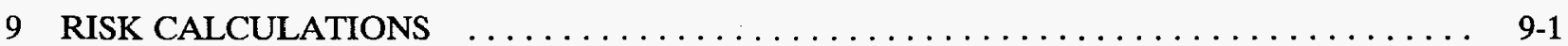

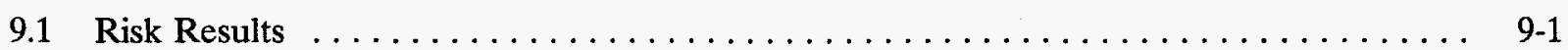

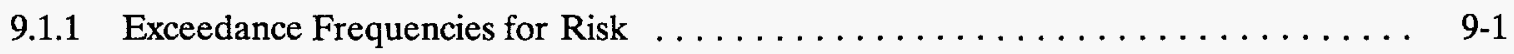

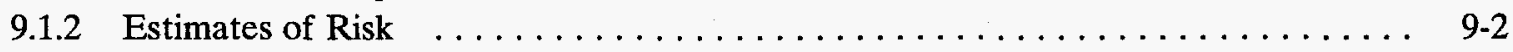

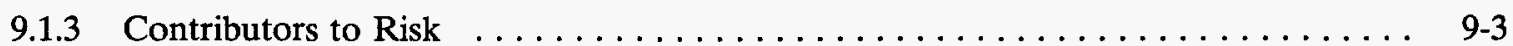

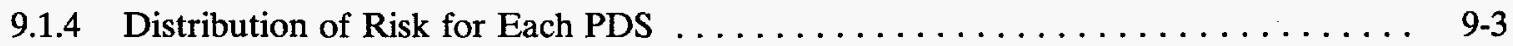

9.1.5 Comparison With the Safety Goals $\ldots \ldots \ldots \ldots \ldots \ldots \ldots \ldots \ldots . \ldots \ldots$

10 COMPARISON TO FULL POWER RESULTS $\ldots \ldots \ldots \ldots \ldots \ldots \ldots \ldots \ldots \ldots \ldots$

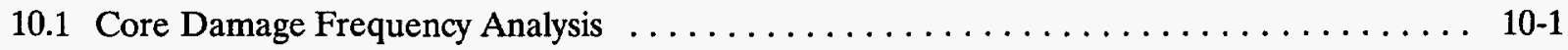

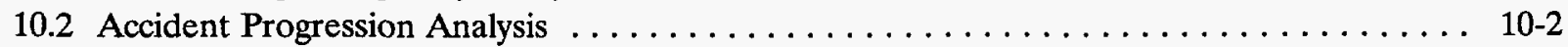

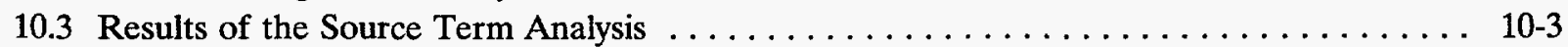

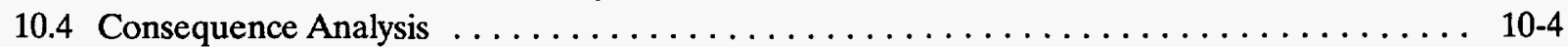

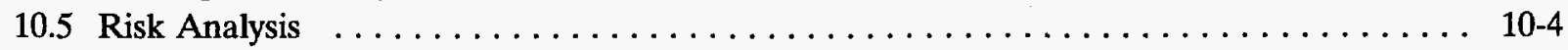

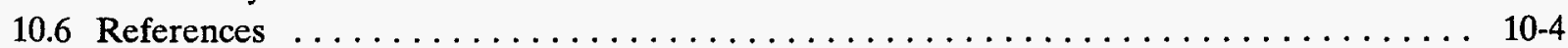


CONTENTS (continued)

Section

Page

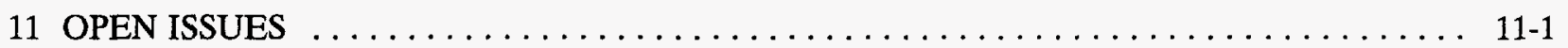

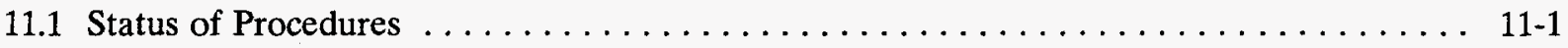

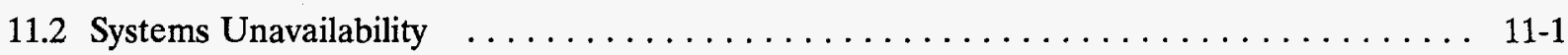

11.3 Impact of Environmental Conditions on Recovery Actions $\ldots \ldots \ldots \ldots \ldots \ldots \ldots \ldots \ldots$

11.4 Changes in Plant Configuration During Mid-Loop Operation $\ldots \ldots \ldots \ldots \ldots \ldots \ldots \ldots$

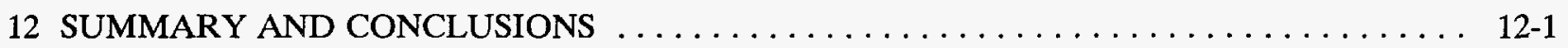




\section{FIGURES}

\section{Section}

Page

2.1 Accident Progression Event Tree for the Abridged Low Power/Shutdown Risk Analysis . . . 2-9

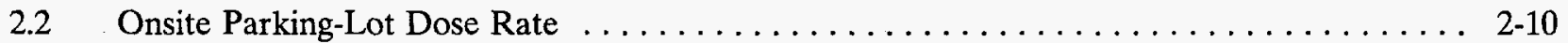

2.3 Offsite Consequence Conditional on Various Accident Progression Bins (Accident Progression Bins Defined in Figure 2.1) $\ldots \ldots \ldots \ldots \ldots \ldots \ldots \ldots \ldots \ldots \ldots \ldots \ldots$

2.4 Comparison of Conditional Probabilities of Consequences for Mid-Loop and Full Power Operation (Conditional on Core Damage and Containment Failure) . . . . . . 2-12

3.1 Overview of Plant Analysis Used for Mid-Loop Operation $\ldots \ldots \ldots \ldots \ldots \ldots \ldots \ldots \ldots$

4.1 Section of Surry Containment $\ldots \ldots \ldots \ldots \ldots \ldots \ldots \ldots \ldots \ldots \ldots \ldots \ldots \ldots \ldots$

4.2 Equipment Hatch Configuration During Mid-Loop Operation and Full Power Operation ... 4-9

6.1 Distribution of Frequencies of APB Groups $\ldots \ldots \ldots \ldots \ldots \ldots \ldots \ldots \ldots \ldots \ldots \ldots \ldots \ldots \ldots$

8.1 Onsite Parking Lot Dose Rate as a Function of Distance from the Containment for Three Source Terms $\ldots \ldots \ldots \ldots \ldots \ldots \ldots \ldots \ldots \ldots \ldots \ldots \ldots \ldots$. $\ldots \ldots \ldots \ldots$

9.1 Results of the Risk Analysis for Internal Initiators $\ldots \ldots \ldots \ldots \ldots \ldots \ldots \ldots \ldots$ 


\section{TABLES}

Section

Page

S.1 Comparison of Distributions of Risk for Mid-Loop and Full-Power Operation

(All Values per Reactor Year; Population Doses in P-Sv per Year)

xvi

5.1 Estimated Average Duration (Hours) of Plant Operational States

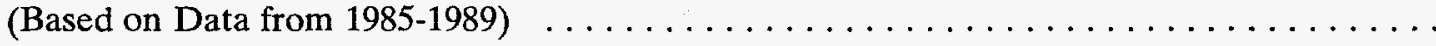

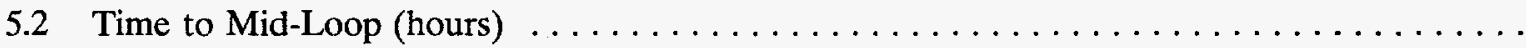

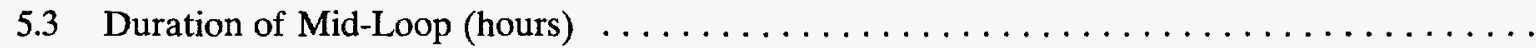

$5-10$

5.4 Definition and Characterization of Time Windows $\ldots \ldots \ldots \ldots \ldots \ldots \ldots \ldots \ldots \ldots$

5.5 Distribution of Core Damage Frequencies for Each Time Window and PDS Group

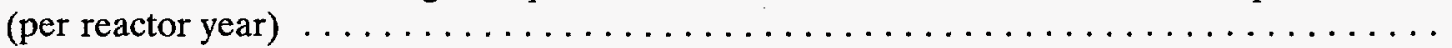

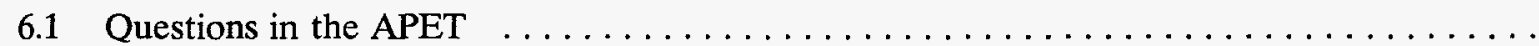

6.2 Variables Sampled in the Accident Progression Analysis $\ldots \ldots \ldots \ldots \ldots \ldots \ldots \ldots \ldots$

6.3 Description of APB Characteristics . . . . . . . . . . . . . . . . . . .

6-16

6.4 Distribution of Conditional Probabilities of APB Groups for Each PDS Group . . . . . . . .

6.5 Conditional Probability of Core Damage Arrest $\ldots \ldots \ldots \ldots \ldots \ldots \ldots \ldots \ldots \ldots \ldots .6 \ldots$

6.6 Probability of Loss of Containment Integrity for Each PDS $\ldots \ldots \ldots \ldots \ldots \ldots \ldots \ldots \ldots$

6.7 Mean Conditional Probability of APB Groups for Each PDS

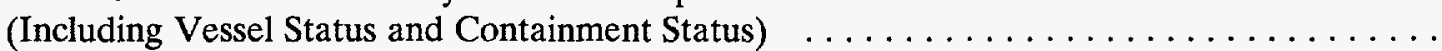

6.8 Mean Conditional Probability of APB Groups for Each PDS

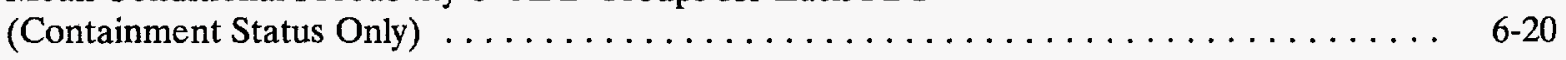

6.9 Mean Conditional Probability of APB Groups for Each Time Window

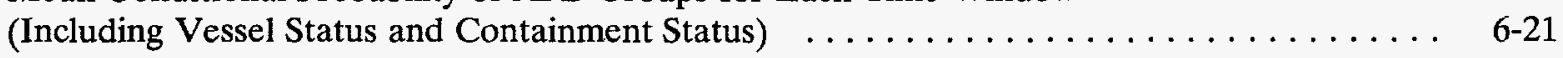

6.10 Distribution of Frequencies of APB Groups $\ldots \ldots \ldots \ldots \ldots \ldots \ldots \ldots \ldots \ldots \ldots \ldots \ldots \ldots \ldots \ldots \ldots$

9.1 Distribution for Annual Risk for the Sample During Mid-Loop Operation Due to Internal Initiators (All Values per Reactor Year; Population Doses in P-Sv per Year) ... . 9-2

9.2 Distribution of Mean Fractional Contribution to Risk for the Plant Damage States . . . . . . 9-7

9.3 Distribution of Risk for the Plant Damage States $\ldots \ldots \ldots \ldots \ldots \ldots \ldots \ldots \ldots$

10.1 Comparison of the PDS Core Damage Frequencies (per reactor year) for Mid-Loop

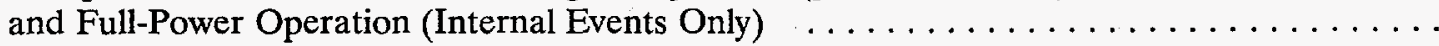

10.2 Comparison of the Mean Probabilities of APBs Conditional on PDS Groups for Mid-Loop and Full-Power Operation (Internal Events Only) $\ldots \ldots \ldots \ldots \ldots \ldots \ldots \ldots \ldots \ldots \ldots$

10.3 Comparison of Distributions of Risks for Mid-Loop and Full-Power Operation (All Values per Reactor Year; Population Doses in P-Sv per Year) 


\section{EXECUTIVE SUMMARY}

\section{S.1 Background}

A systematic evaluation of risk has been performed for mid-loop operation at the Surry Unit 1 plant. Surry is a pressurized water reactor (PWR) with a subatmospheric containment building. The study was performed by Brookhaven National Laboratory (BNL) for the Nuclear Regulatory Commission (NRC) Office of Nuclear Regulatory Research (RES). A sister study of the Grand Gulf nuclear power plant, a boiling water reactor (BWR), is being performed by Sandia National Laboratories.

Probabilistic Risk Assessments (PRAs) for low power and shutdown operations were initiated in support of the NRC's response to the Chernobyl accident, which was an accident initiated at low power conditions, the Diablo Canyon event of April 10, 1987 which led to the issuance of a Generic Letter 88-171 and later modified by the staff's follow-up actions to the incident at the Vogtle plant on March 20, 1990. An analysis of the core damage frequency (Level 1 PRA) for low power shutdown operation at Surry was initiated in late 1990 and carried out in two phases. Phase 1 undertook a coarse qualitative screening analysis of the accident sequences leading to core damage for all plant operational states during low power and shutdown, while in Phase 2 a detailed quantitative analysis of the core damage frequency was performed for mid-loop operation only.

The accident progression and consequence assessment (Level 2 and 3 PRA) was initiated in late 1991 and was also carried out in two phases. An Abridged Risk study was performed from January to May 1992. It was focused on accident progression and consequences, conditional on core damage. Phase 2 is a more detailed study in which the accident frequency analysis was combined with the accident progression and consequence analysis to calculate risk. This Phase 2 study is the subject of this volume of the report. The analysis of core damage frequency for accidents initiated by internal events, internal fire, internal flood, and seismic events are reported in separate volumes.

The objective of the Phase 2 study is to develop methods to compute the risk of the Surry plant during midloop operation and to perform the study. The approach used in the risk assessment was to utilize to the extent possible the component analyses developed as part of the NUREG-1150 program. The assessment also identified those factors that have the most impact on the risk estimates and highlights unique features of the risk analysis performed. The results of the study were also compared against the risk of full power operation as evaluated in the NUREG-1150 study of Surry and the NRC safety goals.

Mid-loop operation occurs when the reactor coolant system (RCS) level is lowered to the mid-plane of the hot leg. This allows the steam generators to be drained so that they can be tested. Mid-loop operation can occur during different types of outage and when the plant is in several different operational states. At Surry, mid-loop operation has occurred in four types of outages: refueling, drained maintenance, non-drained maintenance with the use of the residual heat removal (RHR) system, and non-drained maintenance without the use of the RHR system. Each outage type is characterized by several operating states with each state representing a unique set of operating conditions (temperature, pressure, configuration). Three mid-loop operating states were identified from Surry outage records, two during refueling outages and one in drained maintenance. Each of these operating states is characterized by different decay heat levels and plant configurations, such as number of RCS loops that are isolated and whether the safety/relief valves on the pressurizer have been pulled for maintenance. 
The scope of this study was to perform a risk analysis for mid-loop operation during three plant operating states. Risk estimates were made for accidents initiated by internal events due to equipment failure and human error. Risk estimates were however not made for accidents initiated by internal fires, internal floods or seismic events. In addition, as this study is limited to accidents at mid-loop operation it is not a complete risk estimate for accidents that could occur during low-power and shutdown. In fact, mid-loop operation was selected for more detailed study because in the Phase 1 study this was found to be one of the more vulnerable plant configurations. The current risk estimates for mid-loop operation are therefore likely to be higher than for other plant configurations during low-power and shutdown. Another related point deals with the impact of this study on plant operations during mid-loop conditions at Surry. The study has identified potential vulnerabilities over the last few years and the plant staff have responded (if they found that a response was warranted) by making improvements. While these responses are encouraging and lead to improved plant safety it has meant that we have been trying to analyze a moving target. In order to complete the study we therefore had to use procedures and other plant information available as of April 1993.

\section{S.2 Method}

The approach used in the risk assessment was to utilize to the extent possible the component analyses that were developed for the full power study. However, due to the long time periods over which an accident can occur and due to differences in plant configuration during mid-loop operation, the interface between the core damage frequency analysis and the accident progression analysis was sufficiently different that additional factors had to be incorporated in combining the accident sequences into appropriate plant damage states for entry into the accident progression event tree (APET). It was also possible to simplify (i.e., reduce the number of top events) the full power APET for use in the mid-loop study. In addition to reducing the size of the tree it was necessary to introduce a number of new top events related to containment isolation in order to appropriately describe the accident progression and plant configuration during mid-loop operation.

The source term model used in the full power study was considered suitable for use in the mid-loop study with only minor modifications. This suitability was based on comparisons with point calculations from a deterministic code, MELCOR, and the views expressed by an expert review panel drawn from staff at Sandia and Brookhaven National Laboratories. However the partitioning method used in the full power study to combine the source terms into a smaller number of representative source terms for input to the consequence model had to be modified. This was necessary in order to account for changing radionuclide inventories for the various accidents because they can occur during a long time period after shutdown. The latest version of the MACCS code was used to evaluate the offsite consequence measures. In addition, simple, scoping estimates of onsite doses in the open area of the plant adjacent to the containment (so-called parking lot dose) were also made. The method used to calculate risk was the same as that used in the full power study.

\section{S.3 Results}

The results of the core damage frequency analysis are discussed in detail in Volume 2 of this report, which also includes a comparison with the full power study. In order to appreciate the accident progression analysis and risk estimates the results of the core damage frequency are briefly discussed in this volume. Four statistical measures of the core damage frequency distribution (CDF) for accidents during mid-loop operation are compared with similar measures for accidents during power operation below: 


\begin{tabular}{|l|c|c|}
\hline & \multicolumn{1}{|c|}{$\begin{array}{c}\text { Core Damage Frequency } \\
\text { for Mid-Loop Operation } \\
\text { (per reactor year) }\end{array}$} & $\begin{array}{c}\text { Core Damage Frequency } \\
\text { for Power Operation } \\
\text { (per reactor year) }\end{array}$ \\
\hline \hline 95th Percentile & $1.9 \mathrm{E}-5$ & $1.0 \mathrm{E}-4$ \\
\hline Mean & $4.2 \mathrm{E}-6$ & $4.1 \mathrm{E}-5$ \\
\hline 50th Percentile & $2.0 \mathrm{E}-6$ & $2.5 \mathrm{E}-5$ \\
\hline 5th Percentile & $3.2 \mathrm{E}-7$ & $9.8 \mathrm{E}-6$ \\
\hline
\end{tabular}

The mean core damage frequency of accidents initiated by internal events during mid-loop operation is about an order of magnitude lower than the mean frequency of accidents during full power operation. In addition the mean and median frequencies of the two distributions were within a factor of approximately two. However, the tails of the distributions do overlap and therefore for some cases the mid-loop core damage frequency could be higher than the full power frequency.

Table S.1 presents statistical measures of the distributions for seven consequence measures for accidents during mid-loop operation obtained from this study. Similar statistical measures for full power operation obtained from the NUREG-1150 study of Surry are also included in the table. Table S.1 indicates that the mean risk of offsite early health effects is over two orders of magnitude lower for accidents during mid-loop operation than for full power. This is due to the natural decay of the radionuclide inventory (because the accidents occur a long time after shutdown) particularly the short-lived isotopes of iodine and tellurium, which are primarily associated with early health effects. The distributions obtained for population dose (50 miles and 1000 miles) for mid-loop and full power operation are very similar. However the distributions for latent cancer fatalities differ by a factor of about three. The mid-loop study used the latest version of the MACCS code, which incorporates the BEIR V update to the latent cancer versus dose relationship, whereas NUREG1150 used an older version of MACCS. The latest BEIR V update gives approximately a factor of three higher latent cancers for the same value of population dose.

Finally, scoping estimates of onsite doses were performed which indicate that the parking lot dose rates for accidents involving unisolated containment were high. This would limit the ability to take corrective actions, which cannot be performed from the control room, for this class of accidents.

\section{S.4 Conclusions}

The main finding of the study is that during mid-loop operation the risk of consequence measures related to long-term health effects, latent cancer fatalities and population dose, are high, comparable to those at full power, despite the much lower level of the decay heat and the radionuclide inventory. The reason for this is that containment is likely to be unisolated for a significant fraction of the accidents initiated during mid-loop operation so the releases to the environment are potentially large and the radionuclide species which mostly contribute to long-term health effects (such as cesium) have long half-lives. Accident sequences involving failure to correctly diagnose the situation or take proper actions are the largest contributors to the risk. Another finding of the study is that the risk of early fatalities is low despite the unisolated containment due to the decay of the short-lived radionuclide species such as iodine and tellurium which contribute to early 
fatality risk. The calculated risk estimates have a range of uncertainty extending over approximately two orders of magnitude from the 5 th to the 95 th percentile of the distribution.

\section{Containment Status}

The major factor driving the risk is the status of containment during mid-loop operation. It was judged that there is a high probability that the containment is either unisolated or that it would not have full pressure retaining capability during mid-loop operation. This is particularly the case if the operators fail to diagnose the accident as it was judged unlikely that they would take action to isolate containment or could succeed in doing so within the available time frame. This factor played a significant role in influencing the risk estimates of mid-loop operation. During the course of the study, Surry plant personnel made available new procedures for containment closure during mid-loop operation. However, it was difficult to assess the adequacy of these procedures in ensuring the pressure retaining capability of the containment within the time frame encompassed by this study. This feature contributed significantly to the uncertainty in containment status and the estimate of risk.

\section{Availability of Containment Sprays}

There is no requirement at Surry for the containment sprays to be available during shutdown. Plant records show that the spray systems could be inoperable because of maintenance. Spray availability was modeled as an uncertainty parameter in the risk analysis. Since the sprays perform an important safety function in mitigating the effects of releases, spray unavailability contributed both to the risk and its uncertainty.

\section{Possibility of Core Damage Arrest}

The inclusion of the possibility of arresting the core degradation process before vessel failure is an important feature of this analysis as it was for the full power study. Termination of the accident in-vessel can significantly reduce some of the fission product releases and thus the risk. The potential for core recovery depends on the nature of the accident progression and is different for the various PDS Groups. Overall, the conditional probability of core damage arrest ranged from 0.23 (5th percentile) to 0.44 (95th percentile) with a mean of 0.35 .

\section{Comparison with Full Power Study}

The mean core damage frequency for accidents during mid-loop operation is about an order of magnitude lower than the mean frequency of accidents caused by internal events at full power. However, the risk distributions obtained for comparable long term health consequences are very similar in the two studies. What this finding implies is that the lower decay heat and lower radionuclide inventory of the mid-loop operating state, compared with full power, is offset by the lack of mitigative features. Finally, the mean risk of early health effects is over two orders of magnitude lower for accidents during mid-loop operation than for accidents during full power operation. This is due to the natural decay of those radionuclide species which have the greatest impact on early fatality risk because accidents during mid-loop operation occur a long time after shutdown. 


\section{Comparison With the Safety Goals}

Comparison of the results of this study against the NRC safety goals is done only for the two quantitative health objectives identified in the Commission's policy statement of August 1986. These objectives deal with individual early fatality and latent cancer fatality risks within 1 mile and 10 miles of the site, respectively. The numerical value of these objectives are given in Table S.1. The 95th percentile of the distribution for individual latent cancer fatality risk falls more than an order of magnitude below the objective. The 95th percentile of the distribution for individual early fatality risk falls over two orders of magnitude below the corresponding health objective. The health objectives, however, apply to the total risk of the Surry plant. The risk estimates of this study are for accidents initiated by internal events during mid-loop operaton and therefore reflect only a fraction of the total risk at Surry. 
Table S.1 Comparison of Distributions of Risk for Mid-Loop and Full-Power Operation (All Values per Reactor Year; Population Doses in P-Sv per Year)

\begin{tabular}{|c|c|c|c|c|c|c|c|c|c|c|}
\hline & \multicolumn{2}{|c|}{$\begin{array}{c}\text { Sample } \\
\text { 5th Percentile }\end{array}$} & \multicolumn{2}{|c|}{$\begin{array}{l}\text { Sample } \\
\text { Median }\end{array}$} & \multicolumn{2}{|c|}{$\begin{array}{l}\text { Sample } \\
\text { Mean }\end{array}$} & \multicolumn{2}{|c|}{$\begin{array}{c}\text { Sample } \\
\text { 95th Percentile }\end{array}$} & \multicolumn{2}{|c|}{$\begin{array}{l}\text { Standard } \\
\text { Deviation }\end{array}$} \\
\hline & $\begin{array}{l}\text { Mid- } \\
\text { Loop }\end{array}$ & $\begin{array}{l}\text { Full- } \\
\text { Power }\end{array}$ & $\begin{array}{l}\text { Mid- } \\
\text { Loop }\end{array}$ & $\begin{array}{l}\text { Full- } \\
\text { Power }\end{array}$ & $\begin{array}{l}\text { Mid- } \\
\text { Loop }\end{array}$ & $\begin{array}{l}\text { Full- } \\
\text { Power }\end{array}$ & $\begin{array}{l}\text { Mid- } \\
\text { Loop }\end{array}$ & $\begin{array}{l}\text { Full- } \\
\text { Power }\end{array}$ & $\begin{array}{l}\text { Mid- } \\
\text { Loop }\end{array}$ & $\begin{array}{l}\text { Full- } \\
\text { Power }\end{array}$ \\
\hline Early Fatalities & $1.26 \mathrm{E}-10$ & $7.60 \mathrm{E}-10$ & 3.57E-09 & $7.00 \mathrm{E}-08$ & $4.90 \mathrm{E}-08$ & $2.00 \mathrm{E}-06$ & $1.59 \mathrm{E}-07$ & $5.40 \mathrm{E}-06$ & 1.69E-07 & N.A. \\
\hline Latent Fatalities within $50 \mathrm{mi}$ & $1.55 \mathrm{E}-04$ & N.A. & 8.34E-04 & N.A. & $2.46 \mathrm{E}-03$ & N.A. & $8.78 \mathrm{E}-03$ & N.A. & $3.68 \mathrm{E}-03$ & N.A. \\
\hline Latent Fatalities within $1000 \mathrm{mi}$ & 7.97E-04 & $3.10 \mathrm{E}-04$ & $5.35 \mathrm{E}-03$ & $2.20 \mathrm{E}-03$ & $1.57 \mathrm{E}-02$ & $5.20 \mathrm{E}-03$ & $5.50 \mathrm{E}-02$ & $1.90 \mathrm{E}-02$ & 2.52E-02 & N.A. \\
\hline Population Dose within $50 \mathrm{mi}$ & 3.77E-03 & $5.90 \mathrm{E}-03$ & $1.98 \mathrm{E}-02$ & $2.70 \mathrm{E}-02$ & 5.79E-02 & $5.80 \mathrm{E}-02$ & $1.89 \mathrm{E}-01$ & $2.50 \mathrm{E}-01$ & 8.77E-02 & N.A. \\
\hline Population Dose within $1000 \mathrm{mi}$ & $1.87 \mathrm{E}-02$ & $1.90 \mathrm{E}-02$ & 1.25E-01 & $1.30 \mathrm{E}-01$ & $3.66 \mathrm{E}-01$ & $3.10 \mathrm{E}-01$ & $1.29 \mathrm{E}+00$ & $1.20 \mathrm{E}+00$ & $5.90 \mathrm{E}-01$ & N.A. \\
\hline Individual Early Fatalities Risk within $1 \mathrm{mi}^{*}$ & $6.00 \mathrm{E}-12$ & $1.40 \mathrm{E}-11$ & $1.27 \mathrm{E}-10$ & $8.70 \mathrm{E}-10$ & $1.74 \mathrm{E}-09$ & $1.60 \mathrm{E}-08$ & $6.94 \mathrm{E}-09$ & $4.90 \mathrm{E}-08$ & $5.52 \mathrm{E}-09$ & N.A. \\
\hline Individual Latent Fatalities Risk within $10 \mathrm{mi}^{*}$ & $1.20 \mathrm{E}-10$ & $1.60 \mathrm{E}-10$ & $7.48 \mathrm{E}-10$ & $4.90 \mathrm{E}-10$ & 2.09E-09 & 1.70E-09 & $7.10 \mathrm{E}-09$ & $8.10 \mathrm{E}-09$ & $3.01 \mathrm{E}-09$ & N.A. \\
\hline
\end{tabular}

N.A. - Not Available

*NRC quantitative health objectives:

- Individual early fatality risk within one mile to be less than $5 \times 10^{-7}$ per reactor year.

- Individual latent cancer fatality risk within 10 miles to be less than $2 \times 10^{-6}$ per reactor year. 


\section{FOREWORD}

\section{(NUREG/CR-6143 and 6144) \\ Low Power and Shutdown Probabilistic Risk Assessment Program}

Traditionally, probabilistic risk assessments (PRA) of severe accidents in nuclear power plants have considered initiating events potentially occurring only during full power operation. Some previous screening analysis that were performed for other modes of operation suggested that risks during those modes were small relative to full power operation. However, more recent studies and operational experience have implied that accidents during low power and shutdown could be significant contributors to risk.

During 1989, the Nuclear Regulatory Commission (NRC) initiated an extensive program to carefully examine the potential risks during low power and shutdown operations. The program includes two parallel projects performed by Brookhaven National Laboratory(BNL) and Sandia National Laboratories(SNL), with the seismic analysis performed by Future Resources Associates. Two plants, Surry (pressurized water reactor) and Grand Gulf (boiling water reactor), were selected as the plants to be studied.

The objectives of the program are to assess the risks of severe accidents due to internal events, internal fires, internal floods, and seismic events initiated during plant operational states other than full power operation and to compare the estimated core damage frequencies, important accident sequences and other qualitative and quantitative results with those accidents initiated during full power operation as assessed in NUREG-1150. The scope of the program includes that of a level-3 PRA.

The results of the program are documented in two reports, NUREG/CR-6143 and 6144. The reports are organized as follows:

For Grand Gulf:

NUREG/CR-6143 - Evaluation of Potential Severe Accidents during Low Power and Shutdown Operations at Grand Gulf, Unit 1

Volume 1: Summary of Results

Volume 2: Analysis of Core Damage Frequency from Internal Events for Operational State 5 During a Refueling Outage

Part 1: Main Report

Part 1A: Sections 1 - 9

Part 1B: Section 10

Part 1C: Sections 11 - 14

Part 2: Internal Events Appendices $A$ to $\mathrm{H}$

Part 3: Internal Events Appendices I and J

Part 4: Internal Events Appendices $\mathrm{K}$ to $\mathrm{M}$ 
FOREWORD (continued)

Volume 3: Analysis of Core Damage Frequency from Internal Fire Events for Plant Operational State 5 During a Refueling Outage

Volume 4: Analysis of Core Damage Frequency from Internal Flooding Events for Plant Operational State 5 During a Refueling Outage

Volume 5: Analysis of Core Damage Frequency from Seismic Events for Plant Operational State 5 During a Refueling Outage

Volume 6: Evaluation of Severe Accident Risks for Plant Operational State 5 During a Refueling Outage

Part 1: Main Report

Part 2: Supporting MELCOR Calculations

For Surry:

NUREG/CR-6144 - Evaluation of Potential Severe Accidents during Low Power and Shutdown Operations at Surry Unit-1

Volume 1: Summary of Results

Volume 2: Analysis of Core Damage Frequency from Internal Events during Midloop Operations

Part 1: Main Report

Part 1A: Chapters 1 - 6

Part 1B: Chapters $7-12$

Part 2: Internal Events Appendices A to D

Part 3: Internal Events Appendix E

Part 3A: Sections E.1 - E.8

Part 3B: Sections E.9 - E.16

Part 4: Internal Events Appendices $\mathrm{F}$ to $\mathrm{H}$

Part 5: Internal Events Appendix I

Volume 3: Analysis of Core Damage Frequency from Internal Fires during Midloop Operations

Part 1: Main Report

Part 2: Appendices

Volume 4: Analysis of Core Damage Frequency from Internal Floods during Midloop Operations

Volume 5: Analysis of Core Damage Frequency from Seismic Events during Midloop Operations

Volume 6: Evaluation of Severe Accident Risks during Mid-loop Operations

Part 1: Main Report

Part 2: Appendices 


\section{ACKNOWLEDGEMENTS}

The authors wish to thank Chris Ryder of the NRC and W. T. Pratt of Brookhaven National Laboratory for their review and suggested improvements to the project. The authors also wish to acknowledge Kathy Ryan and Barbara Kponou for their patience and secretarial support during the project, and Cheryl Conrad for her technical support. 


\section{ACRONYMS}

$\begin{array}{ll}\text { Acronym } & \\ \text { ACC } & \text { Accumulator } \\ \text { AEOD } & \text { Office for Analysis and Evaluation Operational Data, US NRC } \\ \text { AFW } & \text { Auxiliary Feedwater } \\ \text { AHU } & \text { Air Handling Unit } \\ \text { ANS } & \text { American Nuclear society } \\ \text { AOT } & \text { Allowed Outage Time } \\ \text { AOV } & \text { Air Operated Valve } \\ \text { AP } & \text { Abnormal Procedure } \\ \text { ASEP } & \text { Accident Sequence Evaluation Program } \\ \text { ASME } & \text { American Society of Mechanical Engineers } \\ \text { ATWS } & \text { Anticipated Transient Without Scram } \\ \text { BAT } & \text { Boric Acid Tank } \\ \text { BHEP } & \text { Basic Human Error Probability } \\ \text { BAST } & \text { Boric Acid Storage Tank } \\ \text { BIT } & \text { Boron Injection Tank } \\ \text { BNL } & \text { Brookhaven National Laboratory } \\ \text { BRT } & \text { Boron Recovery Tank } \\ \text { CAS } & \text { Compressed Air System } \\ \text { CCW } & \text { Component Cooling Water } \\ \text { CD } & \text { Core Damage } \\ \text { CDF } & \text { Core Damage Frequency } \\ \text { CEDM } & \text { Control Element Drive Mechanism } \\ \text { CESSAR } & \text { Combustion Engineering Standard Safety Analysis Report } \\ \text { CFR } & \text { Code of Federal Regulation } \\ \text { CIS } & \text { Containment Isolation Signal } \\ \text { CLCS } & \text { Consequence Limiting Control System } \\ \text { CPC } & \text { Charging Pump Cooling } \\ \text { CPS } & \text { Containment Pressure Suppression } \\ \text { CRA } & \text { Control Rod Assembly } \\ \text { CS } & \text { Containment Spray } \\ \text { CSD } & \text { Cold Shutdown } \\ \text { CSR } & \text { Cable Spreading Room } \\ \text { CSS } & \text { Containment Spray System } \\ \text { CST } & \text { Condensate Storage Tank } \\ \text { CVCS } & \text { Chemical and Volume Control System } \\ \text { CW } & \text { Circulating Water } \\ \text { DHR } & \text { Decay Heat Removal } \\ \text { ECA } & \text { Emergency Contigency Action } \\ \text { ECCS } & \text { Emergency Core Cooling System } \\ \text { EDG } & \text { Emergency Diesel Generator } \\ \text { EF } & \text { Error Factor } \\ \text { ELO } & \text { End of Licensed Life } \\ & \end{array}$




\begin{tabular}{|c|c|}
\hline Acronym & Definition \\
\hline EP & Emergency Procedure \\
\hline EPS & Emergency Power System \\
\hline ESF & Emergency Safety Feature \\
\hline ESFAS & Emergency Safety Feature Actuation System \\
\hline ESGR & Emergency Switchgear Room \\
\hline ESR & Emergency Switchgear Room \\
\hline FAI & Fail as Is \\
\hline $\mathrm{FCV}$ & Flow Control Valve \\
\hline FMEA & Failure Mode and Effect Analysis \\
\hline FO & Fail Open \\
\hline FW & Feed Water \\
\hline GOP & General Operating Procedure \\
\hline HAZOP & Hazard and Operability Study \\
\hline HEP & Human Error Probability \\
\hline HHSI & High Head Safety Injection \\
\hline HPI & High Pressure Injection \\
\hline HPR & High Pressure Recirculation \\
\hline HRA & Human Reliability Analysis \\
\hline HSD & Hot Shutdown \\
\hline HVAC & Heating Ventilation and Air Conditioning \\
\hline $\mathrm{HX}$ & Heat Exchanger \\
\hline HZP & Hot Zero Power \\
\hline IAEA & International Atomic Energy Agency \\
\hline IAW & In Accordance With \\
\hline IE & Initiating Event \\
\hline INEL & Idaho National Engineering Laboratory \\
\hline IPE & Individual Plant Evaluation \\
\hline IRRAS & Integrated Reliability and Risk Analysis System \\
\hline ISD & Intermediate Shutdown \\
\hline ISLOCA & Interfacing Systems LOCA \\
\hline ISR & Inside Spray Recirculation \\
\hline KV & Kilo-volt \\
\hline LCO & Limiting condition of Operation \\
\hline LER & Licensee Event Report \\
\hline LHS & Latin Hypercube Sampling \\
\hline LHSI & Low Head Safety Injection \\
\hline LOCA & Loss of Coolant Accident \\
\hline LOSP & Loss of Offsite Power \\
\hline LPR & Low Pressure Recirculation \\
\hline LP\&S & Low Power and Shutdown \\
\hline LTOP & Low Temperature Overpressurization \\
\hline MCC & Motor Control Center \\
\hline MCR & Main Control Room \\
\hline MELCOR & $\begin{array}{l}\text { A Computer Code for Nuclear Reactor Severe Accident Source } \\
\text { Term and Risk Assessment Analysis }\end{array}$ \\
\hline MFW & Main Feedwater \\
\hline
\end{tabular}




$\begin{array}{ll}\text { Acronym } & \\ \text { MOP } & \text { Maintenance Operating Procedure } \\ \text { MOV } & \text { Motor Operated Valve } \\ \text { MSTV } & \text { Main Steam Trip Valve } \\ \text { MW } & \text { Mega-watt } \\ \text { MWt } & \text { Mega-watt Thermal } \\ \text { NC } & \text { Normally Closed } \\ \text { NO } & \text { Normally Open } \\ \text { NPSH } & \text { Net Positive Suction Head } \\ \text { NRC } & \text { Nuclear Regulatory Commission } \\ \text { NRR } & \text { Nuclear Reactor Regulation, US NRC } \\ \text { NRV } & \text { Non-Return Valve } \\ \text { NSAC } & \text { Nuclear Safety Analysis Center } \\ \text { NSS } & \text { Normal Station Service } \\ \text { NSS } & \text { Nuclear Steam System } \\ \text { OD } & \text { Operator Depressurization } \\ \text { OOS } & \text { Out of Service } \\ \text { OP } & \text { Operating Procedure } \\ \text { OSR } & \text { Outside Spray Recirculation } \\ \text { PCS } & \text { Power Conversion System } \\ \text { PCV } & \text { Pressure Control Valve } \\ \text { PG } & \text { Primary Grade } \\ \text { PORV } & \text { Pilot Operated Relief Valve } \\ \text { POS } & \text { Plant Operational State } \\ \text { PPM } & \text { Parts Per Million } \\ \text { PPRS } & \text { Primary Pressure Relief System } \\ \text { PRA } & \text { Probabilistic Risk Assessment } \\ \text { PRT } & \text { Pressurizer Relief Tank } \\ \text { PRZR } & \text { Pressurizer } \\ \text { PSA } & \text { Probabilistic Safety Analysis } \\ \text { PSF } & \text { Performance Shaping Factor } \\ \text { PSIA } & \text { Pound Per Square Inch Absolute } \\ \text { PSID } & \text { Pound Per Square Inch Defferential } \\ \text { PSIG } & \text { Pound Per Square Inch Gauge } \\ \text { PTL } & \text { Pull-to-lock } \\ \text { PTS } & \text { Pressurized Thermal Shock } \\ \text { R\&D } & \text { Refueling and Drained Maintenance } \\ \text { RC } & \text { Reactor Coolant } \\ \text { RCCA } & \text { Reactor Control Cluster Assembly } \\ \text { RCP } & \text { Reactor Coolant Pump } \\ \text { RCS } & \text { Reactor Coolant System } \\ \text { REA } & \text { Rod Ejection Accident } \\ \text { RES } & \text { Office of Nuclear Regulatory Research, US NRC } \\ \text { RF } & \text { Recovery Factor } \\ \text { Range Factor } \\ \text { Residual Heat Removal } \\ \text { Remote Monitoring Panels } \\ \end{array}$




\begin{tabular}{|c|c|}
\hline Acronym & Definition \\
\hline RMT & Recirculation Mode Transfer \\
\hline RMTS & Recirculation Mode Transfer System \\
\hline RPS & Reactor Protection System \\
\hline RPV & Reactor Pressure Vessel \\
\hline RSS & Reserve Station Service \\
\hline RTND & Reference Temperature for Transition to Nil-Ductility \\
\hline RTS & Return to Service \\
\hline RVLIS & Reactor Vessel Level Indication System \\
\hline RWST & Refueling Water Storage Tank \\
\hline RX & Reactor \\
\hline RY & Reactor year \\
\hline SBO & Station Blackout \\
\hline SCSS & Sequence Coding Search System \\
\hline SFP & Spent Fuel Pool \\
\hline SG & Steam Generator \\
\hline SGRCT & Steam Generator Reactivity \\
\hline SGRTS & Steam Generator Recirculation and Transfer \\
\hline SGTR & Steam Generator Tube Rupture \\
\hline SI & Safety Injection \\
\hline SIAS & Safety Injection Actuation System \\
\hline SIS & Safety Injection System \\
\hline SLB & Steam Line Break \\
\hline SNL & Sandia National Laboratories \\
\hline SRV & Safety Relief Valve \\
\hline SV & Safety Valve \\
\hline SWS & Service Water System \\
\hline TAF & Top of Active Fuel \\
\hline TOP & Temporary Operating Procedure \\
\hline TWC & Through the Wall Crack \\
\hline UFSAR & Updated Final Safety Analysis Report \\
\hline VCT & Volume Control Tank \\
\hline VEPCO & Virginia Electric Power Company \\
\hline WR & Wide Range \\
\hline
\end{tabular}




\section{INTRODUCTION}

\subsection{Background}

This report presents the results of a Level 2 (accident progression) and Level 3 (consequence) analysis of the Surry nuclear power plant for possible accidents initiated while the plant is in mid-loop operation. The analysis was performed by Brookhaven National Laboratory (BNL) for the Nuclear Regulatory Commission (NRC) Office of Nuclear Regulatory Research (RES). This Level 2/3 analysis was combined with an analysis ${ }^{1}$ of the core damage frequency (Level 1) for accidents initiated by internal events to produce a risk assessment. A sister study of the Grand Gulf nuclear power plant, a boiling water reactor (BWR), is being performed by Sandia National Laboratories.

Probabilistic Risk Assessments (PRAs) for low power and shutdown operations were initiated in support of the NRC's response to the Chernobyl accident, which was an accident initiated at low power conditions, and later modified by the staff's follow-up actions to the incident at the Vogtle plant on March 20, 1990. The Level 1 PRA of Surry during low power and shutdown operation was initiated in late 1990 and carried out in two phases. Phase 1 undertook a coarse qualitative screening analysis of the accident sequences leading to core damage for all plant operational states during low power and shutdown, while in Phase 2 a detailed quantitative analysis of the core damage frequency was performed for mid-loop operation only. The Level 2 and 3 PRA was initiated in late 1991 and has also been carried out in two phases. In Phase 1 an Abridged Risk study was performed from January to May 1992. It was focused on accident progression and consequences, conditional on core damage. A summary of the Abridged study is contained in Chapter 2 of this report. Phase 2 is a more detailed study in which the accident frequency analysis was combined with the accident progression, source term and consequence analysis to calculate risk. This Phase 2 study is the subject of this volume of the report. The analysis of core damage frequency for accidents initiated by internal events, internal fires, internal floods, and seismic events are reported in separate volumes.

\subsection{Study Objectives}

The objective of this study is to develop methods to compute the risk of the Surry plant during mid-loop operation and to perform the study. The approach used in the risk assessment was to utilize to the extent possible the component analyses developed as part of the NUREG-1150 program. ${ }^{2}$ The assessment also identified those factors that have the most impact on the risk estimates and highlights unique features of the risk analysis performed. Finally the results of the study were compared against the risk of full power operation as evaluated in the NUREG-1150 study of Surry and the NRC safety goals.

\subsection{Scope of Study and Major Assumptions}

The analysis reported in this volume is a risk evaluation of mid-loop operation at the Surry Unit 1 power plant, when the reactor coolant system level is lowered to the mid-plane of the hot leg. Mid-loop operation can occur in several plant operational states (POSs) of different outage types. At Surry, four types of outage: 


\section{Introduction}

refueling, drained maintenance, non-drained maintenance with the use of the residual heat removal (RHR) system, and non-drained maintenance without the use of the RHR system, were defined in the Level 1 analysis. Each outage type is characterized by several POSs with each POS representing a unique set of operating conditions (temperature, pressure, configuration). Three mid-loop POSs were identified from Surry outage records in the Level 1 analysis, POS 6 and POS 10 in refueling outage, and POS 10 in drained maintenance. Each of these POSs is characterized by different decay heat levels and plant configurations, such as number of reactor coolant system (RCS) loops that are isolated and whether the safety/relief valves on the pressurizer have been pulled for maintenance.

The scope of the study is limited to an analysis of accidents initiated by internal events due to equipment failure and human error during mid-loop operation. In addition the study reflects procedures and other plant information available prior to April 1993. Risk estimates were not made for accidents initiated by internal fires, internal floods, and seismic events. As this study is limited to accidents during mid-loop operation it is not a complete risk estimate for accidents that could occur during low power and shut down operation. Mid-loop operation was selected for detailed study because the screening analysis carried out in Phase 1 indicated that this was one of the more vulnerable plant configurations during low power and shutdown. Therefore, the risk estimates for mid-loop operation are likely to be higher than for other plant configurations at low power and shutdown.

The major assumptions of the analysis are as follows:

(1) Time windows and decay heat levels: Decay heat level is a key parameter in the accident analysis due to the long time interval, depending on the POS and outage type, over which an accident can potentially occur during mid-loop operation. Four time windows with corresponding decay heat levels were constructed in the Level 1 analysis and it was assumed that the decay heat level (which varies continuously) of each time window can be adequately represented by its value at the mid-point of the time window.

(2) Containment Status: Several assumptions had to be made on the status of the containment during midloop operation. These assumptions are documented in more detail in Chapter 4 and relate to the pressure capability of the containment. The pressure capability ranges from no pressure retaining capability (leakage at inception of release) to full design capability (as at full power operation). The ability of containment to retain fission products released from damaged fuel is the dominant factor affecting risk.

(3) Source Term: It was assumed that the source term code, SURSOR ${ }^{3}$, which was developed for the full power study would adequately apply to low power and shutdown conditions as well. This assumption was checked through spot comparisons with calculations based on the mechanistic code MELCOR ${ }^{4}$ and by a review performed by a Source Term Advisory Group comprised of BNL and SNL staff.

(4) Accident Progression: Assumptions were made in various parts of the accident progression event tree on branch point probabilities, split fractions, etc. These are documented in Chapter 6 .

(5) Consequences: The consequence calculation assumed the same emergency response for the offsite population in the low population zone surrounding Surry and the same long-term protective actions as the NUREG-1150 study. 
(6) Onsite Doses: The scoping calculation of onsite doses assumed that the releases were directly from the containment to the environment through the equipment hatch and not through the personnel hatch so no in-building doses were calculated.

(7) Human Reliability: Several assumptions have been made regarding human errors, including failure to diagnose or failure to take action, which play a large role in both the Level 1 and Level 2 analyses. These assumptions are documented in Volume 2 report and in Chapters 5 and 6 of this volume.

\subsection{Strengths and Limitations}

The strengths of this study are:

(1) It is a systematic evaluation of risk during mid-loop operation at the Surry Unit 1 plant, including accident frequency, accident progression, source term and consequence analysis with a determination of uncertainty in each of the component analyses and in the final risk measures.

(2) The risk analysis takes into account the long time after shutdown that the accidents can occur and the impact of the consequent decay in power level and radionuclide inventory on the risk. In particular, new latent cancer weights were derived for source term partitioning and used in the consequence calculation.

(3) The newest version of the MELCOR code, version 1.8.2, was used to calculate the timing of key events in the accident progression which were then used in the accident progression event tree.

(4) The accident progression event tree has sufficient detail to account for a significant portion of the likely paths of evolution of the accident.

(5) The study includes a scoping calculation of onsite dose rates at locations in the vicinity of the plant during the accident.

The study has the following main limitations:

(1) There was no formal expert elicitation process used, as in the NUREG-1150 study, to provide values and distributions for key variables in the accident progression. Assignments for these variables had to be made internally at BNL or derived from analogy with full power conditions. The selection of the key variables themselves was also made internally at BNL. Thus the uncertainty analysis is not as robust as it could have been with input from an expert panel.

(2) The scope of the study is limited to accidents initiated by internal events (due to equipment failure or human error) during mid-loop operation. Risk estimates were not made for accidents initiated by internal fires, internal floods and seismic events. The final risk numbers should therefore not be interpreted to reflect the risk of all plant operational states during low power and shutdown operation. 


\section{Introduction}

\subsection{Organization of This Report}

This report is published in six volumes as described briefly in the Foreword. The first volume of NUREG/CR6144 provides a summary of the results of the full scope PRA (levels 1, 2, and 3) that has been performed for the Surry plant for severe accidents that might occur during mid-loop operation.

Volumes 2 through 6 present a detailed description of the results of the constituent analyses. Volume 2 describes the analysis of the core damage frequency (CDF) from internal events initiated during mid-loop operation. An analysis of the CDF from internal fire and internal floods is presented in Volumes 3 and 4, respectively. The CDF from seismic events is addressed in Volume 5.

This volume of NUREG/CR-6144, Volume 6, presents the risk results for accidents during mid-loop operation at Surry. Part 1 of this volume presents the analysis and the results in some detail; Part 2 consists of appendices which contain further detail. Following a summary and introduction, Chapter 2 of this volume presents the results of Phase 1 of this study which consisted of an abriaged risk study.

The rest of the chapters describe the more detailed Phase 2 study. Chapter 3 briefly describes the methods used in the study. A description of the plant is given in Chapter 4. The interface between the level 1 and level 2 analyses is described in Chapter 5. Chapter 6 presents the results of the accident progression analysis. Chapter 7 presents the results of the source term analysis, and Chapter 8 gives the results of the consequence analysis. Chapter 9 summarizes the risk results, including the contributors to uncertainty. The results for midloop operation are compared with the full power results in Chapter 10. Remaining open issues are addressed in Chapter 11, and finally Chapter 12 presents the conclusions drawn from the study.

\subsection{References}

1. Chu, T. L., et al., "Evaluation of Potential Severe Accidents During Low Power and Shutdown Operations at Surry Unit-1: Analysis of Core Damage Frequency from Internal Events During Mid-loop Operations," Brookhaven National Laboratory, NUREG/CR-6144, Volume 2, June 1994.

2. U. S. Nuclear Regulatory Commission, "Severe Accident Risks: An Assessment for Five U.S. Nuclear Power Plants,” NUREG-1150, Vols. 1-3, December 1990 - January 1991.

3. Jow, H. N., W. B. Murfin and J. D. Johnson, "XSOR Codes User's Manual," NUREG/CR-5360, Sandia National Laboratories, December 1989.

4. Summers, R. M., et. al., "MELCOR 1.8.0: A Computer Code for Nuclear Reactor Severe Accident Source Term and Risk Assessment Analyses," NUREG/CR-5531, Sandia National Laboratories, SAND90-0364, January 1991. 


\section{SUMMARY OF ABRIDGED STUDY ON RISK DURING MID-LOOP OPERATION}

\subsection{Background and Objectives}

The abridged risk study was conducted from January through April 1992. The objective of the analysis was to make a preliminary determination of risk of the accident progression and the consequences of accidents during mid-loop operation at the Surry plant, Unit 1 . The study was designed to obtain results for regulatory decisions that were to be made in the early summer of 1992.

The abridged risk study was carried out to compute estimates of the conditional consequences (probability of the various events during the accident progressions multiplied by the consequences), given the occurrence of core damage. Traditional risk estimates, computed by multiplying the conditional consequences and the frequency of the sequences leading up to core damage, could not be made because the frequencies had yet to be determined in companion Level 1 and human reliability analysis (HRA) studies. Uncertainty was taken into account in a manner consistent with the detail of the abridged study.

\subsection{Methodology}

The methodology of the abridged study was an abbreviated version of the NUREG-1150 1 study. The calculations began with the assumption that core damage had occurred, making the consequences conditional. Given core damage, the possible accident progressions were delineated with a simple accident progression event tree (APET) limited to nine top event questions. The timing of key events in the accident progression was based on deterministic calculations with the MELCOR ${ }^{2}$ code. The likelihood of the various accident progressions is reflected by branch point probabilities in the APET. In large-scale risk studies, such as NUREG-1150, the assignment of such probabilities is made by a formal expert elicitation process; in the abridged study, because of resource limitations, these assignments were made by the BNL staff. Thus, the probabilities are not as rigorous as they could be; this is one of several limitations of the study. This lack of rigor was partially offset by repeating the calculations with other reasonable input values; together, these repeated calculations constitute an uncertainty analysis.

Through the uncertainty analysis, distributions, instead of point values, were assigned to the branch points. The distributions are subjective, but account for many possible values of the branch points. Point values were selected from the distributions with a form of Monte Carlo sampling known as Latin Hypercube Sampling (LHS). ${ }^{3}$ After making sets of inputs, each set is assigned to the branch points and multiplied through to the ends of the APET. The calculations were repeated using the sets of inputs to build a probability distribution at the end of each pathway.

Having delineated accident progressions with the APET, the source terms of the progressions were calculated with the parametric SURSOR ${ }^{4}$ code developed for the NUREG-1150 program. SURSOR determines source terms from the characteristics of the pathways through the APET and other inputs. As in the APET calculations, distributions are assigned to the variables and sampled with LHS to form many sets of input 


\section{Summary of Abridged Study on Risk During Mid-Loop Operation}

values for repeated calculations. The result is a distribution of source terms for each accident progression pathway.

Two sets of consequence measures were determined; an onsite dose rate (within the site boundary and designated as a parking lot dose rate), and offsite consequences, including early fatalities, population dose, and latent cancers.

- The parking lot dose rate was computed using a recent model by Ramsdell ${ }^{5}$ and a combination of the older Wilson ${ }^{6}$ and Regulatory Guide 1.145 models. $^{7}$ (Dose rates inside the containment or the reactor building were not calculated because the releases were assumed to take place through the equipment hatch directly to the outside).

- Offsite consequences were computed using the MACCS code. ${ }^{8}$ Uncertainty was not propagated through the consequences as it was through the APET and the source term calculations.

Conditional risk was computed for each accident progression pathway by multiplying the consequences by their associated probabilities determined from the APET. The products of the pathways were summed. This process was repeated for each Monte Carlo sample of the source terms. Then, high, medium, and low results were reported. In the NUREG-1150 study, ${ }^{1}$ high, medium and low results are represented by the 95 th percentile, median and 5th percentile values of the distribution of the results. However, in this study, the number of samples taken was not sufficient enough to define them statistically. Therefore, they were referred to as high, medium and low results. They would approach the statistical 95th, 50th or 5th percentiles, if sufficient numbers of samples were taken.

\subsection{Accident Progression Analysis}

The abridged analysis was based on a preliminary screening analysis of the systems reliability and characterization of the accident sequences leading to core damage for the internally initiated events at the Surry Unit 1 plant. ${ }^{9}$ From this coarse screening analysis ${ }^{9}$ mid-loop operation, which can occur during drained maintenance or refueling outages, was determined to be one of the most vulnerable plant conditions, mainly due to the reduced inventory in the RCS. The dominant causes of accidents during mid-loop operation are loss of residual heat removal (RHR) and loss of offsite power. Loss of RHR accident sequences occur largely due to operator errors, such as failure to diagnose an accident or failure to take proper action. Operating experience at nuclear power plants indicate a relatively high incidence of loss of RHR. For this category of accidents, the recovery probability is largely determined by the human reliability analysis (HRA). Since the HRA results have a large band of uncertainty, it also was included as an uncertainty parameter. For accidents initiated by a loss of offsite power, the probability of recovering offsite power during the accident progression determines the probability of recovering core cooling capability, and terminating the accident.

For the abridged analysis, it was assumed that all the reactor loops were isolated and the safety/relief valves were removed for maintenance, which provides a vent path from the RCS to the containment.

The time to enter mid-loop after shutdown and the duration of mid-loop operation vary widely; from one day to more than one month. These times were selected as an uncertainty parameter to be varied in the sampling process. Longer times after shutdown are characterized by a lower decay heat level which potentially increases 


\section{Summary of Abridged Study on Risk During Mid-Loop Operation}

the time available to take actions to recover core cooling capability before the core is uncovered, and also reduces the inventory of fission products available for release.

To determine the extent of detail needed for the APET, extensive use was made of the accident progression analysis for the Surry plant carried out for the NUREG-1150 program, ${ }^{1}$ which was a PRA of the plant at full power. That study showed that the major cause of release at Surry was containment bypass, followed by basemat melt-through. The probability of early failure of the containment caused by various mechanisms such as a hydrogen or steam explosion and late failure resulting from gradual pressurization was either very small or negligible. Thus, once the containment boundary is closed, the containment retains the fission products most of the time (except by very late basemat melt-through). In other words, phenomena such as direct containment heating or steam explosions were not important contributors to the estimated probability of containment failure and the eventual release of fission products. For accidents during low power and shutdown operation where the decay heat is significantly less and the reactor pressure is generally low, there are no particular reasons to believe that the performance of a closed containment would be any worse than for accidents occurring at full power. Two important factors for determining the containment's response during an accident in mid-loop operation are the status of its integrity and the availability of containment sprays.

From several discussions with the Surry personnel, it was learned that while the containment is considered "closed" during mid-loop operation at Surry, closure does not ensure that the containment can contain the pressure which could be generated during a severe accident and prevent release of fission products. ${ }^{10}$ This is due primarily to the presence of a temporary restraining plug, that has no overpressure capability, in place of the escape tunnel in the containment equipment hatch. Therefore, in the abridged study, no credit was given to the containment barrier; it was assumed that the fission products would leak to the environment once they were released to the containment. This aspect simplified the abridged APET. Because the integrity of the containment is already lost at accident initiation, many questions normally needed to assess the potential for containment failure are no longer relevant.

Sprays are important because they are the major containment cooling system during severe accidents, and can reduce the source terms by scrubbing. There is no requirement under the existing technical specifications to have any of the containment sprays available once the plant enters the RHR entry condition at Surry. ${ }^{10}$ Consequently, all of the containment sprays could be out of service during mid-loop operation. Spray availability was used as one of the uncertainty parameters in this study.

Figure 2.1 shows the APET used in the abridged study. The first three questions refer to the status of containment. In the abridged study, the containment was assumed to be leaking from the start of the accident. Once the status of the containment is identified, the fourth question asked is the timing of core-cooling recovery, which determines the extent of core damage. Arrest of core degradation before failure of the vessel during a severe accident could significantly decrease the magnitude of release of fission products. Therefore, the timing of recovery of core-cooling capability was divided into five periods; Very early, Early, Intermediate, Late, and Never. The timing of Very early extends to the point where core cooling is recovered without any core damage. Early is recovery of cooling during the relatively short period after the cladding rupture of the fuel rods, but before significant core melting. Intermediate is the period in which the recovery of core cooling will arrest the progress of core melt without breaching the vessel. From consultation with the Source Term Advisory Group, this intermediate period was assumed to extend until $45 \%$ core melting occurred. If core cooling is recovered during the Late period (which, here, is defined to be more than $45 \%$ of the core melted), the vessel is assumed to be breached by the core debris. Never indicates no core cooling recovery. 


\section{Summary of Abridged Study on Risk During Mid-Loop Operation}

The time of accident initiation varies widely. Therefore, the BNL staff determined the time of accident initiation by sampling from the joint distributions of the time to enter the mid-loop operation and the duration of mid-loop operation for each observation. Data from the Surry plant, which were collected for the screening level 1 analysis, ${ }^{9}$ were used to determine the distribution of the time of accident initiation; the MELCORcalculated timing of the core-melt progression was adjusted by the decay heat to determine the time available for recovery of core cooling for the accident sequences whose times of accident initiation were different from those selected for the MELCOR calculations. The recovery probability was based on the HRA recovery curve for human error, ${ }^{11}$ the offsite power recovery curve, ${ }^{9}$ and hardware availability for each of the time periods (the latter from data used in the screening level 1 study).

The next three questions in the APET address spray availability and whether the cavity is dry or wet, which determines the extent of core-concrete interaction. Spray availability was included as an uncertainty parameter. Because the containment during mid-loop operation at Surry was assumed to have no pressureholding capability, the branches related to Closed and Open containment were not developed further in this study. This APET was applied to each of the major cutsets leading to core damage sequences identified in the preliminary screening level 1 study in which core damage was defined to have occurred when the coolant level dropped to the top of active fuel.

The outcomes of the accident sequences in the APET were classified into eight bins (including a No Release bin) depending on the extent of core damage, vessel breach and spray availability (Fig. 2.1). In estimating the final risks conditional on core damage, only accident sequences which were actually predicted to result in core damage were included; accident sequences which were terminated in the Very early period were not included in the calculations of conditional risk. The conditional probability of arrest of core damage before vessel breach for the abridged analysis was estimated to vary from a high of about 0.75 to a low of about 0.4 with both the mean and median being approximately 0.55 . The corresponding conditional probability at full power estimated in the NUREG-1150 study of Surry ranged from a high (95th percentile) of 0.7 to a low (5th percentile) of about 0.2 with a mean of 0.5 and a median of 0.45 .

\subsection{Source Term Analysis}

The parametric code, SURSOR, ${ }^{4}$ that was developed in NUREG-1150 for Surry, was used to define source terms in the abridged study. Two measures were taken to assure the adequacy of the source terms: The first involved comparing the calculations from MELCOR with the data used in and results from SURSOR. Second, a Source Term Advisory Group was established to provide guidance, and any additional information on modifying the SURSOR code for the present study.

Considering the differences between full power and shutdown operations, the Source Term Advisory Group identified two parameters in SURSOR as important and possibly different than the values used in NUREG1150. The first parameter is the fraction of the fission products in the core that are released to the vessel before vessel breach. The second parameter is the fraction of the fission products released to the vessel that are subsequently released to the containment. The distributions of these two parameters as defined in NUREG-1150 were compared with MELCOR calculations to establish the values to be used.

SURSOR was used to predict the fission product release fractions for the five accident progression bins (APBs), APB-4 through APB-8, presented in Figure 2.1. Source terms for APB-1 through APB-3 were not considered because they were not expected to lead to any significant offsite consequences. (Due to early 
recovery, there is no core damage for APB-1 and only clad damage for APB-2 and APB-3). Two hundred sets (or observations) of release fractions were produced for each of the five bins to address source term uncertainty.

To limit the number of offsite consequence calculations, but still provide a range of uncertainty, 19 source term samples were randomly selected (from the 200 source term samples, using the LHS sampling method) for each of the five APBs for offsite consequence calculations.* When combined with the two time parameters, associated with the duration of mid-loop operation during the drained maintenance and the refueling outages respectively, this gave 38 source term samples for each APB.

In addition to release fractions, a complete description of a source term requires specification of the timing, energy, and height of the release. The timing of the release affects both the radioactive decay of the inventory and the warning time for offsite emergency response (e.g., evacuation). The release times and durations were obtained from MELCOR calculations. Since the release time is measured from accident initiation (which in the case of mid-loop operation may be many days after shutdown of the reactor) it is not meant for calculating radioactive decay after reactor shutdown, but can be used to determine the timing for emergency response. The warning time for offsite emergency response is the time at which notification is provided to the public to begin emergency response procedures as measured from the time of accident initiation. In the abridged study, the warning time was assumed to be 60 minutes after accident initiation.

An important parameter in the source term definition for accidents initiated during mid-loop operation, which is not considered in a full power analysis, is the time of accident initiation measured from reactor shutdown. This parameter determines the inventory available for release at accident initiation. The extended time period between accident initiation and reactor shutdown for an accident during mid-loop operation will result in significant radioactive decay, and consequently, a much reduced fission product inventory available for release. Because of its importance to consequences, it was treated as one of the uncertainty parameters in the abridged study. A randomly selected value of the time of accident initiation over the duration of mid-loop operation was assigned to each source term defined in this study.

\subsection{Consequence Analysis}

\subsubsection{Onsite Consequences}

The onsite dose rate is a sum of the inhalation and cloud exposure dose rates based on the radionuclide concentration in the wake region of a building. A scoping value of onsite dose rate was estimated using the following wake centerline concentration models: Ramsdell, ${ }^{5}$ Wilson, ${ }^{6}$ and Reg. Guide $1.145^{7}$

The scoping calculations were performed for three source terms referred to as high, medium, and low (Gap release). The Wilson/Reg. Guide 1.145 labelled box in Figure 2.2 is based on the Reg. Guide 1.145 prediction, limited from above by the values predicted by the Wilson model. The results in Figure 2.2 for the onsite dose

This is the minimum number of source term samples needed to provide a $5 \%$ to $95 \%$ range for the consequence measures. However, because of the low confidence level associated with such a small sample, they are simply referred to as the upper and lower limits of the calculations, with no percentiles associated with them. 


\section{Summary of Abridged Study on Risk During Mid-Loop Operation}

rate $(\mathrm{Rem} / \mathrm{h})$ indicate a variation of about two orders of magnitude as a function of the source term. The onsite dose rates are high, and are likely to lead to early fatalities for exposed workers. In view of the relatively large number of onsite personnel during shutdown operations, these dose rates outside the containment suggest that a careful examination should be made of onsite evacuation schemes to limit the consequences in the event of an accident.

\subsubsection{Offsite Consequences}

MACCS $^{8}$ calculations of the offsite consequences were made for all the source terms generated by LHS sampling ${ }^{3}$ of the SURSOR results. There were nineteen sample groups (one for Drained Maintenance and one for Refueling outages), each containing four distinct sets of release fractions for the nine radionuclide groups represented in the MACCS calculations. The time of release for each group was determined using the LHS technique. The radionuclide core inventories for Surry at various times after shutdown were taken from Reference 12. Then, the initial inventory for each source term was calculated using a logarithmic interpolation between the two closest data points.

The following additional assumptions were used:

- Release power: $1.0 \mathrm{MW}$ (sensitivity calculations with $0.0 \mathrm{MW}$ ).

- Release elevation: $28^{\prime}(8.54 \mathrm{~m})$, the height of the equipment hatch above ground.

Figure 2.3 shows the results for the early and latent fatalities predicted by MACCS. APB- 5 through APB- 8 contain thirty eight data points each. The median value of early fatalities is shown only for APB-7; zero values were predicted for the remaining bins.

\subsection{Conditional Probabilities of Consequences}

Once the consequences are calculated for each of the release bins, conditional risk can be evaluated by combining the accident progression analysis, source term analysis, and consequences. If the core damage frequencies of the PDS had been available from the level 1 analysis, absolute risk could have been calculated for this particular POS. However, since they were unavailable, risk was calculated as conditional on core damage; i.e., the results presented are averaged over various accident progressions, given core damage.

Figure 2.4 shows ranges of four risk measures (conditional on core damage), the early fatalities, late cancer fatalities, the population dose at 50 miles, and the population dose at 1000 miles, calculated for the accidents initiated by internal events during mid-loop operation at Surry. The upper and lower bounds shown in the figures do not represent any particular statistical measures because the number of samples was too small to attach any statistical significance to them. However, if sufficient samples are used, these bounds are expected to asymptotically approach the 5 th and 95 th percentiles. For comparison, the figure show the same risk measures for full power operation at Surry from the NUREG-1150 study; to make this comparison, the calculated risk results of NUREG-1150 were converted in an approximate fashion to conditional probabilities of the various consequence measures; conditional on core damage and on containment failure. The comparison shows that the conditional probability of early fatalities during mid-loop operation is considerably less than the conditional probability of early fatalities at full power either given core damage or given 


\section{Summary of Abridged Study on Risk During Mid-Loop Operation}

containment failure. This result is expected since the fission products will have had a longer time to decay and the species which have the greatest influence on the early fatalities generally have short half lives.

Figure 2.4 also shows that the latent cancer fatalities and population doses are higher than those predicted for the full power accidents conditional on core damage. However, these long-term health effects are comparable for accidents conditional on containment failure because these risk measures are more affected by slow-decaying species and the longer decay time has less impact on these species. Therefore, the risks are similar once containment is failed. Since the containment is assumed to be essentially open during mid-loop operation in the abridged study, the offsite risk of latent health effects averaged over core damage sequences is higher for mid-loop operation than for full power operation.

These comparisons of the conditional probabilities of consequences for mid-loop and full power operation are conditional on the occurrence of core damage or containment failure, i.e., assuming the same frequency of core damage or the same probability of containment failure. However, the risk profile is determined by the product of these conditional risks with the frequencies of occurrence of the conditions giving rise to the risk. If the frequencies of core damage or containment failure accidents are significantly different during mid-loop operation from those at full power, the risk profiles will be dominated by those accident frequencies.

\subsection{References}

1. U. S. Nuclear Regulatory Commission, "Severe Accident Risks: An Assessment for Five U.S. Nuclear Power Plants," NUREG-1150, Vols. 1 - 3, December 1990 - January 1991.

2. Summers, R. M., et. al., "MELCOR 1.8.0: A Computer Code for Nuclear Reactor Severe Accident Source Term and Risk Assessment Analyses," NUREG/CR-5531, Sandia National Laboratories, SAND90-0364, January 1991.

3. Iman, R. L., et al., "A FORTRAN 77 Program and Users Guide for the Generation of Latin Hypercube and Random Sampling Use with Computer Codes," Sandia National Laboratory, NUREG/CR-3624, March 1984.

4. Jow, H. N., W. B. Murfin and J. D. Johnson, "XSOR Codes User's Manual," NUREG/CR-5360, Sandia National Laboratories, December 1989.

5. Ramsdell, J. V., "Diffusion in Building Wakes for Ground-Level Releases," Atmospheric Environment, Vol. 24B, No. 3, pp. 377-388, 1990.

6. Wilson, D. J., "Dilution of Exhaust Gases From Building Surface Vents," ASHRAE Trans., 83 (Pt. 1), pp. 168-176, 1977.

7. U. S. Nuclear Commission Regulatory Guide 1.145, Revision 1, November 1982.

8. Chanin, D. I., et. al., "MELCOR Accident Analysis Consequence Code System," Sandia National Laboratories, NUREG/CR-4691, Sandia National Laboratories, SAND86-1562, Vols. 1 - 3, February, 1990.

9. Chu, T-L., et al., "PWR Low Power and Shutdown Accident Frequencies Program: Phase 1-Coarse Screening Analysis," Draft Letter Report, November 1991. Available in the NRC Public Document Room, 2120 L Street, NW, Washington, DC. 
2 Summary of Abridged Study on Risk During Mid-Loop Operation

10. A Letter from T. L. Chu, Brookhaven National Laboratory to C. Lovett, Surry, Feb. 1992.

11. Swain, A. D., "Handbook of HRA," NUREG/CR-1278, August 1983.

12. Denning, R. S., R. Freeman-Kelly, P. Cybulskis, and L. A. Curtis, "Source Term Calculations for Assessing Radiation Dose to Equipment," NUREG-CR-4949, July 1989. 


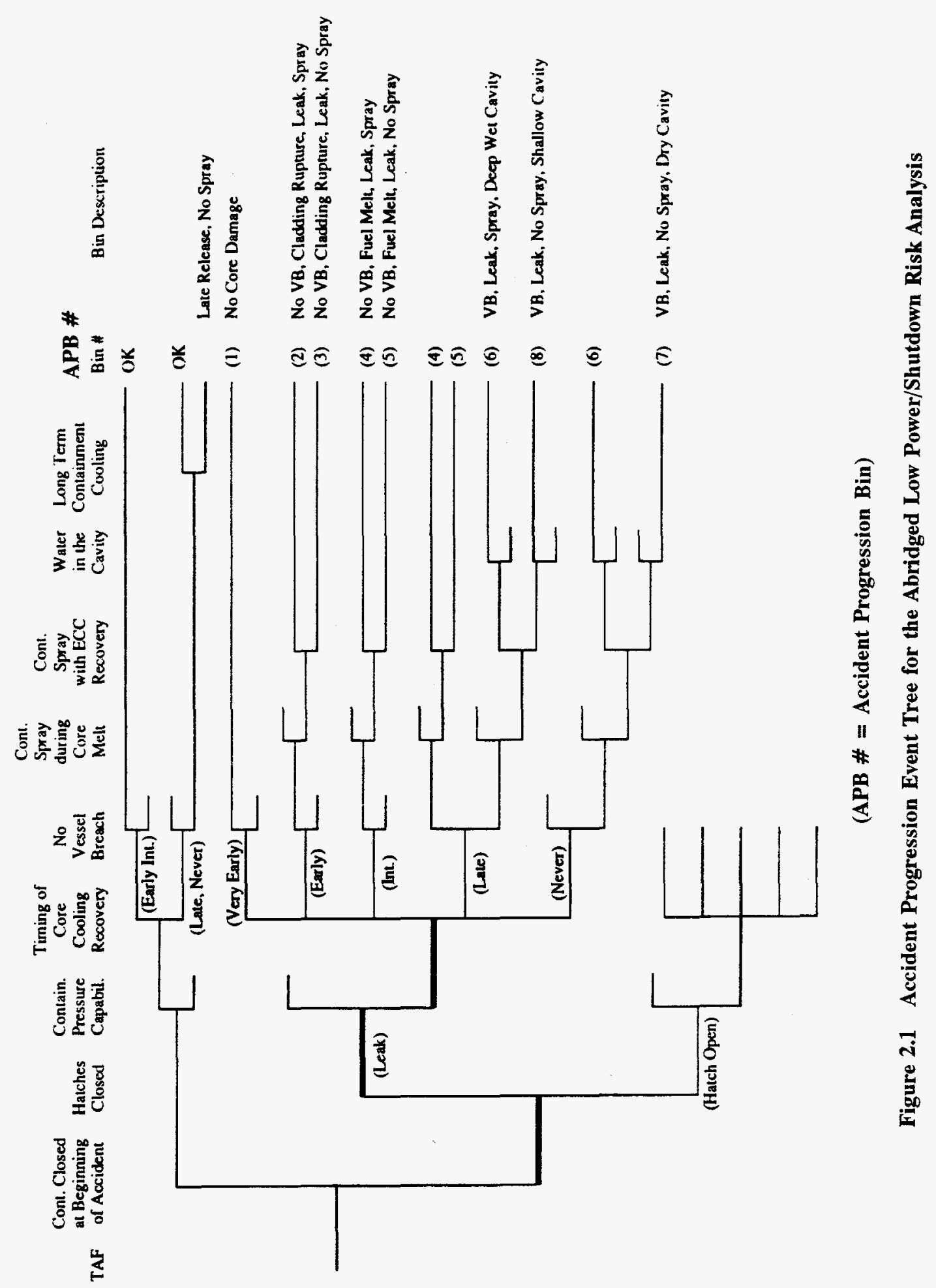


2 Summary of Abridged Study on Risk During Mid-Loop Operation
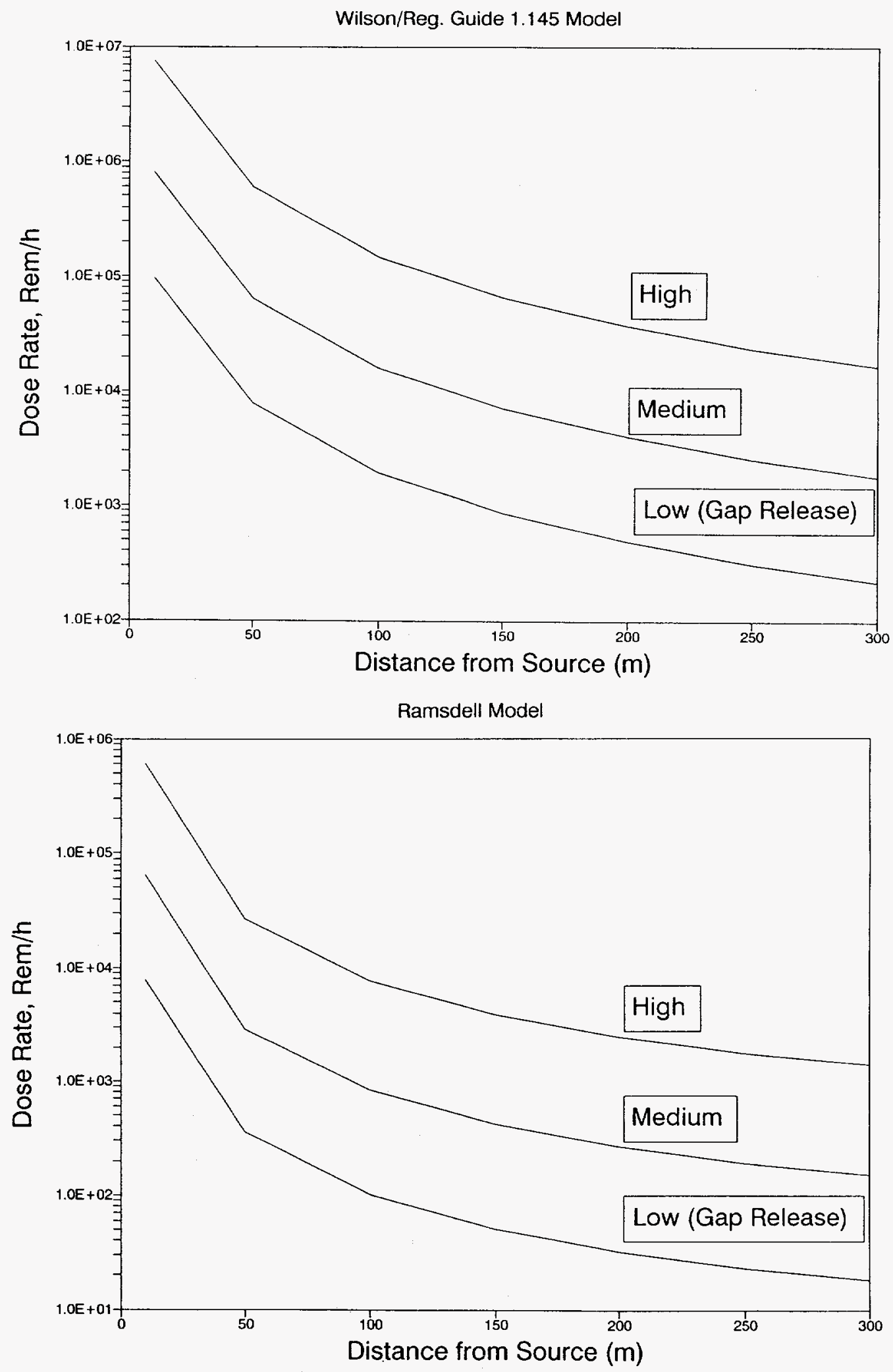

Figure 2.2 Onsite Parking-Lot Dose Rate 
2 Summary of Abridged Study on Risk During Mid-Loop Operation

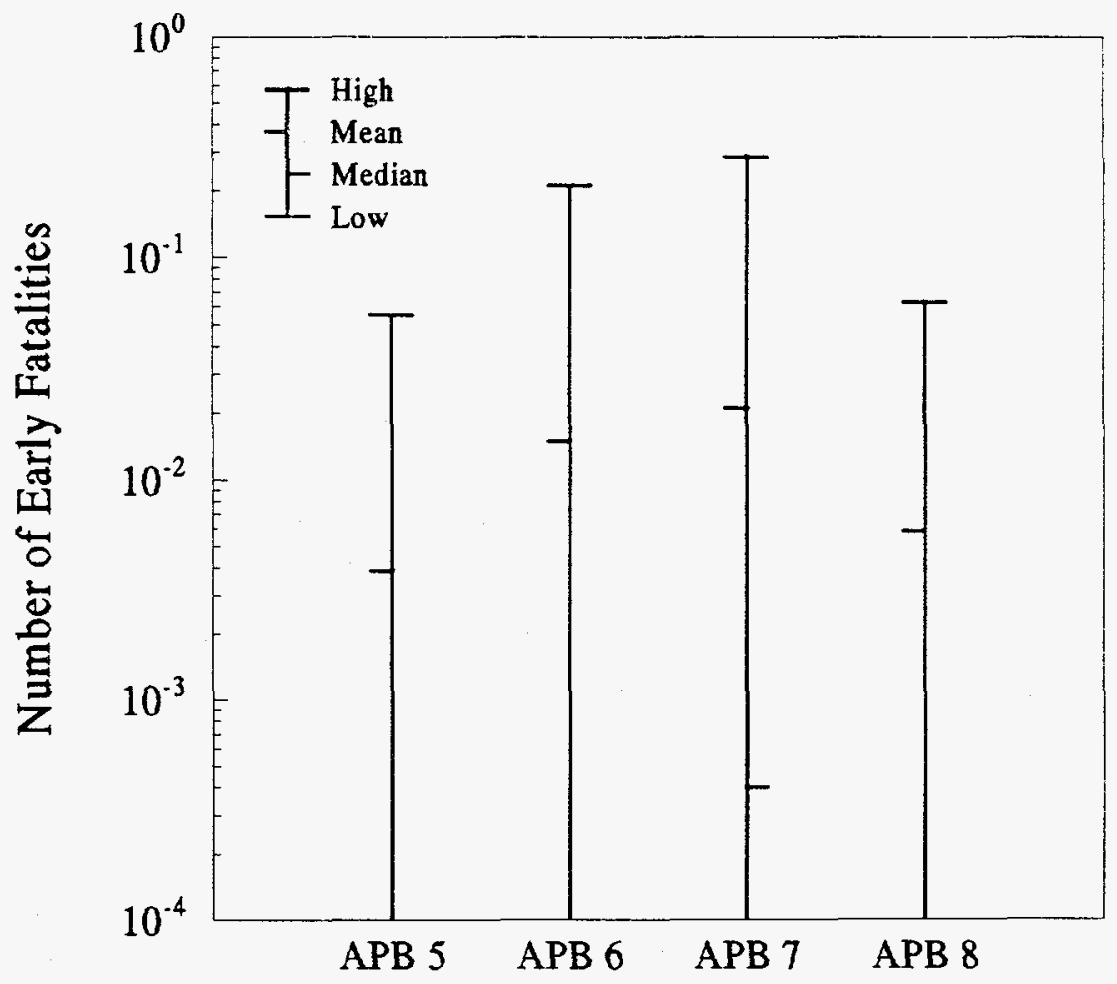

Note: The median values for APB 5, APB 6 and APB 8 were zero.

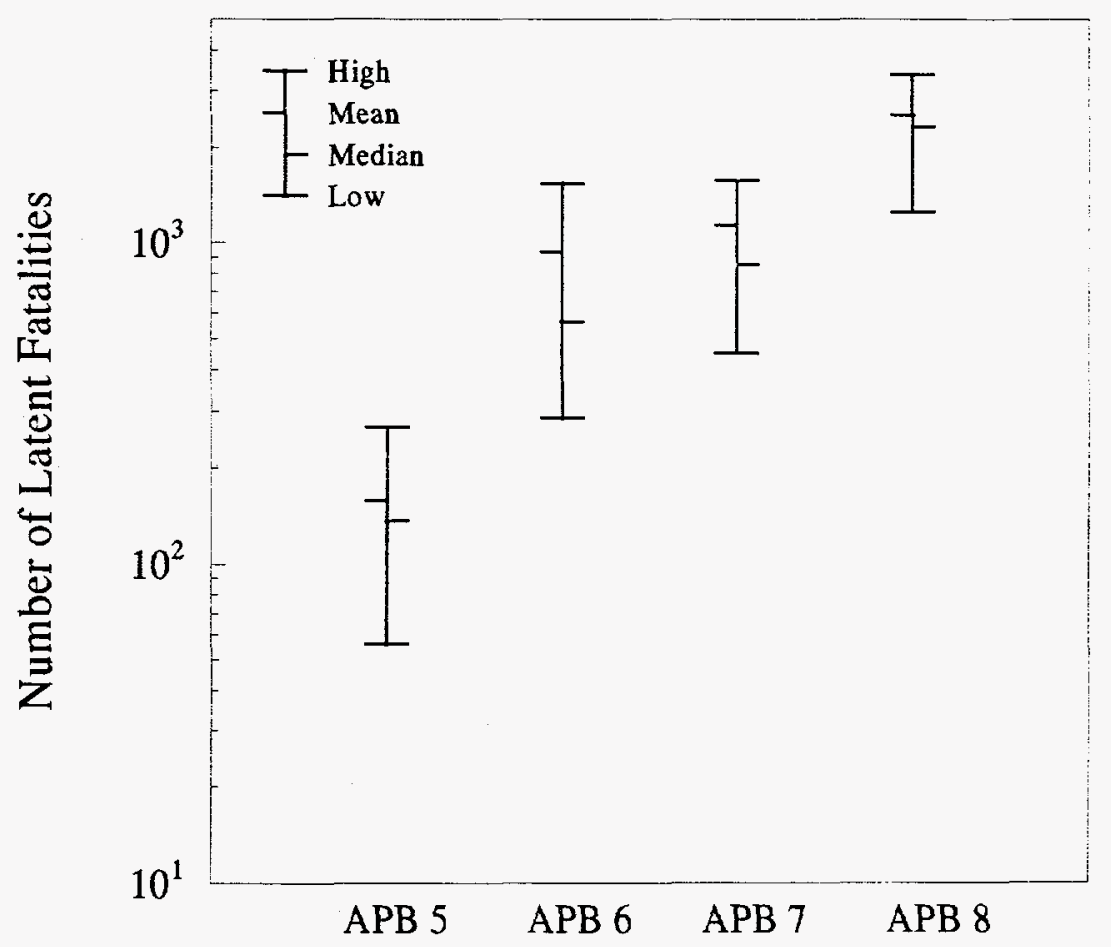

Figure 2.3 Offsite Consequence Conditional on Various Accident Progression Bins (Accident Progression Bins Defined in Figure 2.1) 
2 Summary of Abridged Study on Risk During Mid-Loop Operation
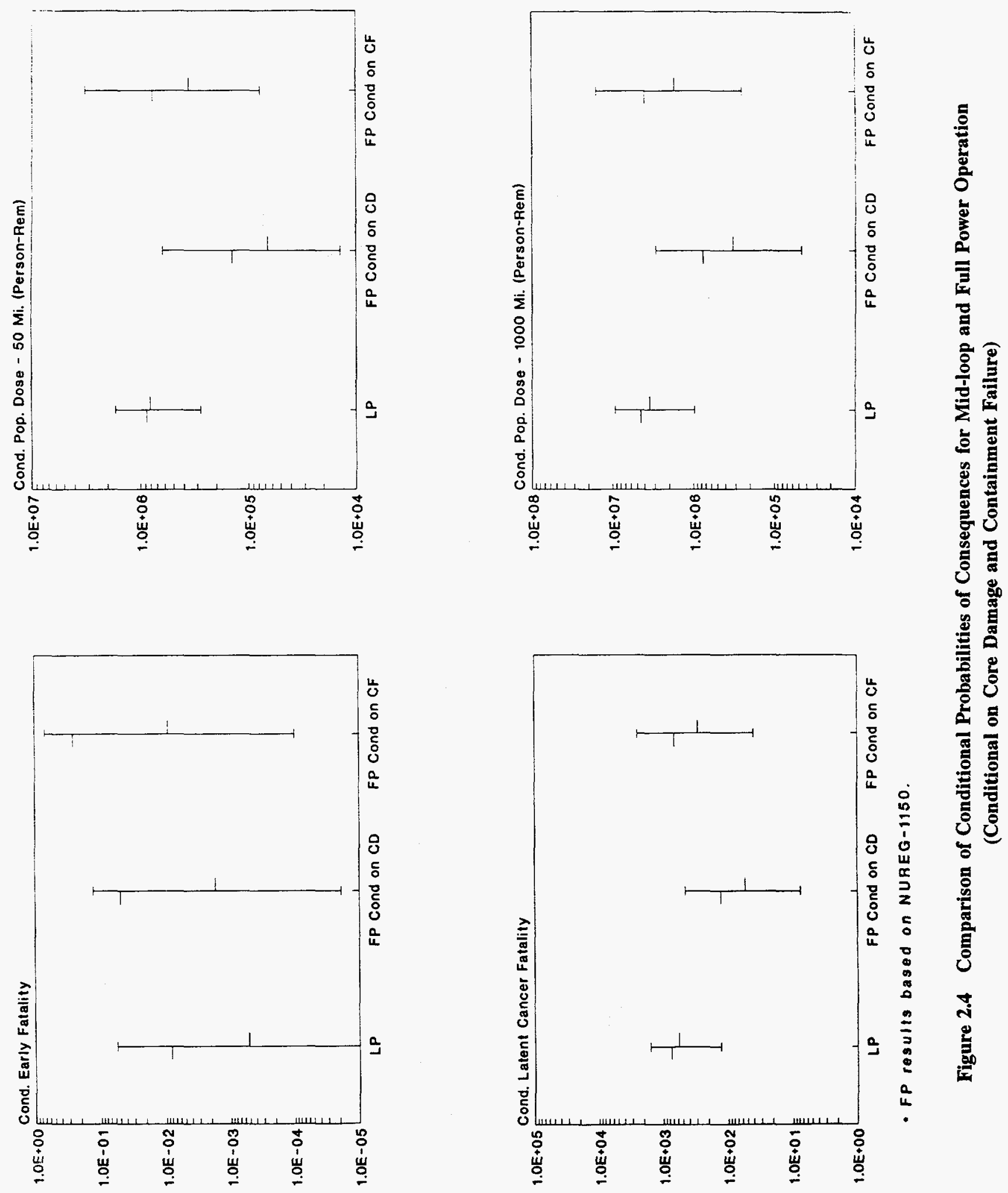


\section{METHODOLOGY}

The approach used in the current risk assessment was to utilize to the extent possible the component analyses developed as part of the NUREG-1150 program. ${ }^{1}$ The components of the analyses used to compute risk are displayed schematically in Figure 3.1. This figure is very similar to a figure presented in reference 2 which describes the risk assessment performed for full power operation at Surry. Both approaches have the same four elements (accident frequency, accident progression, source term, and consequence analysis) but some of the components of the analysis had to be modified to reflect differences between the plant conditions at full power and during mid-loop operation.

\subsection{Overview of NUREG-1150 Methodology}

Figure 3.1 displays schematically the components of the analysis process which consists of four elements:

1) Systems analysis and models of plant response to various initiating events, quantification of accident sequences leading to core damage;

2) Analysis of the accident progression to determine various possible ways the accident could evolve given core damage;

3) Source term analysis, the releases to the environment for the various outcomes of the accident progression;

4) Consequence analysis, the health and economic impacts of each of the source terms.

Risk is calculated by combining the frequency of core damage, the conditional probability of the release paths, and the value of the consequences of each source term conditional on the release into a single risk measure. By repeating the calculation several times with different input values (over specified ranges) of key parameters, a distribution of risk estimates is obtained from which the uncertainty in the risk can be determined.

\subsubsection{Accident Frequency Analysis}

The accident frequency analysis consists of the fault trees and event trees delineating the sequences leading to core damage. In four out of the five NUREG-1150 studies, the SETS code ${ }^{3}$ was used to perform the initial accident frequency analysis. The ultimate outcome of the initial accident frequency analysis is the group of minimal cut sets leading to core damage. The minimal cutsets are then grouped into plant damage states (PDSs), based on similarity of plant conditions, to define the entry points for the subsequent accident progression analysis. 


\section{Methodology}

\subsubsection{Accident Progression Analysis}

In NUREG-1150, accident progression was analyzed using a single accident progression event tree (APET) developed for each plant which was evaluated with the EVNTRE code. ${ }^{4}$ The specification of each PDS defines the entry conditions to the APET. The APET developed for Surry in NUREG-1150 had 71 event questions and many of the questions had several outcomes; there were thus far too many paths through the tree to allow consideration of each individual path in terms of the subsequent source term and consequence analysis. The outcomes of the paths were grouped into accident progression bins (APBs) which have similar characteristics and define the entry conditions for the source term analysis. Mechanistic and deterministic code calculations, experimental observations, and a formal expert elicitation process were employed in NUREG-1150 to determine values of key parameters and their ranges in quantifying the model of accident progression.

\subsubsection{Source Term Analysis}

For each accident progression bin (APB), the source term in NUREG-1150 was calculated by a parametric code, SURSOR. ${ }^{5}$ This code is based on a mass-balance approach which considers the fractions of the radionuclide inventory released to the vessel, from the vessel to the containment, and from the containment to the environment. SURSOR incorporates the results of detailed mechanistic codes such as MELCOR, ${ }^{6}$ MAAP, ${ }^{7}$ and the Source Term Code Package ${ }^{8}$ as well as distributions provided by expert judgement into a fast-running code which can be executed repeatedly with different values of input parameters to provide distributions of source terms for each APB. The number of APBs is large enough so that evaluating the consequences of each source term in each bin (there are potentially tens of thousands of source terms) is not practical. In NUREG-1150, the source terms were classified into source term groups by the PARTITION program. ${ }^{9}$ Partitioning is a procedure for grouping of the source terms based on the similarity of their consequences, that is, the early and late health effects arising from the magnitude and timing of the release of the radionuclide core inventory specified in each source term. Each source term is assigned an early fatality effect weight (which may be zero) and a chronic fatality effect weight and the source terms are divided into groups which have similar values of the weights. A further subdivision of the groups is made on the basis of the release timing relative to the warning and emergency evacuation times. In each source term group, an average (mean) source term is defined and then used for the detailed consequence calculation.

\subsubsection{Consequence Analysis}

The consequence measures, early fatalities, population dose (person-rem), and latent fatalities, are calculated for each source term group by the MACCS ${ }^{10}$ code. The output of MACCS for each source term group is a distribution of the consequences, conditional on occurrence of the source term, which incorporates the uncertainty (variability) due to weather. However, in the NUREG-1150 process, the consequence analysis differs from the three earlier components, accident frequency/plant damage state analysis, accident progression, and source term analysis, in that uncertainties due to important variables and phenomena in the consequence analysis were not propagated through the risk analysis via the Latin Hypercube sampling process ${ }^{11}$ as they were for the other three constituent analyses. 


\subsubsection{Risk Calculations}

Risk is obtained by combining the output from each of the component analyses as shown in Figure 3.1. The uncertainty and sensitivity analysis of the risk is carried out by using a stratified form of Monte Carlo analysis called Latin Hypercube Sampling. ${ }^{11}$ This approach is based on assigning distributions to important variables (through a formal expert elicitation process, for example), creating samples by randomly picking values from the distributions and propagating them through the analysis. The result is a distribution of risk for each of the consequence measures.

\subsection{Methodology of Current Study}

The methodological approach adopted in the current study is mostly based on the NUREG-1150 approach, which is described in detail in references 1 and 2. The sections below therefore describe only those elements of the methodology which are different from the NUREG-1150 approach.

\subsubsection{Accident Frequency Analysis}

The Level 1 analysis, including fault trees, event trees, recovery actions, etc., of the significant accident sequences leading to core damage and their frequencies, was carried out by the IRRAS code. ${ }^{12}$ This analysis is documented in Volume 2 of this report. A summary of the level 1 analysis results is presented in Chapter 5 of this volume. A newly added feature of IRRAS which became available recently was used to group the minimal cut sets into the plant damage states. Seven characteristics were used to construct the plant damage states.

The first characteristic identifies the time frame in which the accident occurs. A major difference between a PRA at full power and at mid-loop operation is the extended time period following shutdown during which an accident can occur. This time period allows for a significant decay of the power level, extends the time available for various phenomena and for recovery actions and leads to a lower value of the radionuclide inventory which can potentially be released. This feature of the shutdown PRA was modeled in the Level 1, accident frequency analysis through the construction of four "time windows" for various time periods following shutdown. Each time window has its own decay heat level and success criteria for accomplishing various recovery actions prior to core damage. The first PDS characteristic therefore identifies the time window in which the accident occurs.

The second characteristic provides the status of ac power. Of particular interest is whether or not ac power is available and if it is not available whether it can be recovered. Human error is an important contributor to the core damage accident frequency for mid-loop operation. The third characteristic therefore identifies if human error contributed to the accident and if it did what was the type of error. The status of the reactor coolant system can significantly impact accident progression and this is therefore addressed in the fourth PDS characteristic. For some plant damage states recovering coolant injection after the start of core damage can prevent further core damage and terminate the accident prior to the core melting through the reactor vessel. The fifth characteristic deals with the issue of restoring coolant injection. If core damage occurs and containment integrity is lost then operation of the containment sprays can reduce the airborne fission product aerosol concentration and reduce the amount of radionuclides released to the environment. The sixth characteristic gives the status of the spray system. Finally the status (injected or not injected) of the refueling 
water storage tank is given in the seventh characteristic. The construction of the plant damage states is described in more detail in Chapter 5.

\subsubsection{Accident Progression Analysis}

The accident progression event tree developed for mid-loop operation has been developed largely based on the APET developed for full power operation in the NUREG-1150 study. Some questions were removed and other questions pertinent to mid-loop operation (such as time windows and containment closure) were added. The APET for mid-loop operation consists of 40 questions compared to 71 questions in the full power APET. Due to resource limitations, a formal expert elicitation procedure could not be implemented to construct ranges of values and distributions for key variables. Assignments of these values and ranges were therefore made internally at BNL. The timing of key events in the accident progression is based on calculations carried out with the MELCOR code. ${ }^{6}$ A very important issue which has a major impact on the result is the status of the containment at accident initiation. Assignments of the possible values of this status were made based on discussions and exchange of written communications with the Surry plant personnel. The APET developed for mid-loop operation is described in detail in Chapter 6. The APET was evaluated using the EVNTRE code as in the full power study. It was again necessary to combine the numerous outcomes of the APET into accident progression bins for input to the source term analysis. A similar approach to that used in the full power study was also used in the current analysis. The only additional information needed for the current study was the time window in which the accident occurred. Thus information identifying the time window was carried throughout all of the constituent analyses.

\subsubsection{Source Term Analysis}

The source term analysis used for mid-loop operation was similar to the approach used for full-power operation. The SURSOR ${ }^{5}$ code was reviewed for its applicability to shutdown conditions by an expert group consisting of staff from BNL and SNL. The source term ranges in SURSOR were also compared against predictions with the MELCOR code. In general SURSOR was considered appropriate for use in the current study. The APBs were therefore processed through the SURSOR code in a similar manner to the full power study. The output from SURSOR is a larger number of source terms which need to be grouped into representative source terms. The process was done in the full power study using PARTITION.

Methodologically, the important difference between NUREG-1150 and the present study is a reworking of the partition approach to reflect the long time interval and consequent decay of the inventory in the current study. In effect, accident progression bins and source term groups are defined for each time window. The partitioning of the source terms and the assignment of health effect weights is carried out through a partition procedure designated PARTITION-LPS, which is described in Chapter 7.

\subsubsection{Consequence Analysis}

The consequence measures for the average source term in each source term group were calculated by the MACCS code. ${ }^{10}$ The latest release of MACCS, ${ }^{10}$ version 1.5.11.1, which incorporates the important BEIR V update to the latent cancer - dose relationship, ${ }^{13}$ was used to compute consequences. In contrast, the NUREG-1150 study used an earlier version of MACCS, Version 1.5.11, to compute consequences. The more 
recent version of MACCS gives a higher (by approximately a factor of 3) number of latent cancers, than the earlier MACCS version for the same value of population dose.

\subsubsection{Risk Calculations and Uncertainty}

Risk was obtained by combining the individual results of each of the constituent analyses as shown in Fig. 3.1. The approach was similar to the NUREG-1150 approach. Distributions were assigned to important variables (some distributions were identical to those used in NUREG-1150, others were developed specifically for midloop operation) and samples were then created by randomly picking values from the distributions using Latin Hypercube Sampling. ${ }^{11}$ For each sample the values assigned to each variable were propagated through the analysis to determine risk estimates for each consequence measure. By repeating the calculation for 100 samples (or observations) distributions of risk estimates were obtained from which the uncertainty in risk was determined.

\subsection{Scoping Calculation of Onsite Doses}

A scoping calculation of onsite doses, outside of the main risk calculation, was carried out at the request of NRC to gain some insight into plant conditions at the time of the release which could possibly have an effect on various recovery actions in different locations of the plant. This calculation is based on taking ranges of high and low source terms in various time windows and interfacing them with deterministically estimated weather conditions. Two different correlations, one of which includes recent work on building wake correlations, were used to compute the "parking lot" dose as described in Chapter 8.

\subsection{References}

1. U. S. Nuclear Regulatory Commission, "Severe Accident Risks: An Assessment for Five U.S. Nuclear Power Plants," NUREG-1150, Vols. 1-3, December 1990-January 1991.

2. Breeding, R. J., et al., "Evaluation of Severe Accident Risks: Surry Unit 1," NUREG/CR-4551, Volume 3, Rev. 1, Parts 1 and 2, Sandia National Laboratories, December 1993.

3. Stack, D. W., “A SETS User's Manual for Accident Sequence Analysis," Sandia National Laboratories, NUREG/CR-3547, SAND83-2238, January 1984.

4. Griesmeyer, J. M. and L. N. Smith, "A Reference Manual for the Event Progression Analysis Code (EVNTRE)," NUREG/CR-5174, Sandia National Laboratories, September 1989.

5. Jow, H. N., W. B. Murfin and J. D. Johnson, “XSOR Codes User's Manual,” NUREG/CR-5360, Sandia National Laboratories, December 1989.

6. Summers, R. M., et al., "MELCOR 1.8.0: A Computer Code for Nuclear Reactor Severe Accident Source Term and Risk Assessment Analyses," NUREG/CR-5531, Sandia National Laboratories, SAND90-0364, January 1991. 


\section{Methodology}

7. Fauske and Associates, Inc., "MAAP Modular Accident Analysis Program User's Manual," Vols. I and II, IDCOR Technical Report 16.2-3, February 1987.

8. Gieseke, J. A., et al., "Source Term Code Package: A User's Guide," Battelle Columbus Division, NUREG/CR-4587, BMI-2138, July 1986.

9. Iman, R. L., et al., "PARTITION: A Program for Defining the Source Term/Consequence Analysis Interface in the NUREG-1150 Probabilistic Risk Assessments, User's Guide," Sandia National Laboratories, NUREG/CR-5253, May 1990.

10. Chanin, D. I., et al., "MELCOR Accident Consequence Code System (MACCS)," Sandia National Laboratories, NUREG/CR-4691, Vols. 1-3, February 1990.

11. Iman, R. L., et al., "A FORTRAN 77 Program and Users Guide for the Generation of Latin Hypercube and Random Sampling Use with Computer Codes," Sandia National Laboratory, NUREG/CR-3624, March 1984.

12. Russell, K. D., et al., "Integrated Reliability and Risk Analysis System (IRRAS) Version NEW5," Developed by Idaho National Engineering Laboratory, 1993.

13. National Research Council Committee on Biological Effects of Ionizing Radiation (BEIR V), "Health Effects of Exposure to Low Levels of Ionizing Radiation," National Academy of Sciences, Washington, DC, 1990. 
3 Methodology

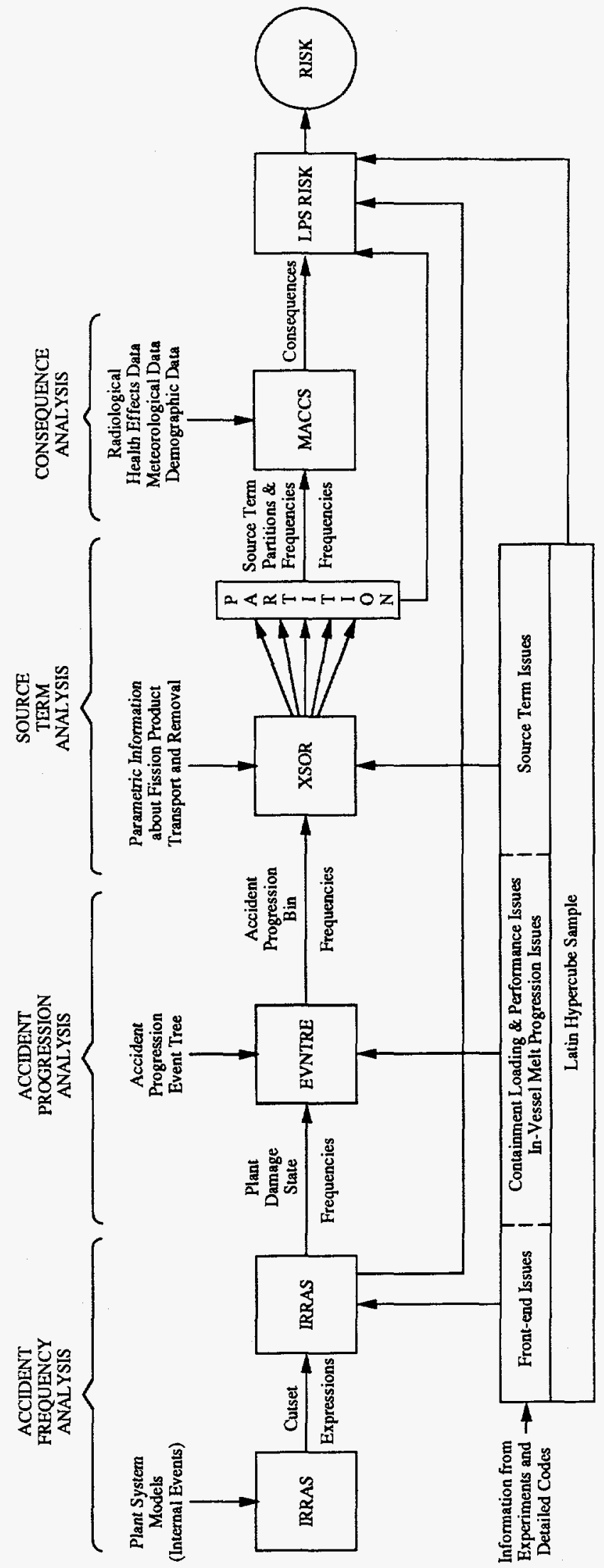



Vol. 6, Part 1 


\section{PLANT DESCRIPTION}

\subsection{General Description}

Surry Unit 1 is a 2441 MWth pressurized water reactor (PWR) designed and constructed by Westinghouse. It is operated by the Virginia Electric Power Company. Surry is a three-loop plant; the reactor coolant system has three U-tube steam generators and three reactor coolant pumps. The containment and balance of plant were designed and constructed by Stone and Webster. Commercial operation of Unit 1 began in 1972.

Emergency ac power at the site is supplied by three diesel generators (DGs). One DG is aligned to Unit 1, the other to Unit 2, and the third DG functions as a swing diesel which can be aligned to either unit. Emergency dc power is supplied by separate battery banks at each unit. The DGs have their own separate set of batteries for starting power. The auxiliary feedwater (AFW) system has three trains. Two trains have electric pumps, the third train has a steam turbine driven pump. The condensate storage tank provides suction for the AFW system. The chemical volume and control system has three charging pumps which also serve as the high-pressure injection (HPI) pumps. There are two low pressure injection (LPI) pumps. Both the HPI and the LPI systems can function in the injection or recirculation mode. In the injection mode, they take suction from the refueling water storage tank (RWST) while in the recirculation mode they take suction from the sump. A more detailed description of the safety injection/recirculation systems is provided in sections 4.2.2.1 and 4.2.2.2 below. Surry also has three accumulators which provide a source of immediate, lowpressure, high flow injection.

Overpressure protection for the reactor coolant system is provided by three code safety/relief valves (SRV) and two power operated relief valves (PORV). Surry has an unique service water system which is supplied by gravity flow from an elevated canal. The canal is continuously supplied by river water from the Jamestown river through electric pumps. If ac power is lost, the service water canal will drain in about 30 minutes unless a large number of valves are closed manually.

The Surry containment is a reinforced concrete cylinder with a hemispherical dome. The free volume of the containment is 1.8 million cubic feet and the design pressure is 45 psig. A welded steel liner covers the inner surface of the containment and forms the pressure boundary. A section of the Surry containment is shown in Figure 4.1. Due to design conservatisms, realistic estimates of the loads needed to fail the containment are between two and three times the design pressure. The mean of the distribution for the failure pressure of the Surry containment provided by the expert panel in the NUREG-1150 study was 126 psig. During full-power operation, the Surry containment is maintained at a sub-atmospheric pressure of about 10 psia, i.e., about 5 psia below ambient atmospheric pressure. This feature and the Technical Specifications prevent plant operation much in excess of this pressure therefore the probability of pre-existing leaks and isolation failure during normal operation is extremely low.

Cooling of the containment is normally provided by fan coolers which are not safety grade and will be partially submerged if the sump is filled with water. Emergency cooling of the containment is provided by the containment spray systems (CSS). The CSS is described in more detail in section 4.2.4 below. Another feature of the Surry containment at a low elevation is that there is no connection between the sump and the 
reactor cavity. If a pipe break occurs, the water will flow to the sump. The cavity remains dry unless the containment sprays operate.

The general description given above indicates the main plant systems available during full power operation at Surry. However, during shutdown the plant is configured differently than during full power operation and some of the systems described above will not be available.

\subsection{Plant and System Configuration During Mid-loop Operation}

Three mid-loop operating states were identified and analyzed in the level 1 analysis (refer to volume 2 of this report); two mid-loop operating states during refueling outages (one early in the outage during cooldown using the residual heat removal (RHR) system and the other later after completion of refueling), and another midloop operating state during the cooldown period of a drained maintenance outage. A detailed analysis of plant systems, their response to various accident initiators and their status in accident sequences leading to core damage are contained in Volume 2 of this report. ${ }^{1}$ In this volume, the focus is on those plant systems and features which are important to the progression of the accident and to the possible releases to the containment and the environment following core damage. Accident progression can be influenced by the status of the reactor coolant system, recovery of coolant injection systems, containment integrity, containment spray systems and cavity flooding. These systems and plant features during mid-loop operation are described in the following sections.

\subsubsection{Status of the Reactor Coolant System}

The reactor coolant system (RCS) is at low pressure during mid-loop operation as soon as the plant is placed in the RHR entry level condition. This implies that potential accidents during mid-loop operation will not involve any high pressure sequences such as those modeled in the full power PRA. Also during mid-loop operation the relief valves in the pressurizer are open connecting the pressurizer to the pressurizer relief tank which is vented to the process vent system. The vessel head vent is connected to the discharge side of the through piping that consists of a section of tygon tube which can withstand about 40 psia of pressure. Additionally, the safety valves could be removed for maintenance during mid-loop and a temporary partition placed on the opening. This creates the possibility of a direct vent path into containment for any released fission products in the event of any accident. These features of the RCS during mid-loop operation have been incorporated in the accident progression event tree described in Chapter 6.

\subsubsection{Emergency Core Cooling Systems (ECCS)}

The ECCS at Surry consists of the High Pressure Injection/Recirculation (HPI/HPR) system and the Low Pressure Injection/Recirculation (LPI/LPR) system. ECCS is important to the accident progression because for some plant damage states it could be restored after the start of core damage. If the ECCS is restored while the damaged core is still in the reactor vessel it may be possible to terminate the accident prior to vessel meltthrough. A relatively high probability of terminating the accidents invessel was estimated in the accident progression analysis for three out of the four plant damage states. If the core debris has melted through the vessel and is attacking the reactor cavity restoration of the ECCS will supply water to the cavity and flood the 
core debris. A flooded cavity could terminate the core-concrete interaction and considerably mitigate the associated source term. If core-concrete interactions continue, flooding of the cavity would lead to a scrubbing of the fission product release. The possibility of flooding the cavity is also incorporated in the accident progression analysis described in Chapter 6.

\subsubsection{High Pressure Injection/Recirculation System}

The Surry high pressure injection/recirculation (HPI/HPR) system consists of three centrifugal charging pumps and associated piping and valves. Following an accident, the charging pumps are used to provide primary coolant injection and recirculation as well as maintain flow to the RCP seals. The charging pumps are one of the three major components of the Safety Injection (SI) System. The other two components are accumulators and low pressure injection pumps. The primary purposes of the SI system are: (i) to inject borated water into the RCS to flood and cool the core following a LOCA; and (ii) to remove heat from the core for extended periods of time following a LOCA. The HPI system also functions to deliver boric acid to the RCS from the boric acid transfer system if emergency boration is required. The HPI/HPR system provides coolant makeup, early and late core heat removal or emergency boration for reactor shutdown.

The suction source of the charging pumps in the high pressure injection mode is the RWST. Before the contents of the RWST are exhausted, the Engineered Safety Features (ESF) system automatically initiates a recirculation mode transfer (RMT) signal. The operator can also terminate the injection mode and initiate the recirculation mode by manually repositioning the required valves. In the recirculation mode of operation, the HPR is used to provide core heat removal late in an accident sequence. The charging pumps draw suction from the discharge of the low pressure safety injection pumps in the low pressure recirculation (LPR) system.

To minimize the possibility of accidentally overpressurizing the RCS, technical specifications require that whenever the average temperature of the core is less than $350^{\circ} \mathrm{F}$, the following charging pump conditions must be maintained: (i) a maximum of one charging pump operable; and (ii) two charging pumps must be demonstrated inoperable at least every 12 hours by verifying that their circuit breakers are racked out or that their control switches are in the pull-to-lock position. The surveillance requirements specify that a complete systems test be performed during refueling shutdown to demonstrate correct response to an activation of the safety injection signal. The HPI/HPR system configuration at shutdown, including mid-loop operation, is discussed at length in Volume 2 of this report. ${ }^{1}$

\subsubsection{Low Pressure Injection/Recirculation System}

The low pressure injection/recirculation (LPI/LPR) system provides emergency coolant injection and recirculation following a loss of coolant accident (LOCA) when the reactor coolant system (RCS) depressurizes below $180 \mathrm{psig}$. In the injection mode, the LPI system takes suction from the RWST. In the recirculation mode, the LPR system is aligned to take suction from the containment sump. During the recirculation mode following drainage of the RWST to a low-low level, the LPR discharge also provides the net positive suction head (NPSH) for the high pressure recirculation system.

The LPI/LPR system consists of two $100 \%$ capacity pump trains. During normal plant operations, the low pressure injection pumps are in standby, lined up to pump borated water from the RWST to the RCS cold 
legs. Each LPI pump has a capacity of $3250 \mathrm{gpm}$ at a temperature of $300^{\circ} \mathrm{F}$ and a pressure of 300 psig with a design head of $225 \mathrm{ft}$. Actual pump capacity, however, depends on pump discharge pressure.

Technical specifications require that the pumps, piping, valves, etc. of the LPI/LPR system be operable at all times. A detailed description of the LPI/LPR system configuration in the shutdown POSs, including mid-loop operation, is contained in Volume 2 of this report. ${ }^{1}$

\subsubsection{Containment Configuration During Mid-Loop Operation}

At the inception of the Abridged Study, the status of containment isolation during mid-loop operation was raised with VEPCO staff during a visit to Surry. At that time it was determined that while containment was considered "closed" during mid-loop operation, what closure meant was that all penetrations were isolated from the outside, some with temporary barriers, so that there is no air/vapor exchange with the environment. However, "closure" in the above sense did not mean that the containment was capable of withholding the pressure that could be generated during the course of a severe accident and prevent the release of fission products to the environment. The operating procedure checklist 1-OP-1G (Surry Power Station Unit 1 Refueling Containment Integrity and RCS Mid-Loop Containment Closure Checklist), which was acquired from Surry staff on this visit, had as its objective the achievement of containment integrity in the abovementioned sense of an air/vapor barrier not the design pressure capability. The containment closure procedure and closure time mentioned in the January 6, 1989 letter of VEPCO to NRC in their response to Generic Letter GL87-12 were also the procedures and times required to achieve containment isolation in the sense of no air/vapor exchange with the environment.

The difference in containment configuration between normal operation and POS 6, mid-loop operation, of the refueling outage appears to be that during the refueling outage there is a temporary plug in place where the emergency escape trunk is usually installed during normal operation. This is shown schematically in Figure 4.2. The temporary plug was estimated to have only a 3 psi overpressure capability. In normal operation, the escape trunk is installed with the O-rings in place in the interface with the equipment hatch to achieve the design pressure capability.

Based on these considerations, it was assumed in the Abridged Study (refer to Chapter 2 of this report) that for accidents initiated during mid-loop operation which progressed to core damage the containment would leak to the environment from the start of a release into containment. The leak was assumed to take place through the temporary plug in the equipment hatch.

Recognizing perhaps the potential problems regarding containment status during low power and shutdown operation, the Surry staff have developed additional procedures to address the concerns about the closure of the containment during POS 6 or shortly after the initiation of an accident during shutdown operation. According to the most recent Surry procedures, one of the minimum equipment requirements for forced feed and bleed (feed and spill) cooling is containment isolation (Surry Procedure 1-OSP-ZZ-004). The procedure for containment isolation is provided by Surry Operations Surveillance Procedure 1-OSP-CT-214, Containment Closure for Reduced or Potentially Reduced RCS Inventory Conditions. The procedure provides instructions for the preparation, implementation, and documentation of containment closure activities and indicates that it should be carried out before commencing to drain the RCS to a reduced or potentially reduced inventory condition with fuel in the reactor vessel. The procedure lists all the containment penetrations that need to be closed. A single barrier containment isolation is required. However, some penetrations that are required 
for normal operation of the plant may not be isolated during containment closure. The procedure states that valves associated with these penetrations that are in the open position for normal plant operation should be noted as such, but should not be considered as a containment closure discrepancy. Discrepancies that would prevent the achievement of a containment pressure capability of 45 psig are treated as Containment Closure Concerns. One action that may be taken to resolve a Containment Closure Concern is to implement the use of an acceptable barrier to meet Pressurized Containment Isolation: i.e., metal flanges are sealed with red rubber gaskets, bolting material, and torqued to specifications capable of retaining a pressure of 45 psig. There is no discussion in these procedures about what kind of leak tightness is required (or expected) or how it can be assured (e.g. through a leak test) if such a capability exists.

Because only a single barrier is specified, and there exists the possibility that temporary barriers are used for some penetrations, it is likely that the leak tightness and the pressure capability of the containment during POS 6 will not be as good as during normal power operation. On the other hand, if the above procedure succeeds in isolating the containment during POS 6 , leaks from the containment atmosphere in accident conditions, and thus the fission product release, to the outside environment may be significantly reduced.

In addition to the questions about the leak tightness and the pressure capability of the containment, the probability of achieving containment isolation* within the time frame of interest in the presence of degraded containment conditions is another issue which is not addressed by the above procedure.

Since containment status during shutdown is, perhaps, the single most important feature of the plant which affects risk, additional questions on the procedure 1-OSP-CT-214 were addressed to the Surry staff to clarify its scope and intent. The first question was whether implementation of the "single barrier pressurized Containment Isolation" procedure 1-OSP-CT-214 implies that "the containment is completely isolated during all phases of reduced inventory condition?" Surry staff were also asked a second question related to the pressure capability of the containment under the "single barrier containment isolation condition" specified in the procedure and asked if this capability, for both the design and the ultimate capability, was similar to that established for Surry by the NUREG-1150 study (during normal full power operation).

Surry's response to the first question was that the 1/2-OSP-CT-214 procedure "does not ensure that the containment is completely isolated during all phases of reduced inventory conditions." It was pointed out that, under the proposed procedure, the isolation barrier requiring the bulk of the closure time and the resources, the equipment hatch and the escape trunk, would be installed prior to entering reduced inventory and that the procedure "ensures that the majority of the remaining penetrations are closed or capable of being closed by a single isolation barrier (i.e. containment isolation valves) from the main control room". It was also mentioned that "penetrations, which are not or cannot be isolated from the main control room, are listed as discrepancies". However, the statement that the discrepancies would be isolated (by a containment closure team established prior to entering reduced inventory) "in case of an event" coupled with the inability to provide an estimate of the time required to resolve discrepancies and reestablish containment closure leads to some uncertainty about the level of assurance provided by the Surry response, despite the assertion that "any required reestablishment of containment closure should be performed well within the time to core uncovery recommended by Technical Report 865." Regarding the second question, Surry noted that "As an alternative to the escape hatch, a preliminary design for a new barrier is being considered" which would be

* There will be open penetrations that need to be closed after accident initiation. These penetrations include those that are required for normal plant operation during containment closure.

Vol. 6, Part 1 
capable of withstanding 45 psig. It is not clear why a new barrier design is needed (to address the closure/isolation concerns) if the existing barriers can isolate containment "well within" the time frame of relevance to the accident.

Given this uncertainty, particularly the fact the new procedures may still be evolving, it seems prudent to model the probability of pre-existing leakage (as assumed in the Abridged Study) and the containment failure pressure as an uncertainty parameter and perform sensitivity analysis to evaluate the impact of different assumptions regarding containment status. The assumptions made in this regard are described in more detail below in Chapter 6 where the accident progression event tree is developed.

\subsubsection{Containment Spray System}

\subsubsection{Containment Spray Injection System}

Containment heat removal in an emergency at Surry is by means of the containment spray system (CSS) in the injection mode. The containment spray injection system provides initial cooling of the containment atmosphere following an accident which can pressurize the containment, for example a LOCA. The CSS pumps take suction from the refueling water storage tank (RWST), which is filled with chilled $\left(45^{\circ} \mathrm{F}\right)$ borated water, and spray it inside the containment to condense the steam. Containment sprays also provide a mechanism for scrubbing fission products from the released inventory. The Technical Specifications require that the RWST contains between 387,100 and 398,000 gallons of $2300-2500$ ppm borated water chilled to at least $45^{\circ} \mathrm{F}$.

The containment spray system consists of two $100 \%$ capacity trains. Each train is connected to a separate spray ring, and there is an additional ring shared by both trains. The spray pattern from the rings covers about $73 \%$ of the containment atmosphere.

\subsubsection{CSS Configuration During Mid-Loop Operation}

The requirements on the availability of the CSS apply when the RCS temperature and pressure is in excess of $350^{\circ} \mathrm{F}$ and $450 \mathrm{psig}$, respectively. There are no requirements below these limits. When the reactor is operating at power, both CSS trains must be operable.

Considering the operating parameters of mid-loop operation, there are no Technical Specifications which require CSS to be available during this plant operational state. Discussions with Surry personnel indicated, informally, that the probability of at least one train of CSS being available was likely to be fairly high, on the order of 70 percent. Accordingly, spray availability was treated as an uncertainty parameter in the development of the Surry APET in Chapter 6. If CSS is available during POS 6, it would have to be manually actuated since automatic actuation is not available at RCS temperature below $350^{\circ} \mathrm{F}$.

\subsubsection{Recirculation Spray System}

The Inside Spray Recirculation (ISR) and the Outside Spray Recirculation (OSR) systems provide the long term containment cooling and pressure reduction following an accident. At Surry, these systems also provide 


\section{Plant Description}

long term core cooling after the accident. Each of the recirculation spray systems, ISR and OSR, contains two independent pump trains. Each train takes suction from the containment sump and discharges through a separate heat exchanger. There are four heat exchangers, one for each train. The heat exchangers are cooled by service water. Each ISR or OSR train has a separate 180 degree spray ring so there are a total of four spray rings for the recirculation sprays. Two recirculation spray trains, in any combination, are sufficient to provide long term cooling following a loss of coolant accident (LOCA).

The ISR pumps are located inside the containment and are qualified for the harsh post-accident environment. They provide about $3500 \mathrm{gpm}$ of flow. The OSR pumps are located outside the containment and also provide about $3500 \mathrm{gpm}$ of flow each. The recirculation spray systems depend on either the CSS or the ECCS injection system to provide sufficient inventory of water in the sump for their operation and on the service water system for the ultimate heat sink. The requirements on the ISR and OSR systems are for RCS temperatures and pressures in excess of $350^{\circ} \mathrm{F}$ and $450 \mathrm{psig}$, respectively. Above these limits, all four trains must be available. There are no requirements below these limits.

\subsubsection{Recirculation Spray System Configuration During Mid-Loop Operation}

There are no Technical Specifications for ISR and OSR systems below the above limits of $350^{\circ} \mathrm{F}$ and $450 \mathrm{psig}$, which are the operational parameters in POSs 3-13. Thus it is possible that neither of the recirculation spray systems, ISR or OSR, would be available during mid-loop operation. In discussions with Surry plant personnel it was indicated, informally, that the likelihood of availability of at least one train of either ISR or OSR is high ( about 70\%) during shutdown.

\subsubsection{Reactor Cavity}

The reactor cavity at Surry is normally dry as all water in the containment drains to the sump and there is no connection between the sump and the cavity. This feature of the Surry cavity has important implications for the progression of severe accidents and the source terms where the vessel is breached and core-concrete interactions occur. The only way for the cavity to have water is either if the containment sprays operate or if core injection is recovered after vessel breach. This feature has been incorporated in the accident progression event tree described in Chapter 6.

\subsection{References}

1. Chu, T. L., et al., "Evaluation of Potential Severe Accidents During Low Power and Shutdown Operations at Surry Unit-1: Analysis of Core Damage Frequency from Internal Events During Mid-loop Operations," Brookhaven National Laboratory, NUREG/CR-6144, Volume 2, June 1994. 
4 Plant Description

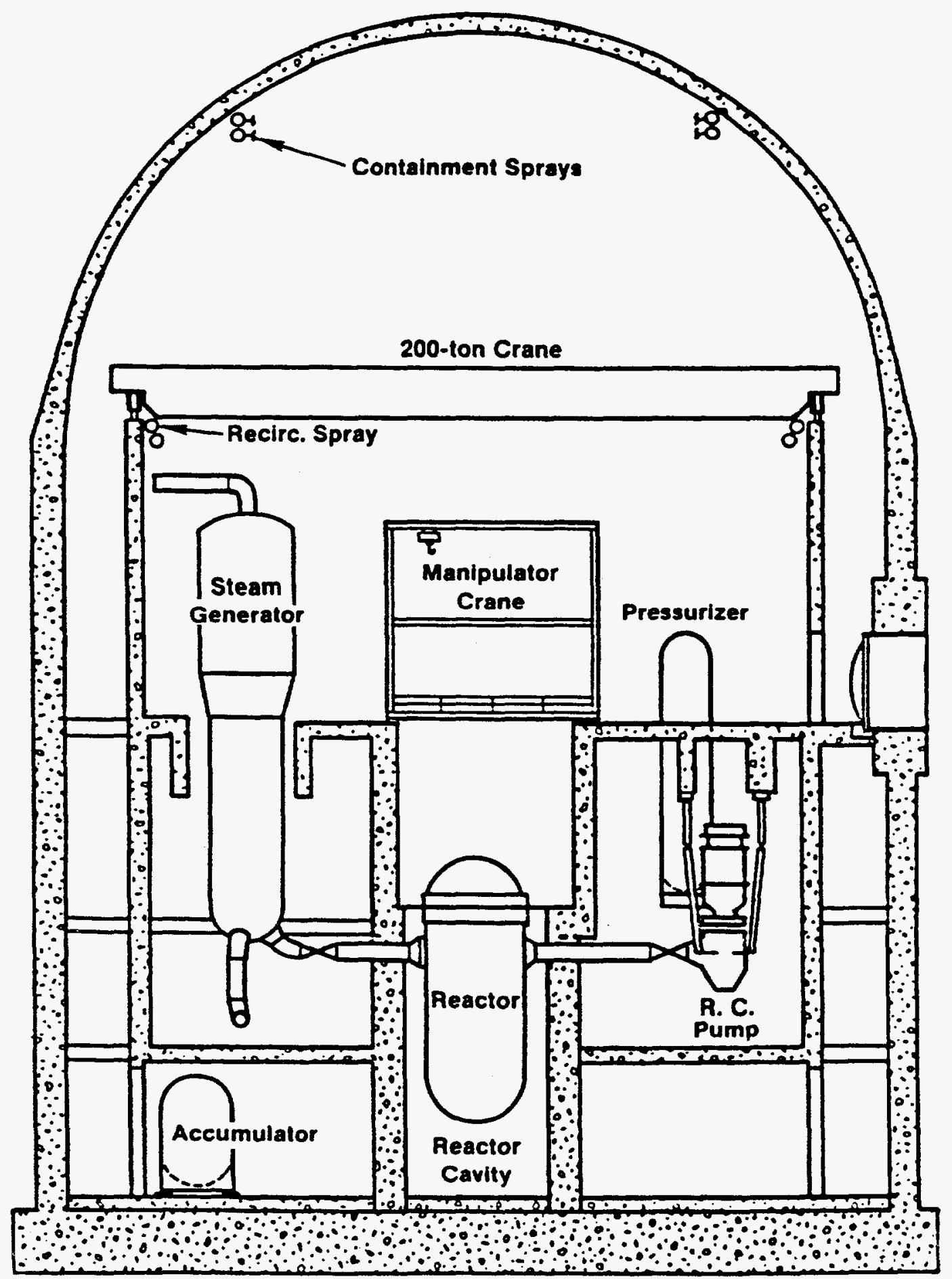

Figure 4.1 Section of Surry Containment 


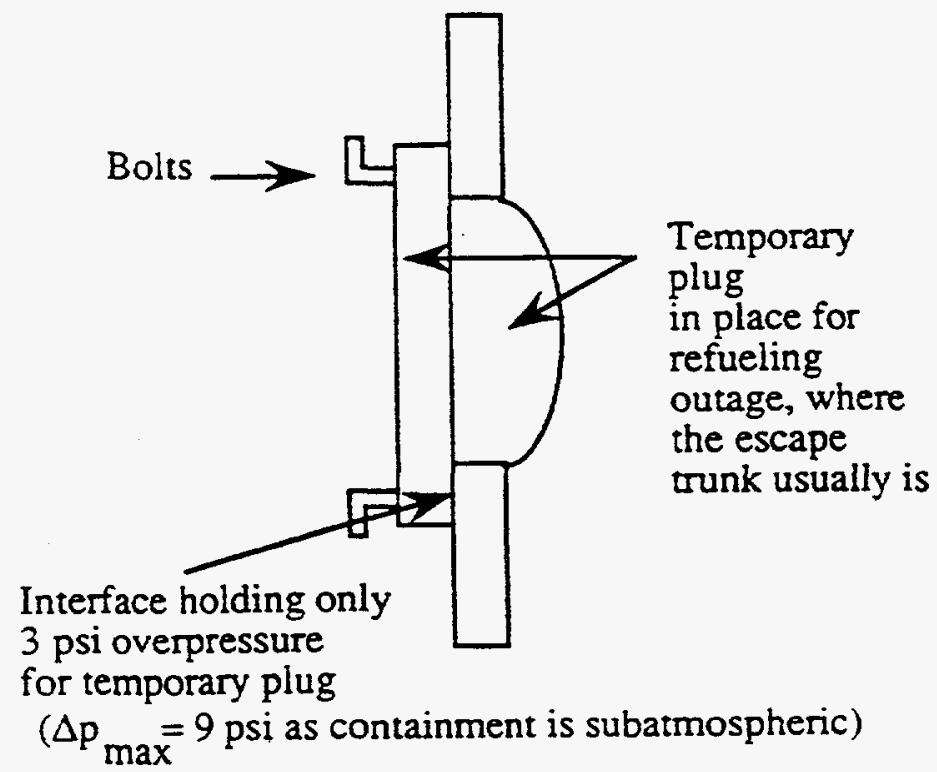

Mid-loop Operation

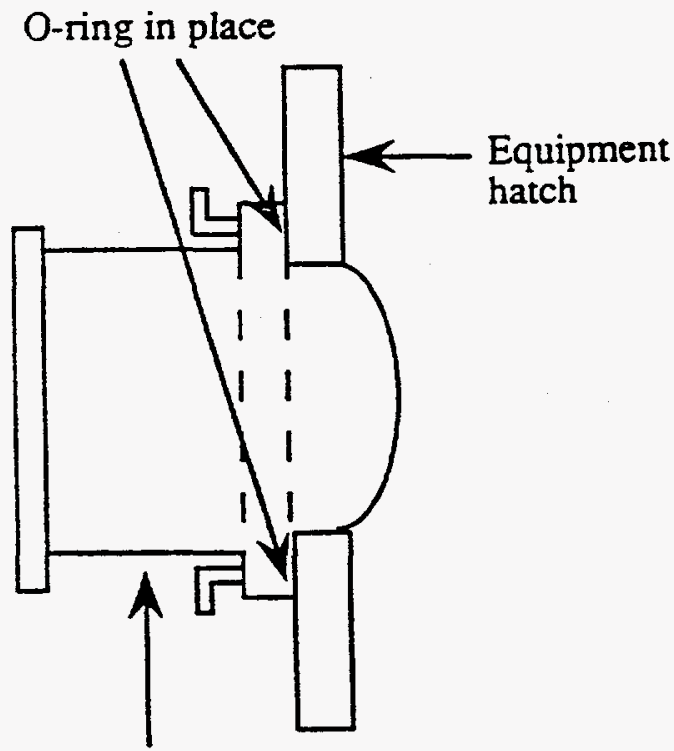

Escape trunk in place: interface with equipment hatch can take the full containment overpressure

Full Power Operation

Figure 4.2 Equipment Hatch Configuration During Mid-loop and Full Power Operation 


\section{ACCIDENT FREQUENCY ANALYSIS INTERFACE}

The analysis ${ }^{1}$ of the core damage frequency (level 1 PRA) for accidents during mid-loop operation is presented in Volume 2 of this report. Volume 2 contains a detailed description of the characteristics of the operational states of the plant during mid-loop operation and describes the initiating events considered. An analysis of the plant's response to the initiating events (including human actions) and the calculation of the frequency of the sequences leading to core damage is also presented. A summary of the core damage frequency analysis is given in Section 5.1 below. The way in which the different accident sequences that can lead to core damage are interfaced with the accident progression analysis is discussed in the remainder of this Chapter. The accident sequences are binned into plant damage states which have the characteristic that all sequences in a given plant damage state behave in a similar manner during the subsequent accident progression. The starting point for the accident progression analysis is therefore defining the plant damage states and calculating their frequency. The characteristics of the plant damage states are described in section 5.2. The calculation of their frequency is presented in section 5.3.

\subsection{Summary of Level 1 Core Damage Accidents}

\subsubsection{Definition of Plant Outage Types and Operational States}

The initiating events and systems analysis performed for Surry Unit 1 in the Level 1 analysis included all operational modes at less than $15 \%$ power defined in the Updated Surry Final Safety Analysis Report. Seven operational modes are defined in the Surry Technical Specifications in terms of reactor criticality, reactor power, temperature, and pressure; five of these, refueling shutdown, cold shutdown condition, intermediate shutdown condition, hot shutdown condition, and refueling operation refer to low power and shutdown conditions.

Four different types of outage were considered in the Level 1 analysis: refueling, drained maintenance, nondrained maintenance with the use of the residual heat removal (RHR) system, and non-drained maintenance without the use of the RHR system. Each outage type is further subdivided into phases defined by the following parameters: Frequency, Plant Configuration, System Availability, Shutdown Activities, Time to Core Uncovery, Maintenance Unavailability, Reactor Coolant System (RCS) Integrity, Containment Integrity, Reactivity, Reactor Coolant Temperature, Reactor Coolant Pressure, Reactor Vessel Level, Time after Shutdown and Duration. The phases are described as plant operating states (POSs). Each outage type is characterized by a number of POSs, the time spent in each POS (a variable determined from plant operating records), and the activities carried out in that POS. The refueling outage, for example, is characterized by 15 POSs as follows:

POS 1: Initiation of low power operation (10-15\% power level) proceeding to hot shutdown (Average Core Temperature $=547^{\circ} \mathrm{F}, \mathrm{RCS}$ pressure $=2235 \mathrm{psig}$ ) .

POS 2: Cooldown with Steam Generators (SGs) to $345^{\circ} \mathrm{F}$.

POS 3: Cooldown with RHR system to $200^{\circ} \mathrm{F}$.

POS 4: Cooldown to ambient temperatures using RHR system. 
5 Accident Frequency Analysis Interface

POS 5: Draining the RCS to Mid-Loop.

POS 6: Mid-Loop Operation.

POS 7: Fill for Refueling.

POS 8: Refueling.

POS 9: Draining RCS to Mid-Loop after Refueling.

POS 10: Mid-Loop Operation after Refueling.

POS 11: Refill RCS completely after Mid-Loop Operation.

POS 12: RCS Heatup Solid and draw Bubble.

POS 13: RCS Heatup to $350^{\circ} \mathrm{F}$.

POS 14: Startup with SGs.

POS 15: Reactor startup and Low Power Operation.

For a drained maintenance outage, POSs 7 through 10 given above would not be applicable. To provide a perspective on the amount of time spent in each of the above POSs, Table 5.1 shows the average duration of each POS for the four outage types based on 1985-1989 plant data.

\subsubsection{Mid-Loop Operation POSs}

Mid-loop operation occurs when the reactor coolant level is drained to the mid-plane of the hot leg. Three mid-loop operation POSs were considered in the accident frequency analysis (refer to Volume 2 of this report). These are POS 6 and POS 10 of a refueling outage, and POS 6 of a drained maintenance outage. In POS 6 of a refueling outage, mid-loop operation is used to perform eddy current testing of the SG tubes, while in POS 6 of drained maintenance it is used to carry out needed maintenance.

In mid-loop the pressurizer power-operated relief valves (PORVs) are open connecting the pressurizer to the pressurizer relief tank (PRT) which is vented to the process vent system through a $3 / 4$ inch line. The vessel head vent is connected to the discharge side of the PORVs through piping that consists of a section of tygon tube which can withstand a pressure of about 40 psia.

During mid-loop operation, based on past practice, there is a possibility that one or more of the reactor loops would be isolated. A review of past data showed that during refueling outages, the loops were isolated prior to reaching POS 6 in one case, and during POS 6 in the other cases. The loops remained isolated until POS 12 was entered, so that all three loops were isolated completely in POS 10. In drained maintenance, on the other hand, one loop is typically isolated. Loop isolation has a very important impact on the ability to use the steam generators to remove decay heat (reflux cooling) in the case of loss of the residual heat removal (RHR) system during mid-loop operation. If the loops are isolated, reflux cooling is not available as a means of controlling the accident.

One important difference between the various mid-loop POSs (in different outage types) is the time after shutdown that the POS occurs and the duration of the POS. These times determine the decay heat level which, in the event of an accident, strongly influences the time of the subsequent accident progression. The time after shutdown at which the accident occurs also strongly influences the fission product inventory 


\section{Accident Frequency Analysis Interface}

potentially available for release if the fuel is damaged. These times, therefore, play a key role in all aspects of the risk analysis. Past outage data at Surry were analyzed to determine distributions of the time to reach mid-loop and the duration of mid-loop operation. Details of the statistical analysis performed are given in Appendix D of Volume 2 of this report. Four statistical measures (i.e., mean, 5th, 50th, and 95th percentile) of these distributions are given in Tables 5.2 (time to reach mid-loop) and 5.3 (duration of mid-loop). These times vary over a wide range; the duration of POS 10, for example, ranges from less than 6 hours to over 2500 hours with a mean of 444 hours. This range greatly affects the evolution of the accident and the likelihood of recovery. The duration times given in Tables 5.1 and 5.3 are different because in Table 5.1 the times are simple averages of the data whereas the mean times in Table 5.3 were obtained by fitting distributions to the data.

A review of past data also showed that during mid-loop operation in a refueling outage the safety valves on the pressurizer were removed for maintenance (sometimes for extended periods). This removal opens a large vent in the RCS. In the event of an accident this vent would allow relief of system pressure and makeup from the refueling water storage tank (RWST). However, it would make reflux cooling impossible due to loss of inventory through the opening. In the accident progression following core damage, the removal of the safety valves also implies the RCS would be at low pressure during the various accident scenarios and that a direct path would exist from the vessel to the containment for the release of fission products. Safety valves are not removed during POS 6 in a drained maintenance outage.

The practice of using mid-loop operation during outages appears to be changing at Surry. In the most recent refueling outage Unit 1 avoided mid-loop operation. The core damage frequency analysis in Volume 2 of the report is based on past practice and does not reflect the most recent outage. It is not clear to what extent the plant can completely avoid going to mid-loop in future outages.

\subsubsection{Description of Time Windows}

The time to enter mid-loop and the average duration of mid-loop operation are important parameters, which have a large impact on the probability of recovering from the accident. The criteria used for success of the safety systems to prevent core damage differ depending on the decay heat level, which is a function of the time that the accident occurs after shutdown. These times also have a significant impact on the progression of the accident and on possible releases and the consequences. In order to incorporate these times formally into the analysis, a "time window" approach was developed. This approach is based on dividing the distribution of times shown in Tables 5.2 and 5.3 into sub-periods called "windows". A total of four time windows after shutdown were defined in the accident frequency analysis. Table 5.4 shows the definition of the time windows. The information in Table 5.4 was reproduced from a more detailed description of the time windows given in Volume 2 of this report. For POS 6, in both refueling and drained maintenance outages, all four windows were applicable; for POS 10 only windows 3 and 4 were applicable.

Each window is characterized by a time interval (measured from the time of reactor shutdown), and a representative level of decay heat, which corresponds to the mid-point of the time interval. The decay heat then determines subsequent parameters such as the time to boiling if the RHR system is lost, the time to reach various pressures which will challenge sub-systems such as the (temporary) tygon tubing, and the pressurizer relief tank (PRT), time to core uncovery and eventually core damage. These times are displayed for each time window in Table 5.4 The definition of time windows used in the accident progression analysis was also used in the definition of the plant damage states, and the accident progression event tree. 


\subsubsection{Summary of Initiating Events}

Initiating events were identified in the Level 1 analysis by reviewing relevant studies and Surry operating procedures and searching licensee event reports. Initiating events that are specifically applicable to mid-loop operation include: loss of RHR, loss of offsite power, loss of $4 \mathrm{kV}$ bus, loss of vital bus, loss of outside instrument air, loss of component cooling water, loss of emergency switchgear room cooling, inadvertent safety feature actuation, and boron dilution events. The most important initiator both in terms of frequency and its impact on the accident analysis is the loss of RHR, followed by loss of offsite power and loss of a $4 \mathrm{kV}$ emergency bus.

\subsubsection{Human Reliability Analysis}

Human error events modeled in the Level 1 analysis included pre-accident errors and post-accident errors. The former were partly adopted from the full power study ${ }^{2}$ performed for Surry, while the latter were specifically developed in the Level 1 analysis through a detailed definition of the event scenario, required actions and the factors which affect operator action. The success likelihood index methodology ${ }^{3}$ (SLIM) was used to derive human error probabilities based on a qualitative evaluation of the actions and parameters affecting operator performance, the performance shaping factors (PSFs). Human errors modeled included failure to diagnose and failure to take action.

\subsubsection{Accident Sequence Quantification and Results}

The accident frequency analysis for mid-loop operation is presented in Volume 2 of this report. The results are summarized here to give a perspective on the subsequent accident progression analysis. A more detailed discussion including consideration of uncertainties is given in Volume 2. Accidents initiated in POS 6 in both drained maintenance and in refueling outages are the most important contributors to the mean core damage frequency. Accidents initiated in POS 10 were estimated to have an order of magnitude lower mean core damage frequency than accidents in POS 6. This result is expected because POS 6 occurs much earlier in an outage than POS 10 so that less time would be available for recovery actions and thus the core damage frequency should be higher in POS 6. The Level 1 analysis generated a total of 2186 core damage cutsets with frequencies greater than the truncation limit of $10^{-10}$ per year. All cutsets with frequencies above $10^{-10}$ per year were incorporated into the plant damage state analysis.

\subsection{Plant Damage State (PDS) Characteristics}

Information about the many different accidents that lead to core damage is passed from the core damage frequency analysis to the accident progression analysis by means of PDSs. Because the accident progression analysis is similar for many of the cutsets identified in the core damage frequency analysis the 2186 cutsets were grouped together into a smaller number of plant damage states. The prime consideration when assigning a core damage accident cutset to a PDS is similarity in the progression of the accident in the vessel and in containment, and in ways to terminate the accident. Therefore all of the sequences binned into a PDS should have similar behavior following the uncovering of the core. 
The plant damage states were identified by a seven-letter indicator that defines seven characteristics that largely determine the progression of the accident. For each characteristic possible attributes are discussed below:

1. Time Window - The time window in which the accident occurs can be easily determined by the basic event names used. Attributes 1,2,3, or 4 are assigned depending on the time window in which the accidents occur.

2. AC Power - This question determines whether or not recovery of offsite power after core damage can prevent further degradation of the condition. If core damage is caused by loss of offsite power, then it may be possible to re-establish injection after offsite power is recovered.

$\mathrm{Y}$ : If $\mathrm{AC}$ power is available in the cutset, then recovery of offsite power is not relevant.

U: This attribute is used when the initiating event is a loss of emergency switchgear room cooling and cooling is not recovered. For such cutsets, the loss of power is not recoverable and vessel breach is unavoidable.

B: If the cutset represents a station blackout, then recovery of offsite power should restore power to the equipment that can be used to prevent vessel breach. Recovery of offsite power is characterized by the recovery curve given in Volume 2 of this report.

F: If the cutset involves a loss of the $4 \mathrm{kV}$ Bus, then restoring power to the bus should restore power to the equipment needed to prevent vessel breach. The recovery of $4 \mathrm{kV}$ bus is characterized by a different recovery curve than that of offsite power.

3. Human Error - If the core damage is the result of human error, then with more time available after core damage and additional alarms as a result of core damage, it is possible that the operators could recover from the error and initiate safety injection to prevent vessel breach. The type of human error can be easily identified by the names of the human error events used. If the error is diagnostic then the attribute is " $D$ ". If it is an action error is involved then the attribute is " $A$ ". If no human error or an unrecoverable human error is involved then the attribute is " $N$ ".

4. RCS Status at Onset of Core Damage - Based on the thermal hydraulic analysis described in Volume 2 of this report, the RCS pressure could reach 600 psi if core damage occurs in time window 1 with only 1 PORV open to relieve system pressure. This is a condition where the potential exists for direct containment heating $(\mathrm{DCH})$ if the core debris melts through the reactor pressure vessel. For those window 1 cutsets in which the pressurizer safety valves are not removed, a letter " $G$ " is assigned. For these cutsets, only two or less PORVs are potentially available to relieve the pressure. For all other configurations the RCS is expected to be at low pressure, which is designated by letter " $\mathrm{L}$ ".

5. ECCS Status - This question determines the cause of failure of the emergency core cooling system (ECCS), which in turn influences the possibility for restoring safety injection to prevent vessel breach.

U: This identifies hardware failure as the reason why ECCS is not available. Under these circumstances it is not possible to establish safety injection. 
5 Accident Frequency Analysis Interface

R: If the cause of ECCS failure is due to either human error, loss of offsite power, or loss of the $4 \mathrm{kV}$ bus, recovery from these events would allow coolant injection to prevent vessel breach.

C: This indicates that ECCS fails during recirculation. The main cause of recirculation failure is plugging of the sump suction. Recovery of ECCS was considered unlikely under these circumstances.

6. Recirculation Spray Status - The operation of the recirculation spray system can reduce the airborne fission product aerosol concentration in containment after core damage. The unavailability of the recirculation spray was determined by a set of basic events that were identified by reviewing the cutsets involving loss of recirculation spray. If the recirculation spray is recoverable then the attribute is " $R$ " if the spray is unrecoverable then " $U$ " is assigned.

7. RWST Status - The RWST inventory is needed if the ECCS is recovered after loss of power or human error. The RWST would not be available for those sequences in which failure occurs in recirculation, gravity feed is successful, or use of the Unit 2 charging pump is successful.

\subsection{Plant Damage State (PDS) Results}

In this section the allocation of the cutsets to the plant damage states is described. Additional details on how individual cutsets were assigned to particular PDSs is given in Appendix A. Initially an algorithm was developed for assigning the cutsets to the various plant damage states using the characteristics discussed in Section 5.2. Designators within the cutsets were identified and matched with the alphanumeric descriptors of the PDS. A total of 48 PDSs were obtained when the algorithm was applied to the 2186 core damage cutsets. The Level 1 analysis generated 10,000 LHS observations using the IRRAS code. ${ }^{4}$ Each sample calculated a frequency for each of the 48 PDSs. The uncertainty ranges included in Appendix A for the 48 PDSs are therefore based on 10,000 LHS observations.

The 48 PDSs generated by the Level 1 analysis were regrouped into four PDS groups to be processed by the accident progression event tree analysis. The main consideration in regrouping was again the similarity of accident progression after core damage and for the convenience of the event tree logic. Appendix A indicates how the 48 PDSs were placed into four more general PDS groups.

It was noted above that the distributions for the 48 PDSs were obtained using 10,000 LHS observations. It would be impractical however to use 10,000 observations for processing through the accident progression analysis and it was therefore decided to use 100 LHS observations. It was therefore necessary to regenerate the uncertainty ranges based on 100 LHS observations for the four PDS groups for input to the accident progression analysis. The uncertainty ranges for the four PDS groups obtained from the smaller number of observations are given in Table 5.5. The uncertainty ranges for the various time windows within each PDS group are also given in Table 5.5 .

The distributions obtained using 10,000 LHS observations differed slightly from the distributions based on only 100 LHS observations. Four statistical measures for the core damage frequency obtained from both sets of observations are given below: 
5 Accident Frequency Analysis Interface

\begin{tabular}{||l|c|c||}
\hline & $\begin{array}{c}\text { Core Damage Frequency Based } \\
\text { on 10,000 LHS Observations }\end{array}$ & $\begin{array}{c}\text { Core Damage Frequency Based } \\
\text { on 100 LHS Observations }\end{array}$ \\
\hline \hline 95th Percentile & $1.5 \mathrm{E}-5$ & $1.94 \mathrm{E}-5$ \\
\hline Mean & $4.9 \mathrm{E}-6$ & $4.2 \mathrm{E}-6$ \\
\hline 50 th Percentile & $2.1 \mathrm{E}-6$ & $2.0 \mathrm{E}-6$ \\
\hline 5th Percentile & $4.8 \mathrm{E}-7$ & $3.2 \mathrm{E}-7$ \\
\hline
\end{tabular}

One can see that the median values of the two distributions are close but that the mean values are further apart. This is to be expected because the means are more influenced by the tails of the distribution. However, the distributions are close and risk numbers obtained using the smaller number of observations should be valid.

From an inspection of the information in Table 5.5 it is apparent that accident sequences in which the operators did not correctly diagnose the situation or take proper actions (plant damage state 2) were the largest contributor (approximately two-thirds of the total) to the mean core damage frequency for mid-loop operation. Table 5.5 also indicates that most of the accidents are predicted to occur in the earlier time windows. This is expected because less time is available for recovery actions in the earlier time windows.

Each of the four plant damage state groups are briefly described below:

PDS Group 1 consists of five blackout PDSs. The PDSs in this group contribute approximately $10 \%$ to the mean core damage frequency. The accidents belonging to this group are initiated by a loss of offsite power. The diesel generators fail to respond, causing a station blackout condition. Attempts are unsuccessful in restoring power in time to provide cooling before core damage. In some of the accidents, gravity feed and bleed delays the onset of core damage until the water in the RWST runs out. The recirculation and containment systems are not available due to the loss of power. In this PDS group, the dominant factor in the accident progression is the recovery of offsite $\mathrm{AC}$ power.

PDS Group 2 consists of accidents attributable to human error. This PDS group contains 20 PDSs and is the largest contributor to the mean core damage frequency for accidents initiated by internal events during midloop operation at Surry. About two-thirds of all core damage accidents belong to this group. In this group operators either fail to diagnose the accidents or to take correct actions, following loss of core cooling due to some initiator. The progression of accidents is somewhat different depending on whether the human error is diagnostic or action. For example, if it is a diagnostic error, it was judged that the same error results in failure to recognize the need for isolating the containment. However, if the error is in action, it was judged that the containment would most likely be closed before core damage. In most cases, electric power and some core cooling systems are available. In this PDS group, the dominating factor in the accident progression is recovery from human errors.

PDS Group 3 consists of accident sequences where core cooling is lost during recirculation. This group contains 17 PDSs and accidents in this group contribute about $18 \%$ to the mean CDF for Surry. The accidents in this group occur only in Time Windows 1 and 2 . In Windows 3 and 4 core cooling does not require recirculation within 24 hours which is the mission time for the Level 1 analysis. In this group, core cooling 


\section{Accident Frequency Analysis Interface}

was successfully initiated and continued until the RWST was emptied; but the recirculation failed and the accident progressed to core damage. The leading cause of recirculation failure was found to be plugged suction from the sump.

PDS Group 4 consists of accidents where core cooling is lost because of loss of the $4 \mathrm{kV}$ bus. This PDS group contains six PDSs and contributes about 5\% to the mean CDF. There are no occurrences of this PDS in Windows 3 and 4. The accidents in this group are similar to those of PDS group 1 (SBOs) except that accidents are initiated by loss of the $4 \mathrm{kV}$ bus. This group is separated from Group 1 since the recovery probabilities are different. The progression of accidents in this group are similar to those in Group 1.

\subsection{References}

1. Chu, T. L., et al., "Evaluation of Potential Severe Accidents During Low Power and Shutdown Operations at Surry Unit-1: Analysis of Core Damage Frequency from Internal Events During Mid-loop Operations," Brookhaven National Laboratory, NUREG/CR-6144, Volume 2, June 1994.

2. Breeding, R. J., et al., "Evaluation of Severe Accident Risks: Surry Unit 1," NUREG/CR-4551, Vol. 3, Rev. 1, Parts 1 and 2, Sandia National Laboratories, October 1990.

3. Embrey, D.E., et al., "SLIM-MAUD: An Approach to Assessing Human Error Probabilities Using Structured Expert Judgment," Brookhaven National Laboratory, prepared for U.S. Nuclear Regulatory Commission, NUREG/CR-3518, Vols. 1-2, March 1984.

4. Russell, K. D., et al., "Integrated Reliability and Risk Analysis System (IRRAS) Version NEW5," Developed by Idaho National Engineering Laboratory, 1993. 
5 Accident Frequency Analysis Interface

Table 5.1 Estimated Average Durations (Hours) of Plant Operational States (based on data from 1985-1989)

\begin{tabular}{|c|c|c|c|c|}
\hline $\begin{array}{c}\text { Plant } \\
\text { Operational } \\
\text { State }\end{array}$ & Refueling & $\begin{array}{c}\text { Drained } \\
\text { Maintenance }\end{array}$ & $\begin{array}{l}\text { Non-Drained } \\
\text { Maintenance } \\
\text { (with RHRS) }\end{array}$ & $\begin{array}{l}\text { Non-Drained } \\
\text { Maintenance } \\
\text { (w/o RHRS) }\end{array}$ \\
\hline 1 & 0.6 & 0.7 & 0.1 & 0.6 \\
\hline 2 & 22.3 & 15.1 & 12.3 & 15.0 \\
\hline 3 & 10.7 & 13.6 & 16.8 & - \\
\hline 4 & 154.4 & 196.3 & 127.9 & - \\
\hline 5 & 45.5 & 20.2 & - & - \\
\hline 6 & 183.0 & 202.0 & - & - \\
\hline 7 & 374.0 & - & - & - \\
\hline 8 & 810.8 & - & - & - \\
\hline 9 & 206.0 & - & - & - \\
\hline 10 & 107.0 & - & - & - \\
\hline 11 & 118.0 & 44.1 & - & - \\
\hline 12 & 1840.0 & 175.0 & - & - \\
\hline 13 & 34.4 & 10.3 & - & - \\
\hline 14 & 69.0 & 40.4 & 21.0 & - \\
\hline 15 & 56.1 & 12.7 & 18.6 & 9.9 \\
\hline
\end{tabular}


5 Accident Frequency Analysis Interface

Table 5.2 Time to Mid-loop (hours)

\begin{tabular}{||c|c|c|c|c||}
\hline POS & Mean & $\begin{array}{c}\text { 5th } \\
\text { Percentile }\end{array}$ & $\begin{array}{c}\text { 50th } \\
\text { Percentile }\end{array}$ & $\begin{array}{c}\text { 95th } \\
\text { Percentile }\end{array}$ \\
\hline \hline $\begin{array}{c}\text { POS 6 } \\
\text { Refueling }\end{array}$ & 191 & 72 & 168 & 389 \\
\hline $\begin{array}{c}\text { POS 10 } \\
\text { Refueling }\end{array}$ & 2619 & 833 & 968 & 4828 \\
\hline $\begin{array}{c}\text { POS 6 } \\
\text { Drained } \\
\text { Maintenance }\end{array}$ & 190 & 27 & 105 & 618 \\
\hline
\end{tabular}

Table 5.3 Duration of Mid-loop (hours)

\begin{tabular}{|c|c|c|c|c|}
\hline POS & Mean & $\begin{array}{c}\text { 5th } \\
\text { Percentile }\end{array}$ & $\begin{array}{c}\text { 50th } \\
\text { Percentile }\end{array}$ & $\begin{array}{c}\text { 95th } \\
\text { Percentile }\end{array}$ \\
\hline \hline $\begin{array}{c}\text { POS 6 } \\
\text { Refueling }\end{array}$ & 238 & 14 & 112 & 876 \\
\hline $\begin{array}{c}\text { POS 10 } \\
\text { Refueling }\end{array}$ & 444 & 6 & 151 & 2586 \\
\hline $\begin{array}{c}\text { POS 6 } \\
\text { Drained } \\
\text { Maintenance }\end{array}$ & 255 & 12 & 109 & 958 \\
\hline
\end{tabular}


Table 5.4 Definition and Characterization of Time Windows*

\begin{tabular}{|c|c|c|c|c|}
\hline & WINDOW 1 & WINDOW 2 & WINDOW 3 & WINDOW 4 \\
\hline Definition & $\leq 75$ hours & $>75$ hours and $\leq 240$ hours & $>240$ hours and $\leq 32$ days & $>32$ days \\
\hline Representative Decay Heat & $13 \mathrm{MW}$ (2 days) & $10 \mathrm{MW}$ (5 days) & 7 MW (12 days) & 5 MW (32 days) \\
\hline Time to Boiling & $15 \mathrm{~min}$. & $20 \mathrm{~min}$. & $27 \mathrm{~min}$. & $37 \mathrm{~min}$ \\
\hline $\begin{array}{l}\text { Time to Tygon Tube } \\
\text { Rupture } \\
\text { ( } 40 \text { psia) }\end{array}$ & $23 \mathrm{~min}$. & $31 \mathrm{~min}$. & $43 \mathrm{~min}$. & $59 \mathrm{~min}$. \\
\hline $\begin{array}{l}\text { Time to PRT Rupture } \\
\text { (100 psig) }\end{array}$ & $51 \mathrm{~min}$. & $63 \mathrm{~min}$. & $78 \mathrm{~min}$. & $96 \mathrm{~min}$. \\
\hline Time to 165 psia & $\begin{array}{l}41 \text { min. with } 2 \text { PORV } \\
43 \text { min. with } 1 \text { PORV }\end{array}$ & $\begin{array}{l}63 \text { min. with } 2 \text { PORV } \\
60 \text { min. with } 1 \text { PORV } \\
\end{array}$ & $\begin{array}{l}227 \text { min. with } 2 \text { PORV } \\
89 \text { min. with } 1 \text { PORV }\end{array}$ & $\begin{array}{l}352 \text { min. with } 2 \text { PORV } \\
147 \text { min. with } 1 \text { PORV }\end{array}$ \\
\hline Time to $615 \mathrm{psig}$ & 145 min. with 1 PORV & - & - & - \\
\hline Time to RWST Depletion & $10 \mathrm{hrs}$ & $13.5 \mathrm{hrs}$ & $18.7 \mathrm{hrs}$ & $38.6 \mathrm{hrs}$ \\
\hline $\begin{array}{l}\text { Time to AFW Initiation } \\
\text { (with } 25 \% \text { SG inventory } \\
\text { remaining) }\end{array}$ & $743 \mathrm{~min}$. & $669 \mathrm{~min}$. & $925 \mathrm{~min}$. & $628 \mathrm{~min}$. \\
\hline Time to Core Uncovery & $120 \mathrm{~min}$. & $157 \mathrm{~min}$. & 209 min. & $273 \mathrm{~min}$. \\
\hline Time to Core Damage & $219 \mathrm{~min}$ & $297 \mathrm{~min}$. & $411 \mathrm{~min}$. & $557 \mathrm{~min}$. \\
\hline
\end{tabular}


5 Accident Frequency Analysis Interface

Table 5.5 Distribution of Core Damage Frequencies for Each Time Window and PDS Group (per reactor year)

\begin{tabular}{|c|c|c|c|c|c|}
\hline PDS Group & $\begin{array}{c}\text { Time } \\
\text { Window }\end{array}$ & $\begin{array}{c}\text { 5th } \\
\text { Percentile }\end{array}$ & $\begin{array}{c}\text { 50th } \\
\text { Percentile }\end{array}$ & $\begin{array}{c}\text { 95th } \\
\text { Percentile }\end{array}$ & Mean \\
\hline \multirow{5}{*}{$\begin{array}{c}1 \\
\text { (Station } \\
\text { Blackout) }\end{array}$} & 1 & $3.32 \mathrm{E}-9$ & $4.67 \mathrm{E}-8$ & $9.39 \mathrm{E}-7$ & $1.98 \mathrm{E}-7$ \\
\hline & 2 & $3.11 \mathrm{E}-9$ & $3.35 \mathrm{E}-8$ & $7.81 \mathrm{E}-7$ & $1.33 \mathrm{E}-7$ \\
\hline & 3 & $1.60 \mathrm{E}-9$ & $1.36 \mathrm{E}-8$ & $2.00 \mathrm{E}-7$ & $4.05 \mathrm{E}-8$ \\
\hline & 4 & $8.56 \mathrm{E}-10$ & $1.07 \mathrm{E}-8$ & $8.87 \mathrm{E}-8$ & $2.38 \mathrm{E}-8$ \\
\hline & Total & $1.87 \mathrm{E}-8$ & $1.20 \mathrm{E}-7$ & $1.65 \mathrm{E}-6$ & $3.95 \mathrm{E}-7$ \\
\hline \multirow{5}{*}{$\begin{array}{c}2 \\
\text { (Human } \\
\text { Error) }\end{array}$} & 1 & 8.19E-9 & $1.27 \mathrm{E}-7$ & $2.32 \mathrm{E}-6$ & $4.90 \mathrm{E}-7$ \\
\hline & 2 & $6.07 \mathrm{E}-8$ & $3.55 \mathrm{E}-7$ & $6.07 \mathrm{E}-6$ & $1.24 \mathrm{E}-6$ \\
\hline & 3 & $4.80 \mathrm{E}-8$ & $2.83 \mathrm{E}-7$ & 4.12E-6 & $9.14 \mathrm{E}-7$ \\
\hline & 4 & $7.49 \mathrm{E}-9$ & $6.51 \mathrm{E}-8$ & $7.43 \mathrm{E}-7$ & $1.85 \mathrm{E}-7$ \\
\hline & Total & $2.07 \mathrm{E}-7$ & $1.03 \mathrm{E}-6$ & $1.28 \mathrm{E}-5$ & $2.83 \mathrm{E}-6$ \\
\hline \multirow{5}{*}{$\begin{array}{c}3 \\
\text { (Recirculation } \\
\text { Failure) }\end{array}$} & 1 & $3.06 \mathrm{E}-8$ & $3.34 \mathrm{E}-7$ & $3.20 \mathrm{E}-6$ & $6.69 \mathrm{E}-7$ \\
\hline & 2 & 7.37E-9 & $4.64 \mathrm{E}-8$ & $3.94 \mathrm{E}-7$ & $1.08 \mathrm{E}-7$ \\
\hline & 3 & 0 & 0 & 0 & 0 \\
\hline & 4 & 0 & 0 & 0 & 0 \\
\hline & Total & $5.34 \mathrm{E}-8$ & $4.08 \mathrm{E}-7$ & $3.26 \mathrm{E}-6$ & 7.77E-7 \\
\hline \multirow{5}{*}{$\begin{array}{c}4 \\
\text { (Loss of } \\
4 \mathrm{kV} \mathrm{Bus)}\end{array}$} & 1 & $2.13 \mathrm{E}-9$ & $3.86 \mathrm{E}-8$ & $5.45 \mathrm{E}-7$ & $1.33 \mathrm{E}-7$ \\
\hline & 2 & $2.22 \mathrm{E}-9$ & $2.82 \mathrm{E}-8$ & $4.21 \mathrm{E}-7$ & 8.82E-8 \\
\hline & 3 & 0 & 0 & 0 & 0 \\
\hline & 4 & 0 & 0 & 0 & 0 \\
\hline & Total & 8.87E-9 & $8.88 \mathrm{E}-8$ & $1.32 \mathrm{E}-6$ & $2.21 \mathrm{E}-7$ \\
\hline Total & & $3.18 \mathrm{E}-7$ & $1.99 \mathrm{E}-6$ & $1.94 \mathrm{E}-5$ & $4.22 \mathrm{E}-6$ \\
\hline
\end{tabular}




\section{ANALYSIS OF THE ACCIDENT PROGRESSION}

The accident progression analysis starts with information received from the accident frequency analysis: frequencies and definitions of the plant damage states (PDSs). The results of the accident progression analysis are passed to the source term analysis and the risk analysis. The methods used in this accident progression analysis are similar to those used in the NUREG- $1150^{1}$ study. Details of the methodology and the results of the PRA performed for accidents during full power operation at Surry are presented in NUREG/CR-4551, Vol. $3 .^{2}$

The main tool for performing the accident progression analysis is an event tree. The Accident Progression Event Tree (APET) treats the progression of an accident from the onset of core damage to the release of fission products, if any, or a successful termination of the accident. The APET accounts for the physical processes occurring in the vessel and containment during the various accident sequences (such as hydrogen burning and direct containment heating), and the availability and status of various safety equipment which could be used to mitigate the severity of the accident (such as safety injection systems and containment sprays). The APET also accounts for the capability of the containment to retain the fission products under severe accident loads. A series of questions are asked which represent these events and phenomena. Each path through the APET defines a unique accident progression path that potentially could give rise to the release of fission products. The number of questions in a APET can vary, depending on the details desired, and the number of relevant, important phenomena to be modelled.

The APET is not meant to be a substitute for detailed, mechanistic codes, rather it forms a high-level model of the accident progression. The APET is an integrating framework for synthesizing the results of these codes together with expert judgment on the strengths and weaknesses of the codes. In this way, the full diversity of possible accident progressions can be considered and the uncertainty in the many phenomena involved can be included. The APET was evaluated by the computer code EVNTRE. ${ }^{3}$

The following section contains an overview of the APET used for this study. Details, including a complete listing of the APET and a discussion of the possible outcomes to each question, may be found in Appendix B of this report. Section 6.2 summarizes how the APET is quantified. It explains how the many numerical values for branching ratios and parameters were obtained. Section 6.2 also lists the variables that were sampled in the accident progression analysis for Surry shutdown study. A brief summary of supporting deterministic calculations is provided in section 6.3. Section 6.4 describes the binning process and the binning characteristics. The results of the accident progression analysis for each PDS and "Time Window" are presented in Section 6.5.

\subsection{Description of the Accident Progression Event Tree}

In constructing the APET for Surry during mid-loop operation, extensive use was made of the results of the accident progression analysis for the Surry plant $^{2}$ carried out for the NUREG- 1150 program, which was a PRA of the plant at full power. The NUREG-1150 study showed that the major cause of fission product release was from accidents in which the containment was bypassed, followed by basemat melt-through (BMT) by the molten core debris. The study indicated that phenomena such as direct containment heating (DCH) or steam 


\section{Analysis of the Accident Progression}

explosions were not important contributors to the estimated probability of containment failure and the eventual release of fission products. Nor did hydrogen burning or gradual pressurization of the containment significantly contribute to the containment failure. Thus, an important finding of the full power study was that once the Surry containment boundary is closed, the containment retains the fission products most of the time (except for very late basemat melt-through) even when excessive core damage occurs. For accidents during low power and shutdown operation the decay heat is significantly less, the reactor pressure is generally low and the pressure generated in the containment is lower than for accidents occurring at full power. Therefore, early containment failure modes such as DCH and hydrogen burning could be excluded in the low power and shutdown risk study if the capability of the containment to hold pressure is the same as that of full power. However, since the containment was assumed to leak at pressures above 45 psig in this study while the full power risk analysis was based on a containment failure pressure of 126 psig as discussed in section 4.2.3, containment failure caused by such phenomena as $\mathrm{DCH}$ and hydrogen burning could not be eliminated from this study based on the results of the full power analysis. Therefore, these failure modes are included in the APET in this study.

The APET for this study contains 40 questions while the full power study has 71 questions. Table 6.1 lists the 40 questions used in the Surry APET for accidents during mid-loop operation. The complete listing of the APET and a discussion of each question is found in Appendix B. The APET for mid-loop operation is largely based on the APET of the NUREG-1150 full power study. It was modified to reflect the conditions during mid-loop operation by removing some questions and adding several questions pertinent to the shutdown conditions.

Some of the modifications made to the NUREG-1150 APET to reflect the conditions during mid-loop operation are listed below:

1) Questions on fan coolers were removed. They were not relevant even in the full power study.

2) Questions on accumulators were removed; accumulators are blocked out during mid-loop operation.

3) Questions on Interfacing Systems LOCAs were removed; the level 1 analysis ${ }^{4}$ does not have these sequences.

4) A question on scram was removed since the reactor has already been successfully shutdown.

5) Questions concerning steam generator tube ruptures and heat removal by the steam generators were removed. Level 1 results do not include steam generator tube rupture sequences. Failure of heat removal by steam generators is already considered in the level 1 analysis.

6) Several questions on temperature-induced reactor coolant pump seal failure and other breaks were removed. This phenomenon contributes to reducing the high pressure vessel failure probability. Since the majority of accidents initiated during the shutdown period are with the reactor vessel at low pressure (only a very small fraction of the accidents during Window 1 are at intermediate pressure) as discussed in the previous chapter (Section 5.2), these questions were considered not pertinent.

7) Containment failure by the "rocket mode" were removed; this failure mode requires a high vessel pressure (2500 psi) which is not possible for accidents during mid-loop operation. 
8) Containment failure by BMT was not included in the tree because MELCOR ${ }^{5}$ calculations showed that the rate of erosion of the basemat is very slow compared to the thickness of the basemat (refer to section 6.3).

9) Containment failure by gradual overpressurization was not considered to be feasible based on MELCOR calculations which indicated very slow pressurization rates (refer to section 6.3).

10) A question on the "Time Window" was added.

11) Questions on the status of containment closure and containment pressure capability were added.

12) Questions on human error and recovery from human error were added; human error is the largest cause of accidents during mid-loop operation in the level 1 analysis (Section 5.2).

13) Questions on recirculation failure were added; failure of recirculation due to sump plugging is a significant cause of accidents during mid-loop operation in the level 1 analysis (Section 5.2).

14) Questions on loss of a $4 \mathrm{kV}$ bus and its recovery were added; loss of the $4 \mathrm{kV}$ bus and the resultant loss of the injection pumps was found to be a significant cause of accidents during mid-loop operation in the level 1 analysis (Section 5.2).

15) Since the results of the NUREG-1150 study indicated that the pressure generated by hydrogen burning could be substantially above $45 \mathrm{psig}$, it was assumed that a large hydrogen burn would fail containment if it occurred (i.e., detailed calculations on the magnitude of the pressure generated during a hydrogen burn were not performed specifically for this study). The APET still includes questions on whether conditions exist for hydrogen ignition in the containment.

The APET is broken into five time periods. The time periods are:

Initial: Questions 1 through 11 determine the conditions at the beginning of the accident.

Early: Questions 12 through 20 cover the in-vessel accident progression period up to the time of vessel breach (VB).

Intermediate: Questions 21 through 25 determine the progression of the accident at and immediately after vessel breach (VB), including the possibility of containment failure at VB.

Late: Questions 26 through 37 determine the progression of the accident during core-concrete interaction $(\mathrm{CCI})$.

Very Late: Questions 38 through 40 determine the accident progression in the period following CCI, including the possibility of containment failure due to hydrogen combustion.

The time period applicable to each question for the APET is indicated in Table 6.1. The clock time for each period varies depending on the time window when the accident is initiated. The table below shows these time 
6 Analysis of the Accident Progression

periods for each time window based on the results of MELCOR calculations. Details of the MELCOR calculations are provided in Appendix E.

Accident Timing Used in the Surry APET for Each Time Window

(Minutes Measured from the Start of the Accident)

\begin{tabular}{||l|c|c|c|c|l||}
\hline & Window 1 & Window 2 & Window 3 & Window 4 & \multicolumn{1}{|c|}{ Remarks } \\
\hline End of Early Period & 90 & 125 & 170 & 240 & Core damage \\
\hline Intermediate Period & 216 & 300 & 364 & 530 & Vessel breach \\
\hline End of Late Period & 400 & 480 & 550 & 710 & Prompt CCI \\
\hline Very Late & 1440 & 1440 & 1440 & 1440 & $24 \mathrm{hrs}$ \\
\hline
\end{tabular}

\subsection{Overview of the APET Quantification}

This section discusses the types of questions used in the APET and summarizes the quantification method.

In addition to the number and name of the question, Table 6.1 shows how the questions were evaluated or quantified. If the question is sampled, the table also indicates how it is sampled, i.e., if the distribution is based on the distribution of frequencies of core damage accidents and PDSs provided by the level 1 analysis, assigned internally by BNL staff, from the electric power recovery distribution, ${ }^{2}$ from recovery distribution for human errors, ${ }^{6}$ or from a distribution provided by one of the expert panels of the NUREG-1150 study. The item sampled may be either the branching ratio or the parameters defined at that question. For questions which are sampled and which were quantified internally, the entry ZO in the sampling column indicates that the question was sampled zero-one, and the entry SF means the questions was sampled with split fractions. If the sampling column is blank, the branching ratios for that question, and the parameter values defined in that question, if any, are fixed. The branching ratios of the PDS questions change to indicate which PDS is being considered. Some of the branching ratios depend on the relative frequency of the PDSs which make up the PDS group being considered. These branching ratios can change for every sample observation, and may change for some PDS groups but not for others. If the branching ratios change from observation to observation for any one of the four PDS groups, SF is placed in the sampling column for the PDS questions. The abbreviations in the quantification and sampling columns of Table 6.1 are explained at the end of the table.

Twenty-one variables, listed in Table 6.2, were sampled for the accident progression analysis. That is, every time the APET was evaluated by EVNTRE, the original values of these 21 variables were replaced with values selected for the particular observation under consideration. These values were either based on the distribution of accidents provided by the level 1 analysis or selected by the LHS program ${ }^{7}$ from distributions that were defined before the APET was evaluated. As explained earlier, these distributions were determined internally or based on information provided by expert panels in the NUREG-1150 analysis. Some are branch fractions, others are parameter values used in the calculations such as pressure generated by DCH. Several variable listed were used to select the probability that off-site power will be recovered in a specified time interval given that it was not recovered in a previous time interval, each with different start and end times, for each time 
6 Analysis of the Accident Progression

window. There are similar questions regarding recovery from loss of $4 \mathrm{kV}$ bus or human errors. Additional information on the ranges of distribution of these variables can be found in Appendix B of this volume.

\subsection{Supporting Deterministic Calculations}

Several calculations were performed with the MELCOR code ${ }^{5}$ to support the determination of the various time windows and associated success criteria and also to help quantification of the APET. Predictions of the MELCOR code were also used to compare against the source term distributions calculated by the SURSOR code (refer to Chapter 7). The MELCOR calculations are presented in Appendix E, which also includes detailed results for several possible accident scenarios during mid-loop operation.

The major impact of the MELCOR calculations on the APET quantification relates to two potential containment failure mechanisms, namely basemat melt-through by the molten core debris and overpressurization of the containment by steam and noncondensible gases.

\subsubsection{Basemat Melt-through}

As noted above this failure mechanism was found to be a significant cause of fission product releases for accident during full power operation although the core debris was determined to penetrate the basemat very late in an accident sequence. However, the MELCOR calculations presented in Appendix E indicate much slower concrete erosion rates for accidents during mid-loop operation. This lower concrete erosion is caused by the relatively low decay heat for accidents during mid-loop operation. The erosion depth was calculated to be about $0.75 \mathrm{~m}$ (compared with a basemat thickness of $3 \mathrm{~m}$ ) 30 hours after the start of an accident in time window 1 (the representative decay heat is highest in this time window). Even in the full power analysis, it was calculated to take several days to breach the basemat. Since the probability of not recovering some safety injection system in this time period is extremely small, it was determined that basemat melt-through is not a credible failure mode for accidents during mid-loop operation.

\subsubsection{Containment Overpressurization}

Overpressurization of the containment by steam and noncondensible gases was found to be not a credible failure mode for accidents during mid-loop operation also based on MELCOR calculations. This is true even if the containment is assumed to leak at pressures above 45 psig. Again the low decay heat levels associated with accidents during mid-loop operation means that the driving force for containment pressurization is also low and the rate of pressurization is very slow. Detailed results are presented in Appendix E.

\subsection{Description of the Accident Progression Bins}

As each path through the APET is evaluated, the result of that evaluation is stored by assigning it to an Accident Progression Bin (APB). The accident progression bins are the means by which information is passed from the accident progression analysis to the source term analysis. A bin is defined by specifying the attribute or value for each of 12 characteristics or quantities which define a certain feature of the evaluation of the 


\section{Analysis of the Accident Progression}

APET. The definition of APBs and the method of their assignment in this study is similar to those of the NUREG-1150 study except for one very important difference; an additional attribute was added to characterize the "Time Window". The "Time Window" information is passed to the consequence calculation to account for the different fission product decay times. Table 6.3 lists the 12 characteristics of the APBs: the detailed listing of the attributes of these characteristics may be found in Appendix B. The binner, which follows directly after the APET is the data file which forms the input to EVNTRE, is also listed in Appendix B. Some of the bin characteristics such as steam generator tube rupture (SGTR) and reactor coolant system (RCS)-hole size are not relevant or significant for the mid-loop risk analysis, but were still included to match the requirement of the SURSOR code. ${ }^{8}$ The "Time Window" characteristic is not required by the SURSOR code but is passed to the consequence analysis.

Characteristic 1 primarily concerns the time of containment failure. There are seven attributes. Four of these attributes concern the time of containment failure, two concern Event $\mathrm{V}$, and one is for no containment failure. Interfacing systems LOCAs (Event $\mathrm{V}$ ) were not applicable to mid-loop operation and therefore attributes $\mathrm{A}$ and $\mathrm{B}$ were not used. BMT and eventual overpressure failure due to the inability to restore containment heat removal in the days following the accident were the failures that occurred in the Final period in the full power study. These failure modes were determined to be not credible for accidents during mid-loop operation and therefore attribute $\mathrm{F}$ was not used.

Characteristic 2 concerns the periods in which the sprays operate. The division into the nine attributes is a straightforward sorting out of the various combinations of time periods. The final time period is of little consequence for the fission product release, but it must be included because there are cases where the sprays operate only in this period and, for each characteristic, the binner must have a location in which to place every outcome.

Characteristic 3 concerns the CCIs. There are six possibilities which cover the meaningful combinations of prompt CCI, delayed CCI, and no CCI, with the amount of water in the cavity.

Characteristic 4 concerns the pressure in the reactor vessel before vessel breach; there are four levels. The pressures shown in parentheses are approximate pressures just before VB. The RCS pressures during most of the core degradation period for accidents in mid-loop were in the intermediate to low pressure range. Attributes A and B were therefore not used.

Characteristic 5 concerns the mode of vessel breach; there are six possibilities, including no VB.

Characteristic 6 concerns SGTR. Steam generator tube ruptures were not identified in the Level 1 analysis so that the attribute for this characteristic was always $\mathrm{C}$.

Characteristic 7 concerns how much of the core not in high pressure melt ejection (HPME) that is available to participate in the CCI. The fractions 0.30 and 0.70 divide the range into three portions. As the amount released at vessel breach is assumed to be high the fraction of the core available for $\mathrm{CCI}$ is set to medium when HPME occurs.

Characteristic 8 concerns the amount of the core zirconium which is oxidized in-vessel before vessel breach. There are two possible values for this characteristic: low and high. The demarcation point between the two ranges is $40 \%$. 
6 Analysis of the Accident Progression

Characteristic 9 concerns the amount of the core involved in HPME; there are four attributes. The possible range is divided into three portions by $20 \%$ and $40 \%$. No HPME is the fourth attribute.

Characteristic 10 concerns the size of the hole that results from containment failure or the type of containment failure. There are four possible attributes.

Characteristic 11 concerns the number of large holes in the RCS after breach. The experts on the Source Term Expert Panel assembled for the NUREG-1150 study who provided distributions for revolatilization from the RCS surfaces after VB gave different distributions depending on whether an effective natural circulation flow would be set up within the vessel. A significant flow could be expected only if there were two large, effective holes in the RCS.

Characteristic 12 concerns the time at which the accident occurs after the reactor has been shutdown. Four time windows are possible as defined in the Level 1 analysis.

A set of summary bins was adopted for presentation purposes, as in NUREG-1150. Instead of the 12 characteristics and the hundreds of possible bins that describe the evaluation of the APET in detail, the summary bins place the outcomes of the evaluation of the APET into a few, very general number of groups. They are:

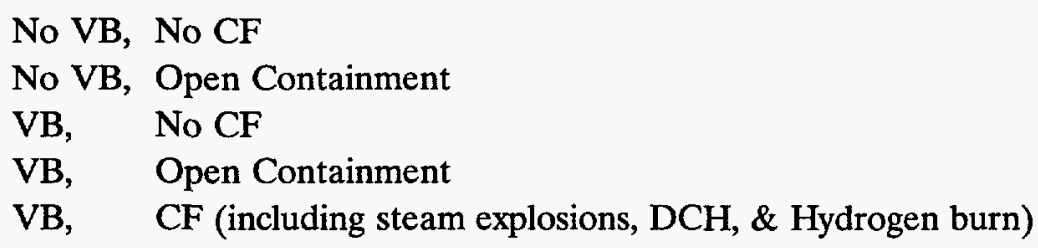

The containment failure (CF) group contains energetic events that cause structural failure of the containment. The "Open Containment" group includes leakage through the equipment hatch or other temporary barriers (which can occur even after "successful" isolation of containment) as well as failure to isolate containment before the onset of core damage.

\subsection{Results of the Accident Progression Analysis}

This section presents the results of the APET evaluation. Table 6.4 shows four statistical measures of the conditioned probability distributions of the summary bins for each PDS Group. As evaluating the APET produces a large number of accident progression bins (APBs), the discussion is primarily focused on events that result in core damage arrest before vessel breach, and loss of containment integrity. Therefore, Tables 6.5 and 6.6 were included to provide information on the distributions of conditional probabilities for core damage arrest and loss of containment integrity for each PDS Group and Time Window. The term "loss of containment integrity" is used in Table 6.6 rather than "containment failure" because of the importance of failure to isolate containment, which is not really "failure" of containment. The term "containment failure" is reserved for energetic events (such as steam explosions, DCH and Hydrogen Combustion) that cause structural failure of the containment.

In order to assess the relative importance of the various accident progression bin groups, the information in Table 6.4 is summarized in Tables 6.7 and 6.8 to provide the mean conditional probabilities of core damage 


\section{Analysis of the Accident Progression}

arrest and loss of containment integrity. The APB groups in which the status of the reactor pressure vessel (no vessel breach or vessel breach) and the containment are given are included in Table 6.7. The APB groups in which only the containment status is given are included in Table 6.8. Similar information is given for the various time windows in Table 6.9. Table 6.10 and Figure 6.1 were included to provide additional statistical measures for the distributions of the absolute frequencies for various accident progression bin groups.

Generally, the containment failure probability is dominated by the probability of whether the containment is successfully isolated prior to core damage. Containment failure due to energetic pressurization either because of DCH or hydrogen burning is relatively small as in the full power study even if the containment is assumed to leak at pressures above 45 psig. This is partly because the fraction of accidents with high or intermediate vessel pressure is very small, and partly because the fraction of accidents where the containment was not isolated is high. Very late containment failure due to basemat melt-through and gradual pressurization due to loss of containment cooling was assumed not to happen based on the results of MELCOR calculations as discussed in section 6.3 .

\subsubsection{Results for Each PDS Group}

\subsubsection{Results for PDS Group 1: Station Blackout (SBO)}

This PDS group contains five PDSs as discussed in Section 5.2. The PDSs in this group contribute approximately $10 \%$ to the mean total core damage frequency. The accidents belonging to this group are initiated by a loss of off-site power and coupled with other failures result in a station blackout. The recirculation and containment systems are not available due to the loss of power. In this PDS, an important factor in the accident progression is the recovery of the off-site AC power.

The mean conditional probability of core damage arrest prior to vessel failure ranges from approximately 0.5 for Time Window 1 to 0.7 for Time Window 4 as shown in Table 6.5. The mean conditional probability averaged over all four time windows is about 0.55 .

The mean conditional probability of loss of containment integrity for this PDS group averaged over all time windows is approximately 0.51 as shown in Table 6.6. Energetic containment failure is significant for this PDS group, with a mean conditional probability of about 0.15 (Table 6.8). This mostly comes from hydrogen burning later in the accident. This mode of failure is prominent in this PDS group, since hydrogen burning is more likely when the power is recovered after a substantial amount of hydrogen has accumulated in the containment.

\subsubsection{Results for PDS Group 2: Human Errors (HX)}

This PDS group contains a large number of PDSs and is the largest contributor to the internal event core damage frequency for mid-loop operation at Surry. About two thirds of all core damage accidents belong to this group. The accidents belonging to this group are attributable to human errors. Following loss of core cooling due to some initiators, operators either fail to diagnose the accidents or to take correct actions. The progression of accidents is somewhat different depending on whether the human error is in diagnosis or action. For example, if it is a diagnostic error, then it is assumed that the same error results in failure to recognize the need for containment isolation. If the error was a failure to take the correct action, it was more likely that 
6 Analysis of the Accident Progression

the containment was closed before core damage. In most cases, the electric power and some core cooling system are available. In this PDS group, the dominating factor in the accident progression is the recovery from human errors.

The mean conditional probability of core damage arrest without vessel failure is about 0.42 averaged over all windows (Table 6.5). This probability is lower than that of PDS group 1 indicating that the recovery probability from human error is less likely than recovery of electric power once the accident progresses to core damage.

The mean conditional probability of loss of containment integrity for this PDS group is very high, about 0.9 (Table 6.6). This result reflects the assumption that the containment would most likely remain unisolated in this PDS group. Energetic containment failure is insignificant for this PDS group (Table 6.8). Since this PDS group is the largest contributor to the core damage frequency, it also significantly contributes to the overall probability of loss of containment integrity.

\subsubsection{Results for PDS Group 3: Recirculation Failure}

The PDSs in this group contribute about $18 \%$ to the mean core damage frequency, although it contains a large number of PDSs. The accidents in this group occur only in Windows 1 and 2 . In this group, core cooling was successfully initiated and was continued until the RWST is emptied; but the recirculation fails and the accident progresses to core damage. The conditional probability of core damage arrest before vessel failure in this PDS group is zero (Table 6.5) since it is assumed that core cooling is permanently lost once recirculation is lost.

The mean conditional probability of loss of containment integrity for this PDS group is relatively low, about 0.13 (Table 6.6). The probability of isolating the containment in this PDS group is considered to be high because core cooling is established and the reactor has been in a stable condition for a relatively long time. Energetic containment failure is unimportant for this PDS group, contributing only about 3\% to containment failure (Table 6.8), mostly from DCH. Hydrogen burning is not likely to fail containment since power is available and hydrogen combustion was determined to occur at relatively low concentrations.

\subsubsection{Results for PDS Group 4: Loss of $4 \mathrm{kV}$ Bus}

This PDS group contributes about 5\% to the mean core damage frequency for accident in mid-loop. There are no occurrences of this PDS in Windows 3 and 4. The accidents in this group are similar to those of PDS group 1 (SBOs) except that accidents are initiated by loss of $4 \mathrm{kV}$ bus. This group is separated from Group 1 since the recovery probabilities are different, however, the accident progression for this group is similar to that of Group 1.

The mean conditional probability of core damage arrest without vessel failure was determined to be about 0.6 (Table 6.5). The mean conditional probability of loss of containment integrity for this PDS group is approximately 0.45 (Table 6.6). Hydrogen burning is a significant contributor to the conditional containment failure probability as in Group 1 (Table 6.8). 
6 Analysis of the Accident Progression

\subsubsection{Core Damage Arrest and Avoidance of Vessel Breach}

It is possible to arrest the core damage process and avoid vessel breach if injection is restored before the core degradation process has gone too far. Recovery of injection depends on the PDS groups. For Groups 1 (SBO) and 4 (Loss of $4 \mathrm{kV}$ bus) the dominant factor is recovery of the off-site $\mathrm{A} / \mathrm{C}$ power or the $4 \mathrm{kV}$ bus. For Group 2 (Human Errors), recovery depends on the operators making correct diagnosis or taking proper actions. For Group 3 (Failure of Recirculation), it is assumed that no recovery action is possible once core damage occurs.

Table 6.5 shows four statistical measures for the distributions of the conditional probability of halting the degradation of the core before the lower head of the vessel fails, for each PDS and Time Window. Overall the mean conditional probability of core damage arrest without vessel failure is about 0.35 for all windows and PDS groups. The core damage arrest for each PDS is discussed above. For each window the average conditional probability of core damage arrest is roughly similar to the conditional probability of PDS Group 2. This result reflects the fact that PDS Group 2 is the largest contributor to the total core damage frequency (refer to Figure 5.1). The average conditional probability of core damage arrest for window 1 is lower than for the other windows. This is mainly because PDS Group 3 is significant contributor in this window (Table 5.8) and the core damage arrest probability for PDS Group 3 is zero.

\subsubsection{Loss of Containment Integrity}

There are four possibilities for loss of containment integrity:

1. Failure to isolate containment;

2. Containment leak due to failure of isolation barriers;

3. $\mathrm{CF}$ at VB due to the events at VB; and

4. CF due to hydrogen combustion before or after VB.

Very late containment failure due to gradual pressurization caused by the loss of containment cooling, or due to basemat melt-through was assessed to be very unlikely based on the results of MELCOR ${ }^{5}$ calculations.

Table 6.6 shows the conditional probability of loss of containment integrity for each PDS and Time Window. The overall mean conditional probability of loss of containment integrity is about 0.67 for all windows and PDS groups. There are no apparent trends among the time windows for the overall probability, although some trends were observed in each PDS as discussed above. The trend in overall probability is obscured by the different composition of the PDS groups for each window. For example, in Window 1, the probability of loss of containment integrity is relatively low since the contribution of PDS group 3 to the window is high and this PDS group has a low probability of containment failure.

Table 6.8 shows the mean conditional probability of the APB groups in which only containment status is identified (isolation failure and early leak are combined into 'Open Containment'). The table shows that the conditional probability of loss of containment integrity is dominated by the probability of whether the containment is successfully isolated prior to core damage. Containment failure due to energetic pressurization either by $\mathrm{DCH}$ or hydrogen burning is relatively small as for accidents at full power even if the containment failure pressure ( $45 \mathrm{psig}$ ) is much less than that of full power (126 psig). This is partly because the fraction of accidents with high or intermediate vessel pressure is very small (i.e., minimizing the potential for $\mathrm{DCH}$ ) 
6 Analysis of the Accident Progression

and partly because the conditional probability of the containment not being isolated at the start of the accident was high.

\subsection{References}

1. U. S. Nuclear Regulatory Commission, "Severe Accident Risks: An Assessment for Five U.S. Nuclear Power Plants," NUREG-1150, Vols. 1-3, December 1990-January 1991.

2. $\quad$ Breeding, R. J., et al., "Evaluation of Severe Accident Risks: Surry Unit 1," NUREG/CR-4551, Vol. 3, Rev. 1, Parts 1 and 2, Sandia National Laboratories, October 1990.

3. Griesmeyer, J. M. and L. N. Smith, "A Reference Manual for the Event Progression Analysis Code (EVNTRE)," NUREG/CR-5174, Sandia National Laboratories, September 1989.

4. Chu, T. L., et al., "Evaluation of Potential Severe Accidents During Low Power and Shutdown Operations at Surry Unit-1: Analysis of Core Damage Frequency from Internal Events During Mid-loop Operations," Brookhaven National Laboratory, NUREG/CR-6144, Volume 2, June 1994.

5. Summers, R. M., et. al., "MELCOR 1.8.0: A Computer Code for Nuclear Reactor Severe Accident Source Term and Risk Assessment Analyses," NUREG/CR-5531, Sandia National Laboratories, SAND90-0364, January 1991.

6. Swain, A. D., "Handbook of HRA," NUREG/CR-1278, August 1983.

7. Iman, R. L., et al., “A FORTRAN 77 Program and Users Guide for the Generation of Latin Hypercube and Random Sampling Use with Computer Codes," Sandia National Laboratory, NUREG/CR-3624, March 1984.

8. Jow, H. N., W. B. Murfin and J. D. Johnson, “XSOR Codes User's Manual," NUREG/CR-5360, Sandia National Laboratories, December 1989. 
6 Analysis of the Accident Progression

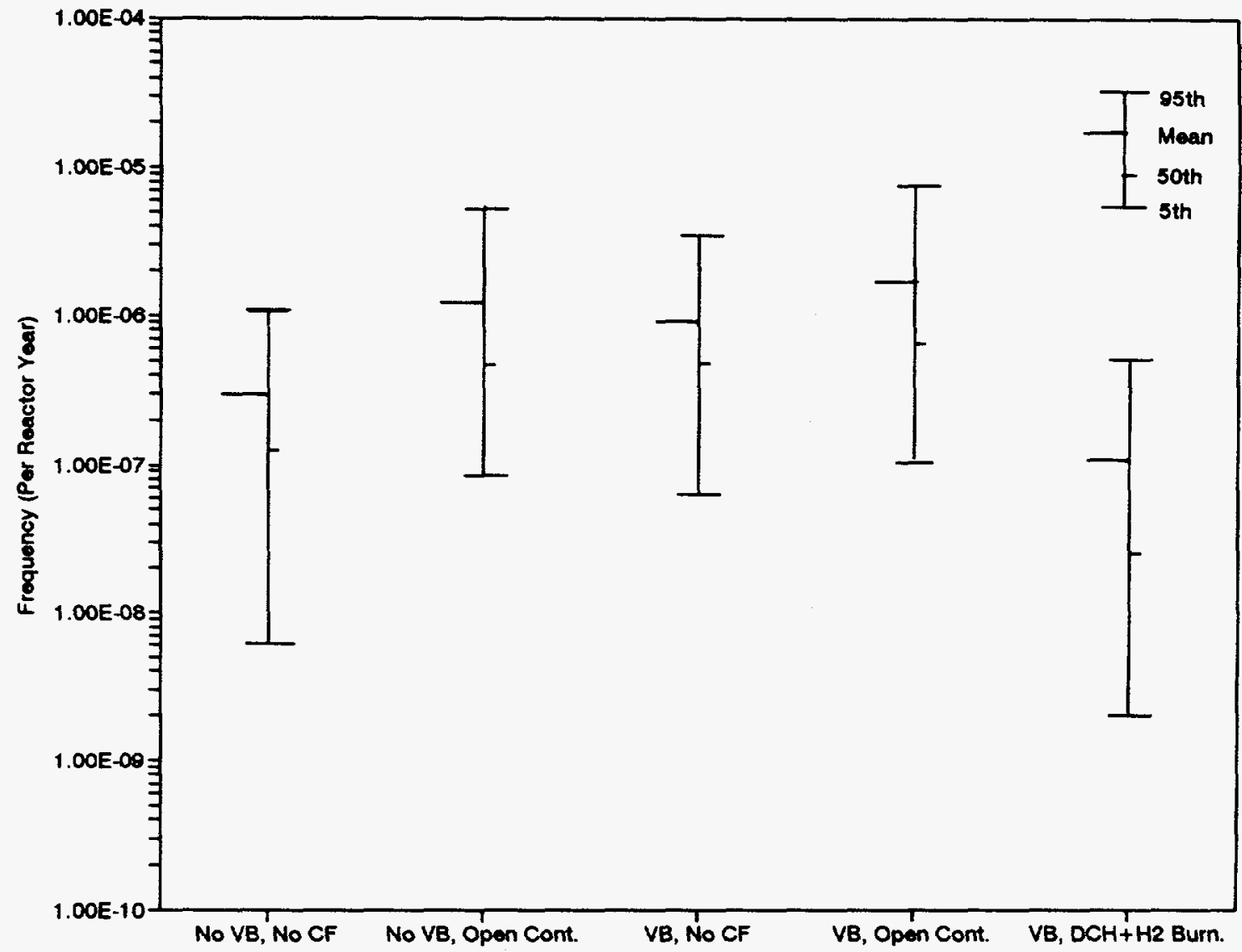

Figure 6.1 Distribution of Frequencies of APB Groups 
Table 6.1 Questions in the APET

\begin{tabular}{|c|c|c|c|c|}
\hline $\begin{array}{l}\text { Question } \\
\text { Number }\end{array}$ & Question & $\begin{array}{c}\text { Accident } \\
\text { Progression } \\
\text { Time Period }\end{array}$ & Quantification & Sampling \\
\hline 1 & Which time window? & Initial & PDS & DS \\
\hline 2 & Size of RCS break? & Initial & PDS & DS \\
\hline 3 & RCS depressurization by the operators? & Initial & & SF \\
\hline 4 & Status of ac power? & Initial & PDS & $\mathrm{ZO}$ \\
\hline 5 & Core damage accident due to human error? & Initial & PDS & $\mathrm{ZO}$ \\
\hline 6 & Status of ECCS? & Initial & PDS & SF \\
\hline 7 & Status of sprays? & Initial & PDS & SF \\
\hline 8 & RWST injected into containment? & Initial & PDS & SF \\
\hline 9 & Initial containment condition? & Initial & Internal & SF \\
\hline 10 & Is containment isolated before core damage? & Initial & Internal & DS \\
\hline 11 & Containment pressure capability & Initial & Internal & DS \\
\hline 12 & Is ac power available early? & Early & ROSP & DS \\
\hline 13 & Recovered from human error before vessel breach? & Early & HRAH & DS \\
\hline 14 & Is core damage arrested before vessel breach? & Early & Summary & \\
\hline 15 & Vessel pressure just before vessel breach? & Early & Internal & $\mathbf{P}$ \\
\hline 16 & $\begin{array}{l}\text { Does an alpha event fail both vessel and } \\
\text { containment? }\end{array}$ & Early & NUREG-1150 & DS \\
\hline 17 & Type of vessel breach? & Early & NUREG-1150 & DS \\
\hline 18 & Early sprays? & Early & Summary & \\
\hline 19 & Is the reactor cavity wet at vessel breach? & Early & Summary & \\
\hline 20 & Baseline containment pressure before VB? & Early & Internal & $P$ \\
\hline 21 & Total pressure rise at vessel breach? & Intermediate & NUREG-1150 & $\mathbf{P}$ \\
\hline 22 & Does a significant ex-vessel steam explosion occur? & Intermediate & NUREG-1150 & SF \\
\hline 23 & Containment failure pressure? & Intermediate & NUREG-1150 & DS \\
\hline 24 & Containment failure at VB? & Intermediate & NUREG-1150 & $\mathrm{ZO}$ \\
\hline 25 & Containment status at VB? & Intermediate & Summary & \\
\hline 26 & Is ac power available late? & Late & ROSP & DS \\
\hline 27 & Recovered from human error late? & Late & HRAH & DS \\
\hline
\end{tabular}


Table 6.1 (continued)

\begin{tabular}{||l|l|c|c|c||}
\hline $\begin{array}{c}\text { Question } \\
\text { Number }\end{array}$ & \multicolumn{1}{|c|}{ Question } & $\begin{array}{c}\text { Accident } \\
\text { Progression } \\
\text { Time Period }\end{array}$ & Quantification & Sampling \\
\hline \hline 28 & Late sprays? & Late & Summary & \\
\hline 29 & Does late ignition occur? & Late & NUREG-1150 & P \\
\hline 30 & Containment failure due to hydrogen burning? & Late & Summary & \\
\hline 31 & Status of containment? & Late & Summary & \\
\hline 32 & Is the debris bed in a coolable configuration? & Late & NUREG-1150 & SF \\
\hline 33 & Does prompt CCI occur? & Late & Summary & \\
\hline 34 & Is ac power available very late? & Late & ROSP & DS \\
\hline 35 & Recovered from human error very late? & Late & HRAH & DS \\
\hline 36 & Very late sprays? & Late & Summary & \\
\hline 37 & Does delayed CCI occur? & Late & Summary & \\
\hline 38 & Does very late ignition occur? & Very Late & NUREG-1150 & P \\
\hline 39 & Containment failure due to hydrogen burning? & Very Late & Summary & \\
\hline 40 & Final containment condition? & Very Late & Summary & \\
\hline
\end{tabular}

\section{Key to Abbreviations in Table 6.1}

DS

HRAH

Internal

NUREG-1150

$P$

PDS

ROSP

SF

Summary

ZO
The branch probabilities are taken from a distribution; depending on the distribution the sampling may be SF or ZO.

Available from the Reliability Analysis Handbook (Ref. 6)

The quantification was performed at Brookhaven National Laboratory by the plant analyst with the assistance of other members of the laboratory staff.

Information from NUREG-1150 analysis

A parameter is determined from a distribution or deterministic calculations.

The quantification follows directly from the definition of the Plant Damage State.

This question was quantified by sampling from a distribution derived from the off-site power recovery data for the plant.

Split Fraction sampling-the branch probabilities are real numbers between zero and one.

The quantification for this question follows directly from the branches taken at preceding questions, or the values of parameters defined in preceding questions.

Zero-one Sampling: the branch probabilities are either 0.0 or 1.0 . 
Table 6.2 Variables Sampled in the Accident Progression Analysis

\begin{tabular}{|c|c|}
\hline $\begin{array}{l}\text { Question } \\
\text { No. }\end{array}$ & Description \\
\hline 1 & Frequencies of accident occurring at each time window for the given PDS group. \\
\hline 2 & $\begin{array}{l}\text { Probability that reactor pressure exceeds } 500 \text { psi when only } 1 \text { PORV is open in Time } \\
\text { Window } 1 .\end{array}$ \\
\hline 10 & $\begin{array}{l}\text { Probability that containment is successfully closed before core damage at each time } \\
\text { window. }\end{array}$ \\
\hline 11 & Probability that containment is isolated but does not have pressure retaining capability. \\
\hline 12 & Probability that off-site power is recovered before vessel breach for each time window. \\
\hline 12 & $\begin{array}{l}\text { Probability that power is recovered to injection pumps from } 4 \mathrm{kV} \text { loss for each time } \\
\text { window. }\end{array}$ \\
\hline 13 & Probability of recovery from human errors for each time window. \\
\hline 16 & Probability that Alpha mode CF occurs, given that RCS is at low pressure \\
\hline 17 & $\begin{array}{l}\text { Probability that VB mode is pressure melt ejection (HPME) given that RCS is at } \\
\text { intermediate pressure. }\end{array}$ \\
\hline 17 & Probability that VB mode is bottom head failure \\
\hline 20 & Baseline containment pressure just before VB. \\
\hline 21 & Pressure rise at VB when VB mode is pour. \\
\hline 21 & $\begin{array}{l}\text { Pressure rise at VB when RCS pressure is at intermediate pressure and reactor cavity is } \\
\text { wet. }\end{array}$ \\
\hline 23 & Containment failure pressure when mean containment capability pressure is 126 psig. \\
\hline 23 & Containment failure pressure when mean containment capability pressure is 45 psig. \\
\hline 26 & Probability that off-site power is recovered late for each time window. \\
\hline 26 & $\begin{array}{l}\text { Probability that power is recovered late to injection pumps from loss of } 4 \mathrm{kV} \text { bus for each } \\
\text { time window. }\end{array}$ \\
\hline 27 & Probability of late recovery from human errors for each time window. \\
\hline 34 & Probability that off-site power is recovered very late for each time window. \\
\hline 34 & $\begin{array}{l}\text { Probability that power is recovered very late to injection pumps from loss of } 4 \mathrm{kV} \text { bus for } \\
\text { each time window. }\end{array}$ \\
\hline 35 & Probability of very late recovery from human errors for each time window. \\
\hline
\end{tabular}


6 Analysis of the Accident Progression

Table 6.3 Description of APB Characteristics

\begin{tabular}{|c|l|l||}
\hline Characteristic & Abbreviation & \multicolumn{1}{c|}{ Description } \\
\hline \hline 1 & CF-Time & Time of containment failure (CF) \\
\hline 2 & Sprays & Periods in which sprays operate \\
\hline 3 & CCI & Occurrence of Core-Concrete Interactions (CCI) \\
\hline 4 & RCS-Pres & Reactor Coolant System (RCS) pressure before vessel breach (VB) \\
\hline 5 & VB-Mode & Mode of VB \\
\hline 6 & SGTR & Steam generator tube rupture (SGTR) \\
\hline 7 & Amt-CCI & Amount of core available for CCI \\
\hline 8 & Zr-Ox & Fraction of zirconium (Zr) oxidized (Ox) in-vessel \\
\hline 9 & HPME & Fraction of the core in the high pressure melt injection (HPME) \\
\hline 10 & CF-Size & Size or type of containment failure \\
\hline 11 & RCS-Hole & Number of large holes in the RCS after VB \\
\hline 12 & Window & Time window when core damage accident is initiated \\
\hline
\end{tabular}


6 Analysis of the Accident Progression

Table 6.4 Distribution of Conditional Probabilities of APB Groups for Each PDS Group

\begin{tabular}{||c|c|c|c|c|c|c||}
\hline $\begin{array}{c}\text { Accident } \\
\text { Progression } \\
\text { Bin Groups }\end{array}$ & $\begin{array}{c}\text { PDS } \\
\text { Group 1 }\end{array}$ & $\begin{array}{c}\text { PDS } \\
\text { Group 2 }\end{array}$ & $\begin{array}{c}\text { PDS } \\
\text { Group 3 }\end{array}$ & $\begin{array}{c}\text { PDS } \\
\text { Group 4 }\end{array}$ & All & $\begin{array}{c}\text { Statistical } \\
\text { Measures }\end{array}$ \\
\hline \hline No VB, & 0.022 & 0.001 & 0.000 & 0.000 & 0.005 & 5th Percentile \\
No CF & 0.409 & 0.030 & 0.000 & 0.396 & 0.068 & Median \\
& 0.351 & 0.046 & 0.000 & 0.383 & 0.079 & Mean \\
& 0.599 & 0.138 & 0.000 & 0.751 & 0.184 & 95th Percentile \\
\hline No VB, Open & 0.019 & 0.291 & 0.000 & 0.006 & 0.135 & 5th Percentile \\
Containment & 0.109 & 0.395 & 0.000 & 0.118 & 0.285 & Median \\
& 0.200 & 0.379 & 0.000 & 0.208 & 0.274 & Mean \\
& 0.564 & 0.436 & 0.000 & 0.661 & 0.380 & 95th Percentile \\
\hline VB, No CF & 0.005 & 0.002 & 0.783 & 0.003 & 0.079 & 5th Percentile \\
& 0.113 & 0.040 & 0.876 & 0.120 & 0.221 & Median \\
& 0.138 & 0.066 & 0.870 & 0.164 & 0.248 & Mean \\
& 0.368 & 0.190 & 0.981 & 0.527 & 0.511 & 95th Percentile \\
\hline VB, Open & 0.013 & 0.380 & 0.008 & 0.009 & 0.198 & 5th Percentile \\
Containment & 0.093 & 0.531 & 0.100 & 0.078 & 0.394 & Median \\
& 0.159 & 0.509 & 0.103 & 0.150 & 0.372 & Mean \\
& 0.430 & 0.577 & 0.201 & 0.545 & 0.504 & 95th Percentile \\
\hline VB, CF & 0.005 & 0.0 & 0.0 & 0.003 & 0.003 & 5th Percentile \\
& 0.136 & 0.0 & 0.010 & 0.078 & 0.018 & Median \\
& 0.152 & 0.0005 & 0.027 & 0.094 & 0.026 & Mean \\
& 0.313 & 0.0009 & 0.074 & 0.239 & 0.074 & 95th Percentile \\
\hline \hline
\end{tabular}

$\mathrm{VB}=$ Reactor Pressure Vessel Breach

$\mathrm{CF}=$ Containment Failure

PDS = Plant Damage States (defined in Chapter 5) 
6 Analysis of the Accident Progression

Table 6.5 Conditional Probability of Core Damage Arrest

\begin{tabular}{|c|c|c|c|c|c|c|}
\hline $\begin{array}{c}\text { PDS Group } \\
\text { Time Window }\end{array}$ & $\begin{array}{c}\text { PDS } \\
\text { Group } 1\end{array}$ & $\begin{array}{c}\text { PDS } \\
\text { Group } 2\end{array}$ & $\begin{array}{c}\text { PDS } \\
\text { Group } 3\end{array}$ & $\begin{array}{c}\text { PDS } \\
\text { Group } 4\end{array}$ & All & $\begin{array}{l}\text { Statistical } \\
\text { Measures }\end{array}$ \\
\hline \multirow{4}{*}{ Window 1} & 0.40 & 0.42 & 0.0 & 0.00 & 0.06 & 5th percentile \\
\hline & 0.49 & 0.45 & 0.0 & 0.64 & 0.20 & Median \\
\hline & 0.49 & 0.44 & 0.0 & 0.58 & 0.22 & Mean \\
\hline & 0.59 & 0.46 & 0.0 & 0.86 & 0.41 & 95th percentile \\
\hline \multirow{4}{*}{ Window 2} & 0.48 & 0.38 & 0.0 & 0.05 & 0.28 & 5th percentile \\
\hline & 0.56 & 0.41 & 0.0 & 0.67 & 0.40 & Median \\
\hline & 0.57 & 0.41 & 0.0 & 0.61 & 0.39 & Mean \\
\hline & 0.67 & 0.43 & 0.0 & 0.87 & 0.46 & 95th percentile \\
\hline \multirow{4}{*}{ Window 3} & 0.47 & 0.42 & \multirow{4}{*}{$\begin{array}{l}\text { No } \\
\text { Bins }\end{array}$} & \multirow{4}{*}{$\begin{array}{l}\text { No } \\
\text { Bins }\end{array}$} & 0.42 & 5th percentile \\
\hline & 0.55 & 0.45 & & & 0.45 & Median \\
\hline & 0.55 & 0.44 & & & 0.45 & Mean \\
\hline & 0.64 & 0.46 & & & 0.48 & 95th percentile \\
\hline \multirow{4}{*}{ Window 4} & 0.59 & 0.38 & \multirow{4}{*}{$\begin{array}{l}\text { No } \\
\text { Bins }\end{array}$} & \multirow{4}{*}{$\begin{array}{l}\text { No } \\
\text { Bins }\end{array}$} & 0.40 & 5th percentile \\
\hline & 0.69 & 0.41 & & & 0.45 & Median \\
\hline & 0.70 & 0.41 & & & 0.46 & Mean \\
\hline & 0.83 & 0.43 & & & 0.56 & 95th percentile \\
\hline \multirow{4}{*}{ All } & 0.45 & 0.39 & 0.0 & 0.03 & 0.23 & 5th percentile \\
\hline & 0.54 & 0.43 & 0.0 & 0.65 & 0.37 & Median \\
\hline & 0.55 & 0.42 & 0.0 & 0.59 & 0.35 & Mean \\
\hline & 0.71 & 0.45 & 0.0 & 0.86 & 0.44 & 95th percentile \\
\hline
\end{tabular}

PDS = Plant Damage States (defined in Chapter 5)

Window $=$ Time Window $($ defined in Chapter 5) 
6 Analysis of the Accident Progression

Table 6.6 Probability of Loss of Containment Integrity* for Each PDS

\begin{tabular}{|c|c|c|c|c|c|c|}
\hline $\begin{array}{l}\text { PDS Group } \\
\text { Time Window }\end{array}$ & $\begin{array}{c}\text { PDS } \\
\text { Group } 1\end{array}$ & $\begin{array}{c}\text { PDS } \\
\text { Group } 2\end{array}$ & $\begin{array}{c}\text { PDS } \\
\text { Group } 3\end{array}$ & $\begin{array}{c}\text { PDS } \\
\text { Group } 4\end{array}$ & All & $\begin{array}{l}\text { Statistical } \\
\text { Measures }\end{array}$ \\
\hline \multirow{4}{*}{ Window 1} & 0.18 & 1.00 & 0.02 & 0.12 & 0.18 & 5th percentile \\
\hline & 0.48 & 1.00 & 0.13 & 0.36 & 0.39 & Median \\
\hline & 0.54 & 1.00 & 0.13 & 0.46 & 0.44 & Mean \\
\hline & 0.97 & 1.00 & 0.23 & 0.97 & 0.81 & 95th percentile \\
\hline \multirow{4}{*}{ Window 2} & 0.15 & 0.65 & 0.01 & 0.11 & 0.41 & 5th percentile \\
\hline & 0.42 & 0.91 & 0.10 & 0.33 & 0.76 & Median \\
\hline & 0.50 & 0.87 & 0.11 & 0.44 & 0.73 & Mean \\
\hline & 0.97 & 0.99 & 0.21 & 0.97 & 0.96 & 95th percentile \\
\hline \multirow{4}{*}{ Window 3} & 0.15 & 0.69 & \multirow{4}{*}{$\begin{array}{l}\text { No } \\
\text { Bins }\end{array}$} & \multirow{4}{*}{$\begin{array}{l}\text { No } \\
\text { Bins }\end{array}$} & 0.63 & 5th percentile \\
\hline & 0.43 & 0.93 & & & 0.90 & Median \\
\hline & 0.51 & 0.90 & & & 0.87 & Mean \\
\hline & 0.97 & 0.998 & & & 0.997 & 95th percentile \\
\hline \multirow{4}{*}{ Window 4} & 0.14 & 0.24 & \multirow{4}{*}{$\begin{array}{l}\text { No } \\
\text { Bins }\end{array}$} & \multirow{4}{*}{$\begin{array}{l}\text { No } \\
\text { Bins }\end{array}$} & 0.24 & 5th percentile \\
\hline & 0.33 & 0.71 & & & 0.65 & Median \\
\hline & 0.45 & 0.66 & & & 0.63 & Mean \\
\hline & 0.97 & 0.998 & & & 0.91 & 95th percentile \\
\hline \multirow{4}{*}{ All } & 0.17 & 0.67 & 0.02 & 0.11 & 0.39 & 5th percentile \\
\hline & 0.44 & 0.93 & 0.12 & 0.35 & 0.70 & Median \\
\hline & 0.51 & 0.89 & 0.13 & 0.45 & 0.67 & Mean \\
\hline & 0.97 & 0.997 & 0.22 & 0.97 & 0.88 & 95th percentile \\
\hline
\end{tabular}

* Loss of containment integrity includes failure to isolate containment and containment failure caused by energetic events such as steam explosions, $\mathrm{DCH}$ and $\mathrm{H}_{2}$ combustion 
6 Analysis of the Accident Progression

Table 6.7 Mean Conditional Probability of APB Groups for Each PDS (Including Vessel Status and Containment Status)

\begin{tabular}{|c|c|c|c|c|c|c|}
\hline \multicolumn{2}{|c|}{ Accident Progression Bin Groups } & \multirow[b]{2}{*}{$\begin{array}{c}\text { PDS } \\
\text { Group } 1\end{array}$} & \multirow[b]{2}{*}{$\begin{array}{c}\text { PDS } \\
\text { Group } 2\end{array}$} & \multirow[b]{2}{*}{$\begin{array}{c}\text { PDS } \\
\text { Group } 3\end{array}$} & \multirow[b]{2}{*}{$\begin{array}{c}\text { PDS } \\
\text { Group } 4\end{array}$} & \multirow[b]{2}{*}{ All } \\
\hline $\begin{array}{l}\text { Vessel } \\
\text { Status }\end{array}$ & $\begin{array}{l}\text { Containment } \\
\text { Status }\end{array}$ & & & & & \\
\hline \multirow[t]{3}{*}{ No VB } & No CF & 0.351 & 0.046 & 0.0 & 0.383 & 0.079 \\
\hline & Open Containment & 0.200 & 0.379 & 0.0 & 0.208 & 0.274 \\
\hline & Total & 0.551 & 0.425 & 0.0 & 0.592 & 0.353 \\
\hline \multirow[t]{5}{*}{ VB } & No $C F$ & 0.138 & 0.066 & 0.870 & 0.164 & 0.248 \\
\hline & Open Containment & 0.159 & 0.509 & 0.103 & 0.150 & 0.372 \\
\hline & $\mathrm{CF}(\mathrm{DCH})$ & 0.004 & 0.0005 & 0.027 & 0.005 & 0.005 \\
\hline & CF (Hydrogen burning) & 0.148 & 0.0 & 0.0 & 0.089 & 0.021 \\
\hline & Total & 0.449 & 0.575 & 1.00 & 0.409 & 0.646 \\
\hline
\end{tabular}

Table 6.8 Mean Conditional Probability of APB Groups for Each PDS (Containment Status Only)

\begin{tabular}{||l|c|c|c|c|c||}
\hline \multicolumn{1}{|c|}{$\begin{array}{c}\text { Accident Progression } \\
\text { Bin Groups }\end{array}$} & $\begin{array}{c}\text { PDS } \\
\text { Group 1 }\end{array}$ & $\begin{array}{c}\text { PDS } \\
\text { Group 2 }\end{array}$ & $\begin{array}{c}\text { PDS } \\
\text { Group 3 }\end{array}$ & $\begin{array}{c}\text { PDS } \\
\text { Group 4 }\end{array}$ & All \\
\hline \hline No CF & 0.489 & 0.112 & 0.870 & 0.547 & 0.327 \\
\hline Open Containment & 0.359 & 0.888 & 0.103 & 0.358 & 0.646 \\
\hline CF (DCH) & 0.004 & 0.0005 & 0.027 & 0.005 & 0.005 \\
\hline CF (Hydrogen burning) & 0.148 & 0.0 & 0.00 & 0.089 & 0.021 \\
\hline
\end{tabular}


Table 6.9 Mean Conditional Probability of APB Groups for Each Time Window (Including Vessel Status and Containment Status)

\begin{tabular}{|c|c|c|c|c|c|c|}
\hline \multicolumn{2}{|c|}{ Accident Progression Bin Groups } & \multirow[b]{2}{*}{$\begin{array}{c}\text { Window } \\
1\end{array}$} & \multirow[b]{2}{*}{$\begin{array}{c}\text { Window } \\
2\end{array}$} & \multirow[b]{2}{*}{$\begin{array}{c}\text { Window } \\
3\end{array}$} & \multirow[b]{2}{*}{$\begin{array}{c}\text { Window } \\
4\end{array}$} & \multirow[b]{2}{*}{ All } \\
\hline $\begin{array}{l}\text { Vessel } \\
\text { Status }\end{array}$ & $\begin{array}{c}\text { Containment } \\
\text { Status }\end{array}$ & & & & & \\
\hline \multirow[t]{3}{*}{ No VB } & No $\mathrm{CF}$ & 0.068 & 0.085 & 0.050 & 0.171 & 0.079 \\
\hline & Open Containment & 0.169 & 0.306 & 0.399 & 0.281 & 0.274 \\
\hline & Total & 0.237 & 0.391 & 0.449 & 0.452 & 0.353 \\
\hline \multirow[t]{5}{*}{ VB } & No CF & 0.465 & 0.163 & 0.046 & 0.179 & 0.248 \\
\hline & Open Containment & 0.253 & 0.426 & 0.496 & 0.355 & 0.372 \\
\hline & $\mathrm{CF}(\mathrm{DCH})$ & 0.012 & 0.0003 & 0.000 & 0.000 & 0.005 \\
\hline & CF (Hydrogen burning) & 0.033 & 0.019 & 0.009 & 0.013 & 0.021 \\
\hline & Total & 0.763 & 0.597 & 0.551 & 0.547 & 0.647 \\
\hline
\end{tabular}

Table 6.10 Distribution of Frequencies of APB Groups

\begin{tabular}{|l|c|c|c|c||}
\hline \multicolumn{1}{|c|}{ APB Groups } & $\begin{array}{c}\text { 5th } \\
\text { Percentile }\end{array}$ & $\begin{array}{c}\text { 50th } \\
\text { Percentile }\end{array}$ & Mean & $\begin{array}{c}\text { 95th } \\
\text { Percentile }\end{array}$ \\
\hline \hline No VB, No CF & $6.25 \mathrm{E}-9$ & $1.25 \mathrm{E}-7$ & $2.91 \mathrm{E}-7$ & $1.05 \mathrm{E}-6$ \\
\hline No VB, Open Containment & $8.63 \mathrm{E}-8$ & $4.66 \mathrm{E}-7$ & $1.23 \mathrm{E}-6$ & $5.48 \mathrm{E}-6$ \\
\hline VB, No CF & $6.58 \mathrm{E}-8$ & $4.76 \mathrm{E}-7$ & $8.90 \mathrm{E}-7$ & $3.33 \mathrm{E}-6$ \\
\hline VB, Open Containment & $1.09 \mathrm{E}-7$ & $6.49 \mathrm{E}-7$ & $1.69 \mathrm{E}-6$ & $7.48 \mathrm{E}-6$ \\
\hline VB, CF & $2.06 \mathrm{E}-9$ & $2.57 \mathrm{E}-8$ & $1.08 \mathrm{E}-7$ & $4.80 \mathrm{E}-7$ \\
\hline
\end{tabular}




\section{SOURCE TERM ANALYSIS}

The source term is the information required to calculate the offsite consequences for each group of accident progression bins (APBs). The source term for a given APB consists of the release fractions of the core inventory for nine radionuclide groups, and additional information about the timing of the releases, the energy associated with the releases, and height of the releases. The nine radionuclide groups defined for the source term analysis are: noble gases, iodine, cesium, tellurium, strontium, ruthenium, lanthanum, cerium, and barium. A source term is calculated for each APB for each observation in the APET analysis.

Because of the large number of source terms and the similarity of many of the source terms, it is not practical to perform consequence calculations for all of them. The source terms were therefore grouped through a partitioning process based on their potential health effects into a much smaller number ( 25 in the present analysis). Consequence calculations were performed only for these 25 source term groups.

The methods and computer codes used for the source term analysis of accidents during mid-loop operation are based on those developed in the NUREG-1150 program. ${ }^{1}$ The applicability of these to mid-loop operation is discussed below. Section 7.1 describes the computer code used for the source term calculations. Section 7.2 discusses the quantification of the source terms. Section 7.3 describes the method used for source term partitioning and presents the results of the partitioning process.

\subsection{Source Term Analysis Model}

The source term analysis for Surry ${ }^{2}$ in NUREG-1150 was performed by a parametric computer code: SURSOR. $^{3}$ The purpose of this code is not to calculate the behavior of the fission products from their chemical and physical properties and the flow and temperature conditions in the reactor and the containment. Instead, SURSOR provides a means of incorporating into the analysis the results of the more detailed codes that do consider these quantities. For example, SURSOR has a parameter that identifies the fraction of fission products in the core that are released to the vessel before vessel breach. Other parameters identify the fraction of fission products released to the containment and the environment. In all 12 parameters are used in SURSOR to define fission product behavior following a core damage accident. SURSOR also provides a framework for synthesizing the results of experiments and mechanistic codes as interpreted by experts in the field to develop uncertainty distributions of the release parameters. Volume 2, Part 4 of NUREG/CR-4551 provides a detailed description of how the various distributions were developed for the 12 parameters in SURSOR. The application of these distributions for accidents during full power operation at Surry is described in Reference 3.

A simple parametric approach is needed because the detailed codes require too many computer resources to be able to compute the source terms for the numerous APBs that resulted from the quantification of the APET. The use of SURSOR for source term estimation for accidents during mid-loop operation at Surry was first investigated in the abridged study (refer to Chapter 2). Two measures were taken in the abridged study to assure the adequacy of the source terms: 


\section{Source Term Analysis}

1) The first involved comparing the calculations from the MELCOR ${ }^{4}$ code using initial and boundary conditions appropriate to mid-loop operation with the parameter data used in and the source term results obtained from SURSOR.

2) Second, the Source Term Advisory Group was established to provide guidance, and any additional information on modifying the SURSOR code for the study of mid-loop operation.

Considering the differences between full power and shutdown operations, the Source Term Advisory Group identified two parameters in SURSOR as important and possibly different than the values used in NUREG1150. The first parameter is the fraction of the fission products in the core that are released to the vessel before vessel breach. The second parameter is the fraction of the fission products released to the vessel that are subsequently released to the containment. The distributions of these two parameters as given in NUREG1150 were compared with MELCOR calculations to establish their values to be used in the study of mid-loop operation. In addition to the above comparison, the environmental releases of fission products obtained from SURSOR and MELCOR were compared. The comparisons show that generally, the MELCOR values fall within the ranges of SURSOR predictions. Although, for some radionuclide categories, the MELCOR calculated values are closer to the upper ranges of the SURSOR predictions, there are no apparent reasons to modify the SURSOR distributions. Consequently, the Source Term Advisory Group did not recommend any change to the SURSOR code for application to the study of mid-loop operation. Appendix C provides a more detailed discussion of the source term comparison.

The distributions for the parameters used in SURSOR have very large ranges. The 5th and 95th percentile values for some of distributions vary by several orders of magnitude. This signifies the uncertainty in source term estimation and reflects the large differences within the reactor safety community surrounding the source terms for any given accident sequence, even if the initial and boundary conditions are well characterized. Furthermore, the initial and boundary conditions are seldom well known, and this lack of knowledge adds additional uncertainty.

\subsection{Quantification of Source Terms}

Most of the parameters in SURSOR are determined by sampling from distributions of the parameters during Monte Carlo simulations. The distributions for the nine radionuclide groups are assumed to be correlated as they were in NUREG-1150. That is, a single LHS variable applies to each parameter in the release fraction equation, and it applies to the distributions for all nine radionuclide groups. For example, if the random number for the release fraction from the core is 0.8 , the 80 th percentile value is chosen from the iodine distribution, the cesium distribution, the tellurium distribution and the other six distributions. However, there are separate distributions for each fission product class.

Of the twelve parameters in SURSOR, the following ten parameters listed below were sampled for source term analysis:

Fraction of the radionuclide in the core released to the vessel before or at vessel breach (VB)

Fraction of the radionuclide released from the vessel to the containment before or at VB

Fraction of the radionuclide in the containment from the RCS release that is released from the containment in the absence of any mitigating effects 
Fractional release of radionuclide from corium during core concrete interaction (CCI)

Containment transport fraction for ex-vessel release

Decontamination factor for containment sprays

Fraction of the iodine deposited in the containment which is revolatilized and released to the environment late in the accident

Fractional release of material deposited in the RCS due to revaporization

Fraction of core radionuclide released to the containment due to direct containment heating (DCH) at VB

Decontamination factor for a pool of water overlying the core debris during CCI

Source terms were computed for all the APBs for each of 100 observations. There are about 150 APBs in each observation. The total number of source terms obtained was 15,443. An approach used in the full power analysis was to summarize the source terms as complementary cumulative distribution functions for the release fractions of eight of the nine radionuclide groups. Four statistical measures of the distributions were used that give the frequencies at which the release fractions are exceeded. Similar curves were generated in this study; they are presented in Appendix C.

Besides the release fractions four other parameters are needed to specify the source term. These are: the height of the release, the energy of the release, the release timing and the release duration. Since the reason for unisolated containment during mid-loop operation was assumed to be the temporary plug in the escape tunnel of the equipment hatch all releases were assumed to take place through this opening. The height of the release was therefore the level of the equipment hatch, $28 \mathrm{ft}(8.4 \mathrm{~m})$ above ground. The release energy of a source term which is input to the consequence code is the average energy release rate over the duration of the release (joules/sec or watts). Energetic releases (containing a large amount of sensible heat) can result in a buoyant plume which can rise to heights much greater than the initial release height leading to greater dilution and smaller consequences near the point of release. The MACCS code models a criterion for plume buoyancy based on atmospheric conditions, windspeed and the sensible heat release rate. The energy during mid-loop operation is low, less than $1 \%$ of the energy at full power. Calculations were performed with a range of possible energy release rates during mid-loop operation and compared with the plume lift-off criterion; it was determined that there were no possible energy release rates which could result in a buoyant plume. Thus the release energy was set equal to zero for all releases during mid-loop operation. The timing of the release and the duration of the release were based on selected calculations performed by the MELCOR code. Details of these calculations are provided in Appendix E. Most of the releases occur in window 1 and window 2 with an unisolated containment. All releases were modeled as single-puff releases. Based on MELCOR results, a release timing of 1 hour and a release duration of 6 hours was assumed for these releases. Somewhat conservatively, these times were assumed for the other releases as well.

\subsection{Partition of Source Terms}

The accident progression and source term analyses resulted in a total of 15,443 source terms for internally initiated accidents during mid-loop operation. It is computationally impractical to carry out a consequence calculation for each source term to obtain the risk for the selected consequence measures. To create an interface between the source term analysis and the consequence calculation, the total number of source terms are grouped into a much smaller number of source term groups. The groups are created such that the source 


\section{Source Term Analysis}

terms within each group have similar properties with respect to consequences, i.e their potential for causing early fatalities and latent cancer fatalities is similar. A frequency weighted mean source term is determined for each group and the consequence calculation is performed for the mean source term.

The grouping of the source terms is designated as "partitioning". The process is described in detail in NUREG/CR-4551, Volume 1 and in Reference 5. It involves definition of an early health effect weight, EH, and a latent health effect weight, $\mathrm{LH}$, for each source term and a grouping of source terms based on these weights. A further subdivision is made on the basis of the timing of the release relative to the time of the emergency evacuation. Then the frequency weighted mean source term is calculated for each group. In the present study, the timing of the release was conservatively estimated to be the same for all releases. Thus no grouping was necessary based on timing of the evacuation relative to the time of release. On the other hand, the effect of radioactive decay as a function of time window was included in the calculation of the early health effect weight. All source terms in Window 4, for example, were assigned an $\mathrm{EH}=0$ based on the equivalent I-131 inventory of Window 4.

The early health effect weight was calculated by converting the radionuclide release associated with each source into an equivalent I-131 release. Surry site-specific calculations of the number of early fatalities as a function of equivalent $I-131$ release were performed in each time window. This estimated number of early fatalities is the $\mathrm{EH}$ for each source term. Details of the calculations including the relationship between the number of early fatalities and the equivalent I-131 release are provided in Appendix C.

The latent health effect, $\mathrm{LH}$, was calculated by assuming a linear relationship between the number of latent cancer fatalities due to a particular radionuclide and the amount of release of that radionuclide. Surry sitespecific consequence calculations were carried out for each time window assuming a fixed release of each of the 60 radionuclides in the nine radionuclide groups contained in MACCS. Based on these calculations and the linear relationship between latent cancer fatalities and the amount of radionuclides released, the amount of latent cancer fatalities for each source term was estimated (a window adjustment factor to adjust the radionuclide inventory in each time window was used to estimate the total release in curies associated with each source term depending on the time window to which it belonged). This estimated number of latent cancer fatalities is the latent health effect weight, $\mathrm{LH}$, associated with each source term. Details of the calculation and results are provided in Appendix C.

Based on the estimates of $\mathrm{EH}$ and $\mathrm{LH}$, the source terms were divided initially into three categories: $\mathrm{EH}>0$ and $\mathrm{LH}>0, \mathrm{EH}=0$ and $\mathrm{LH}>0$, and $\mathrm{EH}=0$ and $\mathrm{LH}=0$. The number of source terms and the percentage of total frequency associated with each of these categories is as follows:

\begin{tabular}{||l|c|c|}
\hline \multicolumn{1}{|c|}{ Category } & Number of Source Terms & \% Total Frequency \\
\hline \hline $\mathrm{EH}>0, \mathrm{LH}>0$ & 213 & 2.8 \\
\hline $\mathrm{EH}=0, \mathrm{LH}>0$ & 15230 & 97.2 \\
\hline $\mathrm{EH}=0, \mathrm{LH}=0$ & 0 & 0 \\
\hline
\end{tabular}

Each of the above categories was treated separately for partitioning. 
For the $\mathrm{EH}>0, \mathrm{LH}>0$ category a grid was created by examining the ranges of the $\mathrm{EH}$ and $\mathrm{LH}$ values, placing the source terms within each cell on the grid and then pooling cells which either have a small frequency or a small number of source terms. Four source term groups were created for this category through this process which is described in more detail in Appendix C. For the $\mathrm{EH}=0, \mathrm{LH}>0$ category, the source terms were grouped along one dimension (the value of $\mathrm{LH}$ ) by creating cells based on the range of values of $\mathrm{LH}$. A total of 21 groups for this category were obtained through this process which is discussed in Appendix C.

A total of 25 source term groups was thus obtained after partitioning. A frequency weighted mean source term was then identified for each of the groups. The mean source terms were used for the consequence calculations. They are displayed in Appendix C.

\subsection{References}

1. U. S. Nuclear Regulatory Commission, "Severe Accident Risks: An Assessment for Five U.S. Nuclear Power Plants,” NUREG-1150, Vols. 1-3, December 1990-January 1991.

2. Breeding, R. J., et al., "Evaluation of Severe Accident Risks: Surry Unit 1," NUREG/CR-4551, Vol. 3, Rev. 1, Parts 1 and 2, Sandia National Laboratories, October 1990.

3. Jow, H. N., W. B. Murfin and J. D. Johnson, "XSOR Codes User's Manual," NUREG/CR-5360, Sandia National Laboratories, December 1989.

4. Summers, R. M., et. al., "MELCOR 1.8.0: A Computer Code for Nuclear Reactor Severe Accident Source Term and Risk Assessment Analyses," NUREG/CR-5531, Sandia National Laboratories, SAND90-0364, January 1991.

5. Iman, R. L., J. C. Helton, and J. D. Johnson, “A User's Guide for PARTITION: A Program for Defining the Source Term/Consequence Analysis Interfaces in the NUREG-1150 Probabilistic Risk Assessments," NUREG/CR-5253, SAND88-2940, Sandia National Laboratories, May 1990. 


\section{CONSEQUENCE ANALYSIS}

Offsite consequences were calculated for the mean source term groups resulting from the partitioning process described in Chapter 7. The calculations were performed using the latest version (Version 1.5.11.1) of the MACCS code. ${ }^{1}$ An approximate scoping calculation of onsite dose rates in the vicinity of the containment (so-called parking lot dose) was also carried out for three selected mean source terms and selected weather conditions based on dose models described in section 8.2 below.

\subsection{Offsite Calculations}

The offsite consequence calculations were performed by the latest version of the MACCS code, ${ }^{1}$ Version 1.5.11.1, which incorporates the BEIR V recommended risk factors for the latent cancer - dose relationship. MACCS tracks the dispersion of the radioactive material in the atmosphere from the plant and computes its deposition on the ground. MACCS then calculates the effects of this radioactivity on the population and the environment. Doses and the ensuing health effects from 60 radionuclides are computed for the following pathways: immersion or cloudshine, inhalation from the plume, groundshine, deposition on the skin, inhalation of resuspended ground contamination, ingestion of contaminated water and ingestion of contaminated food.

MACCS treats atmospheric dispersion by the use of multiple, straight-line Gaussian plumes. Each plume can have a different direction, duration, and initial radionuclide concentration. Dry and wet deposition are treated as independent processes. The weather variability is treated by means of a stratified sampling process.

For early exposure, the following pathways are considered: immersion or cloudshine, inhalation from the plume, groundshine, deposition on the skin, and inhalation of resuspended ground contamination. For the long-term exposure, MACCS considers the following four pathways: groundshine, inhalation of resuspended ground contamination, ingestion of contaminated water and ingestion of contaminated food. The direct exposure pathways groundshine, and inhalation of resuspended ground contamination, produce doses in the population living in the area surrounding the plant. The indirect exposure pathways, ingestion of contaminated water and food, produce doses in those who ingest food or water emanating from the contaminated area around the accident site. The contamination of water bodies is estimated for the washoff of land-deposited material as well as direct deposition. The food pathway model includes direct deposition onto crops and uptake from the soil.

Both short-term emergency response actions and long-term mitigative measures are modeled in MACCS. Emergency response actions include evacuation, sheltering and emergency relocation out of the emergency planning zone (EPZ). Long-term actions include later relocation and restrictions on land use and crop disposition to reduce projected doses below a pre-determined level. Relocation and land decontamination, interdiction, and condemnation are based on projected long-term doses from groundshine and inhalation of resuspended radioactivity. The disposal of agricultural products is based on reducing the yearly doses induced by consumption of these products below a preset criterion based on the Protective Action Guides of the Food and Drug Administration. The removal of farmland from crop production is based on ground contamination criteria. 


\section{Consequence Analysis}

The health effects models link the dose received by an organ to predicted morbidity or mortality. MACCS calculates both early and latent (long-term) health effects. The model for latent cancers implemented in the latest version of MACCS is based on the recommendations of the BEIR V committee. Results for the following consequence measures calculated by MACCS are given in this report: early fatalities, latent cancer fatalities (within 50 miles and 1000 miles) population dose (within 50 miles and 1000 miles).

Early fatalities are defined as those occurring within one year of the release. Population dose, expressed in effective dose equivalents for whole body exposure (person-Sv or person-rem), due to both early exposure and chronic exposure is calculated within a 50 mile and 1000 mile radius of the plant. The latent cancers due to both early exposure and chronic exposure are calculated to 50 miles and 1000 miles from the plant.

\subsubsection{MACCS Input for Surry}

The input parameters for the offsite consequence calculations were mainly based on Reference 2. Certain modifications, based on conditions specific to mid-loop operation and its accident characteristics, are noted below.

Site-specific data for Surry include: reactor power level, weather, population, exclusion zone distance, emergency response, shielding parameters, long-term mitigative actions, land and land use fractions, and economic parameters for calculating offsite costs. Apart from reactor power level, discussed below, the other site data were based on the values in Reference 2. For example, the emergency response assumes that $99.5 \%$ of the population in the EPZ (within a 10 mile radius of the plant) evacuates at a speed of $1.8 \mathrm{~m} / \mathrm{s}(4 \mathrm{mph}$ ) after a 2 hour delay following the declaration of an emergency, i.e., a general warning by the local authorities. The remaining $0.5 \%$ of the population are assumed to follow normal activity. The long-term mitigative actions include relocation of people from contaminated land which could lead to a dose to an individual of 4 rem or more over 5 years ( 2 rem in the first year following the accident and 0.5 rem per year thereafter for 4 years). One year of hourly meteorological data at Surry and the site population distribution as in Reference 2 were used in the input.

The initial reactor power level $(13.2 \mathrm{MW})$ used in the calculation was at the mid-point of Window 1 as defined in Table 5.4. The core inventory of 60 radionuclides at this power level for Surry was evaluated by interpolation from the calculations of the core inventory at Surry as a function of time after reactor shutdown reported in Reference 6. This inventory, displayed in Table C.4 of Appendix C was used for calculating the consequences of all 25 source term groups resulting from the partitioning process. A window adjustment factor, $W F_{w}$, defined in section C.3.2 of Appendix $C$ was used in calculating the consequences for Windows 2,3 , and 4 using the predictions for Window 1.

\subsubsection{Results of Offsite Consequence Calculations}

The results for the offsite consequence measures given in this section are conditional on the occurrence of a release. Information about the frequency of the consequences of different magnitudes is contained in the risk results reported in Chapter 9.

Twenty-five source term groups were obtained after the partitioning process described in Chapter 7. Frequency weighted mean source terms were then identified for each of the groups. The release fractions for 
each of the source term groups are given in Table C.11 of Appendix C. These release fractions together with other input parameters described above were used in the MACCS code to calculate various offsite consequence measures. A complementary cumulative distribution function (CCDF) was calculated for each consequence measure. Each $\mathrm{CCDF}$ is conditional on the occurrence of the source term and gives the probability of exceedance of individual consequence values due to the variability of the weather at the time of the release. The CCDFs were combined with the frequency of the source term groups to calculate risk as described in Chapter 9.

\subsection{Onsite Consequences}

The total onsite dose rate is modeled as a sum of the inhalation and cloud exposure dose rates in the wake region of a building due to the release of the radionuclide inventory following an accident. For the scoping calculation, an uniform release rate was assumed.

The dose rate is calculated as a sum of the cloud inhalation dose rate, $D_{i}^{\text {inh }}$, and the cloudshine dose rate, $D_{i}^{\text {cloud }}$ (based on the 60 radionuclides in the MACCS dosimetry routine):

$$
D=\sum_{i=1}^{i=60}\left[D_{i}^{i n h}+D_{i}^{\text {cloud }}\right]
$$

where,

$$
\begin{aligned}
D_{i}^{\text {inh }} & =(D F I)_{i} \beta Q(t)\left\{\frac{\chi}{Q}\right\}, \mathrm{rem} / \mathrm{sec} \\
D_{i}^{\text {cloud }} & =(D F C)_{\infty i} Q(t)\left\{\frac{\chi}{Q}\right\}, \mathrm{rem} / \mathrm{sec}
\end{aligned}
$$

$\left(D F I_{i}\right.$ - inhalation dose-conversion factor, rem/Ci for the radionuclide $i$;

$(D F C)_{\infty i}$ - semi-infinite cloud dose-conversion factor for the radionuclide $i \frac{\mathrm{rem}-m^{3}}{\mathrm{Ci}-\mathrm{sec}}$;

$\beta$ - breathing rate, $\mathrm{m}^{3} / \mathrm{s}$. In these calculations, the breathing rate $\beta=2.66 \times 10^{-4} \mathrm{~m}^{3} / \mathrm{s}$ following the

MACCS code default value;

$r_{i}$ - fraction of nuclide's $i$ inventory released over the release duration;

$I_{i}$ - total inventory of nuclide $i, \mathrm{Ci}$;

$\tau$ - release duration, sec.;

$Q(t)$ - release rate, assumed to be uniform over the release duration $=r_{i} I_{i} / \tau, \mathrm{Ci} / \mathrm{sec}$;

$\chi / Q$ - dilution factor calculated, as explained below, by three different models, $\mathrm{sec} / \mathrm{m}^{3}$.

The average concentration in the building wake was estimated using the following wake centerline concentration models: Ramsdell, ${ }^{3}$ Wilson, ${ }^{4}$ and Reg. Guide $1.145{ }^{5}$ Brief descriptions of each model are given below. 


\section{Consequence Analysis}

\subsubsection{Ramsdell Model}

The Ramsdell model ${ }^{3}$ calculates the concentration in the far-region of the wake by including the effects of the lateral and vertical diffusion due to background turbulence:

$$
\chi / Q=\frac{1}{\pi U\left[\sigma_{y}^{2}+\left(K A / a^{2} U^{2}\right) F\left(T_{s}\right)\right]^{1 / 2} \times\left[\sigma_{z}^{2}+\left(K A / a^{2} U^{2} S^{2}\right) F\left(T_{s v}\right)\right]^{1 / 2}}
$$

where $K$ is a characteristic dispersion factor for large structures typical of reactor buildings and recommended to have a value of 0.5 in Reference 3 .

In the correlation above,

$$
F(T)=1-[1+x /(U T)] \exp [-x / U T)]
$$

where $T=T_{s}$ or $T_{s v} ; T_{s}=A^{1 / 2} / u^{*}$, sec;

$T_{s v}=T_{s}$ for extremely unstable weather (Class A, Pasquill-Gifford), and $T_{s v}=T_{s} / 2.5$ for extremely stable conditions (class $\mathrm{G}$ );

$S=1$ for extremely unstable weather (Class A, Pasquill-Gifford), and $S=2.5$ for extremely stable conditions (class G);

$u^{*}=a U$, friction velocity, $\mathrm{m} / \mathrm{s} ; a=0.4 / \ln \left(z / z_{0}\right) ;$

$U$ is the average wind speed at $z=10$ meters, $\mathrm{m} / \mathrm{s}$,

surface roughness length $z_{0}=0.1 \mathrm{~m}$; based on this, $a=0.0869$,

$A=$ building area, $m^{2}$;

$\sigma_{y}$ and $\sigma_{z}=$ diffusion coefficients due to the background turbulence.

$x=$ downwind distance from the source.

\subsubsection{Wilson Model}

The Wilson model suggests a correlation for calculating the lower limit on the dilution in the wake (which corresponds to maximum concentration in the wake). This leads to the following expression for $\chi / Q$ :

$$
\left[\frac{\chi}{Q}\right]_{\max }=\frac{1}{0.11} \frac{1}{U x^{2}} \text {. }
$$

where $U=$ average windspeed

$x=$ downwind distance from the source.

As recommended in Ref. 3, a multiplier of 5.0 was used to calculate the ground level release (elevation lower than $0.2 H$, where $H$ is the height of the building).

\subsubsection{NRC Regulatory Guide 1.145 Model}

NRC Regulatory Guide 1.145 contains guidance on the calculation of $\chi / Q$ values for releases through vents that are effectively lower than two and one-half times the height of adjacent solid structures during neutral 


\section{Consequence Analysis}

or stable weather stability conditions. The recommended correlations allow for horizontal plume meander when the windspeed at the 10-meter level is less than $6 \mathrm{~m} / \mathrm{s}$. Equation (2) of the Reg. 1.145 model was used for calculating $\chi / Q$ :

$$
\chi / Q=\frac{1}{\bar{U}_{10}\left(3 \pi \sigma_{y} \sigma_{z}\right)}
$$

$\sigma_{\mathrm{y}}$ and $\sigma_{\mathrm{z}}$ are the standard dispersion parameters

$\bar{U}_{10}$ is the average windspeed at $10 \mathrm{~m}$ height

$\sigma_{y}=a x^{b}$ and $\sigma_{z}=c x^{d}$,

$x$ is the distance from the source, $\mathrm{m}$, and

the dispersion constants $a=0.0722, b=0.9031, c=0.2$, and $d=0.602$ for stable weather, Pasquill-Gifford Class F.

\subsubsection{Calculation Assumptions}

The scoping values of dose rates were calculated with the following set of input parameters corresponding to the Surry building and site:

- distance from source, $x=10$ to 300 meters,

- building projected area, $A=1500 \mathrm{~m}^{2}$, and, finally,

- wind speed at $10 \mathrm{~m}$ elevation, $U=1.2 \mathrm{~m} / \mathrm{s}$.

Wind speed was obtained by an arithmetic averaging of the wind speeds observed at the Surry site during the most stable weather conditions (Class F stability).

\subsubsection{Results}

The bounding calculations were performed for three source terms referred to as high, medium, and low (Gap release). The results are shown in Figure 8.1. The Wilson/Reg. Guide 1.145 result is based on the prediction of the Reg. Guide 1.145 correlation, limited from above by the values predicted by the Wilson model. The results in Figure 8.1 for the dose rate $(\mathrm{Rem} / \mathrm{h})$ indicate a variation of about two orders of magnitude as a function of the source term. The onsite dose rates are high, and are likely to lead to early fatalities or early injuries for exposed workers depending on the exposure period. In view of the relatively large number of onsite personnel during shutdown operations, these dose rates outside the containment suggest that a careful examination should be made of onsite evacuation schemes to limit the consequences. 
8 Consequence Analysis

\subsection{References}

1. Chanin, D., J. Rollstin, J. Foster, and L. Miller, "MACCS Version 1.5.11.1: A Maintenance Release of the Code," NUREG/CR-6059, October 1993.

2. Sprung, J. L., J. A. Rollstin, J. C. Helton, H-N Jow, "Evaluation of Severe Accident Risks: Quantification of Major Input Parameters, MACCS Input," NUREG/CR-4551, Volume 2, Pt. 7, Revision 1, December 1990.

3. Ramsdell, Jr., J. V., "Diffusion in Building Wakes from Ground-Level Releases," Atmos. Env. 241 (3), 377-388, 1990.

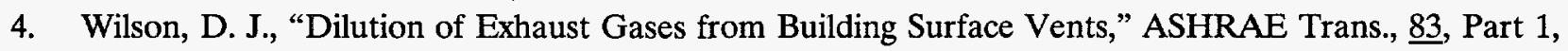
168-176, 1977.

5. U. S. Nuclear Regulatory Commission, Regulatory Guide 1.145, Rev. 1, November 1982.

6. Denning, R. S., R. Freeman-Kelly, P. Cybulskis, L. A. Curtis, "Source Term Calculations for Assessing Radiation Dose to Equipment,” Battelle Columbus Laboratories, NUREG/CR-4949, 1989. 
8 Consequence Analvsis
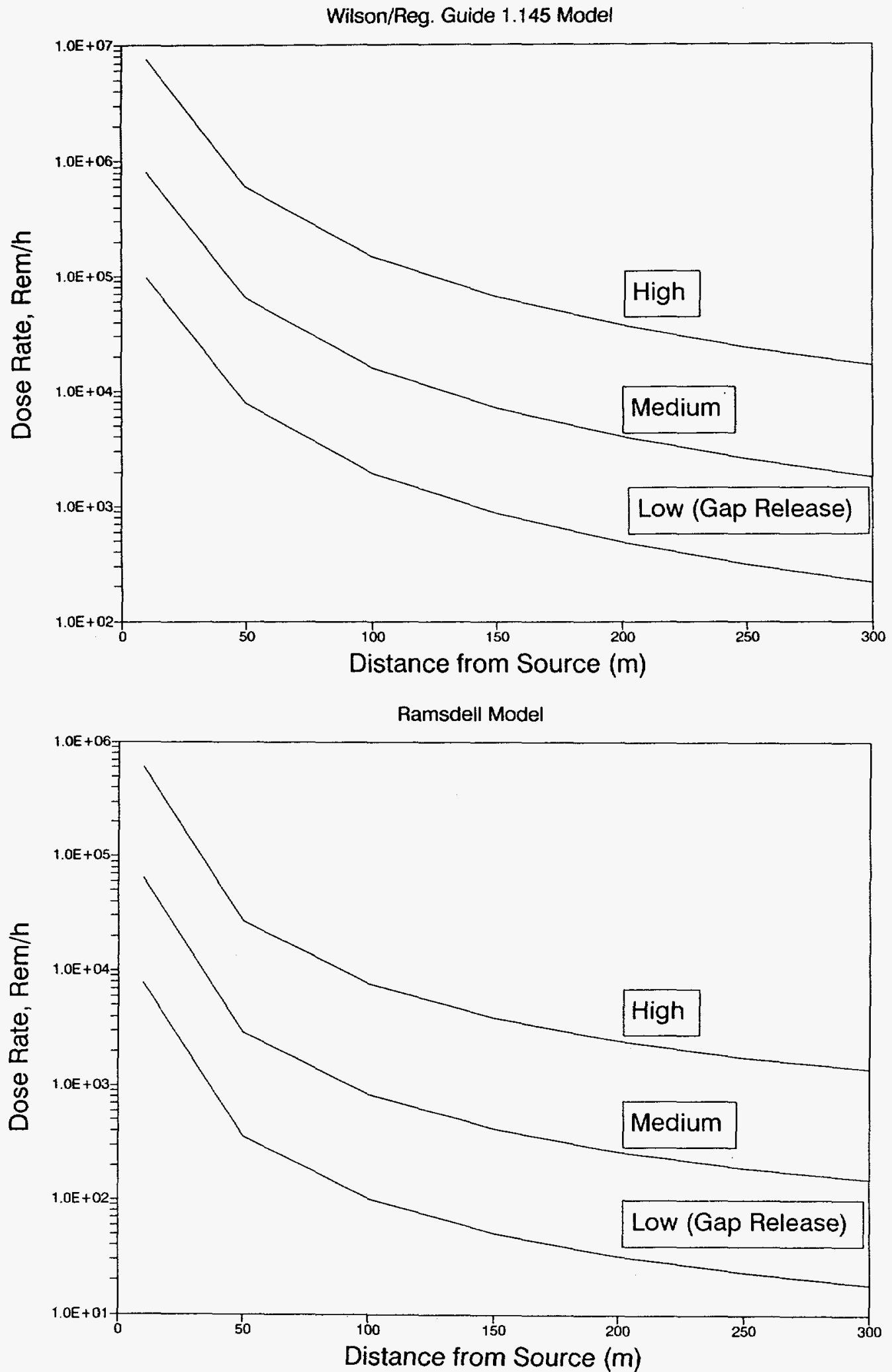

Figure 8.1 Onsite Parking Lot Dose Rate as a Function of Distance from the Containment for Three Source Terms 


\section{RISK CALCULATIONS}

This chapter provides the results of the risk analysis of the Surry plant during mid-loop operation. Risk is determined by bringing together the results of the four constituent analyses; accident frequency (discussed in Volume 2 of this report and summarized in Chapter 5), accident progression (Chapter 6), source terms (Chapter 7) and consequence analyses (Chapter 8). The methods used to perform the risk calculations have been broadly described in Chapter 3. Details of the calculations carried out for each of the risk results are briefly reviewed below. The results are presented in the form of CCDFs, distributions of risk, and mean fractional contributions to risk for the selected consequence measures.

\subsection{Risk Results}

\subsubsection{Exceedance Frequencies for Risk}

The risk analysis was performed for a sample of 100 observations; each observation consists of a frequency for each of the 25 source term groups defined in Appendix C, calculated by summing the frequencies of the accident progression bins assigned to each source term group. For each consequence measure, these 100 observations were combined with the CCDFs for each of the source term groups. This calculational step produces $100 \mathrm{CCDFs}$ for each consequence measure which display the relationship between the frequency of the consequence and the magnitude of the consequence. Statistical measures were generated from these 100 $\mathrm{CCDF}$ curves by analyzing the curves in the vertical direction. For each value of a particular consequence, there are 100 values of the exceedance frequency (one for each observation). From these 100 values the mean, median, 95 th percentile, and 5th percentile were calculated. This was done for each value of the consequence measure, to obtain the plots shown in Figure 9.1. These figures show the relationship between the magnitude of the consequence and the frequency at which the consequence is exceeded, as well as the variation in that relationship. Individual risk was also calculated by dividing the probability of early fatalities and latent cancer fatalities by the population within 1 mile and 10 miles radius of the plant, respectively. Plots of individual risk are also included in Figure 9.1.

Figure 9.1 shows that the risk of early fatalities during mid-loop operation is low. At the upper end (95th percentile) of the range, the risk of one early fatality is below $5 \times 10^{-8}$ per year. The 5 th to the 95 th percentiles indicate the uncertainty in the risk estimates due to uncertainty in the basic parameters in the three sampled constituent analyses (the accident frequency, accident progression, and source term analyses). For latent cancer fatalities and population dose (Figure 9.1), this uncertainty is approximately two orders of magnitude across most of the exceedance curve. Three parameters, in particular, contribute to this uncertainty; the uncertainty in the human error probabilities, the uncertainty in the status of containment, and the uncertainty in the availability of containment sprays. The uncertainties in the release fractions constituting the source terms also contribute to the overall uncertainty.

The variation along a curve in Figure 9.1 is indicative of the variation in risk due to different types of accidents and due to different weather conditions at the time of the accident. Thus the individual curves can be viewed as representing stochastic variability (i.e., the effects of probabilistic events in which it is possible for the accident to develop in more than one way), and the variability between curves can be seen as representing the 


\section{Risk Calculations}

effects of imprecisely known parameters and processes that are mostly nonstochastic. Insights into the risk from different types of accidents, represented by plant damage states, is discussed below.

As the magnitude of the consequence measure increases, the mean curve typically approaches or exceeds the 95th percentile curve. This happens when the mean is dominated by a few large values within the sample because only few observations have nonzero exceedance frequencies at large values of the consequences.

\subsubsection{Estimates of Risk}

Based on the CCDF of risk for each observation a single number may be generated for each consequence measure for each observation. This value is determined by summing the product of the frequencies and consequences for all the points that are used to construct the CCDF for each observation in the sample. The risk estimate averages over the different weather states and includes contributions from all the different types of accidents that can occur. Since the complete analysis consisted of a sample of 100 observations, there are 100 values of risk for each consequence measure. The distribution of risk for the consequence measures, based on these 100 values is shown in Table 9.1 below:

Table 9.1 Distribution for Annual Risk for the Sample During Mid-Loop Operation Due to Internal Initiators (All Values per Reactor Year; Population Doses in P-Sv per Year)

\begin{tabular}{|l|c|c|c|c|c||}
\hline \hline Annual Risk & $\begin{array}{c}\text { 5th } \\
\text { Percentile }\end{array}$ & Median & Mean & $\begin{array}{c}\text { 95th } \\
\text { Percentile }\end{array}$ & $\begin{array}{c}\text { Standard } \\
\text { Deviation }\end{array}$ \\
\hline \hline Early Fatalities & $1.26 \mathrm{E}-10$ & $3.57 \mathrm{E}-09$ & $4.90 \mathrm{E}-08$ & $1.59 \mathrm{E}-07$ & $1.69 \mathrm{E}-07$ \\
\hline Latent Fatalities, 50 mi & $1.55 \mathrm{E}-04$ & $8.34 \mathrm{E}-04$ & $2.46 \mathrm{E}-03$ & $8.78 \mathrm{E}-03$ & $3.68 \mathrm{E}-03$ \\
\hline Latent Fatalities, $1000 \mathrm{mi}$ & $7.97 \mathrm{E}-04$ & $5.35 \mathrm{E}-03$ & $1.57 \mathrm{E}-02$ & $5.50 \mathrm{E}-02$ & $2.52 \mathrm{E}-02$ \\
\hline Population Dose, $50 \mathrm{mi}$ & $3.77 \mathrm{E}-03$ & $1.98 \mathrm{E}-02$ & $5.79 \mathrm{E}-02$ & $1.89 \mathrm{E}-01$ & $8.77 \mathrm{E}-02$ \\
\hline Population Dose, $1000 \mathrm{mi}$ & $1.87 \mathrm{E}-02$ & $1.25 \mathrm{E}-01$ & $3.66 \mathrm{E}-01$ & $1.29 \mathrm{E}+00$ & $5.90 \mathrm{E}-01$ \\
\hline Individual Early Fatalities Risk, $1 \mathrm{mi}$ & $6.00 \mathrm{E}-12$ & $1.27 \mathrm{E}-10$ & $1.74 \mathrm{E}-09$ & $6.94 \mathrm{E}-09$ & $5.52 \mathrm{E}-09$ \\
\hline Individual Latent Fatalities Risk, $10 \mathrm{mi}$ & $1.20 \mathrm{E}-10$ & $7.48 \mathrm{E}-10$ & $2.09 \mathrm{E}-09$ & $7.10 \mathrm{E}-09$ & $3.01 \mathrm{E}-09$ \\
\hline
\end{tabular}

Table 9.1 displays the distributions of the risk for all consequence measures. The distribution for early fatalities shows that the ratio of the 5th to the 95th percentile is approximately three orders of magnitude. For the cases of latent cancer fatalities and population dose, the distributions show that the ratio of the 5th to the 95th percentile is a little less than two orders of magnitude. Where the mean is close to the 95th percentile, it may be inferred that a relatively small number of observations dominate the mean value.

These distributions of risk can be compared with the corresponding distributions for the full power study to obtain insights into how accident progression during mid-loop operation differs from full power operation. This comparison is performed in Chapter 10. 


\subsubsection{Contributors to Risk}

To evaluate the contribution to risk from different types of accidents represented by the plant damage states, the mean fractional contribution to risk (MFCR) has been calculated as follows. If $M F C R_{j k}$ represents the mean fractional contribution to risk for consequence measure $j$ from plant damage state $k$, then

$$
M F C R_{j k}=\frac{\sum\left(\frac{r C_{i j k}}{r C_{i j}}\right)}{n L H S}
$$

where,

$$
\begin{aligned}
& r C_{j}=\text { risk (consequences/year) for consequence measure } j, \\
& r C_{i j}=\text { value of } r C_{j} \text { for observation } i, \\
& r C_{j k}=\text { risk of consequence measure } j \text { due to PDS group } k, \text { and } \\
& r C_{i j k}=\text { value of } r C_{j k} \text { for observation } i .
\end{aligned}
$$

The summation is over all observations $n L H S$ (100 in this case).

Table 9.2 shows the mean fractional contribution to the various risk measures from the four PDS groups: PDS 1 (station blackout), PDS 2 (human error), PDS 3 (recirculation failure and PDS 4 (loss of $4 \mathrm{kV}$ bus). This table shows that PDS 2 is the largest contributor to risk for all consequence measures. The reason for this is that for accidents where operator errors, such as failure to diagnose or take proper action, play a major role in determining the progression of the accident, it was judged unlikely that actions to isolate containment would be taken. As shown in Chapter 6, for PDS 2 the mean conditional probability of the containment being unisolated was estimated to be almost 0.95 for the accident sequences belonging to this plant damage state.

\subsubsection{Distribution of Risk for Each PDS}

Table 9.3 displays the distribution of risk for each of the PDSs for all consequence measures. The distributions for the PDS groups can be compared with the risk distributions in Table 9.1. The distribution for PDS 2 is almost equivalent to the risk distribution for all consequence measures. As pointed out above, the mean conditional probability of the containment being unisolated is very high for accidents in PDS 2 and this contributes strongly to the risk distribution. The distributions for PDS 3 and PDS 4 lie almost entirely below the distribution for PDS 2 and consist of very low estimates of consequences. These PDS groups do not impact the risk distribution significantly. The upper end (95th percentile) of the risk distributions for PDS 1 are near the median of the distribution for PDS 2 and the distribution (the distributions for early health effects overlap more than the distributions for long-term health effects). A small fraction of the accidents, about $16 \%$, in PDS 1 involve an initially isolated containment which is subsequently challenged by phenomena such as hydrogen combustion. These types of accidents contribute to the upper end of the risk range for PDS 1. 


\subsubsection{Comparison With the Safety Goals}

Comparison of the results of this study against the NRC safety goals is done for the two quantitative health objectives identified in the Commission's policy statement of August 1986. These objectives deal with individual early fatality and latent cancer fatality risks within 1 mile and 10 miles of the site, respectively. The numerical value of these objectives are given in Table 9.3. The 95th percentile of the distribution for individual latent cancer fatality risk falls more than an order of magnitude below the objective. The 95th percentile of the distribution for individual early fatality risk falls over two orders of magnitude below the corresponding health objective. However, the health objectives apply to the total risk of the Surry plant and therefore include all modes of operation and accidents caused by internal and external events. The risk estimates of this study are for accidents initiated by internal events during mid-loop operation and therefore reflect only a fraction of total risk of the Surry plant. 


\section{Risk Calculations}
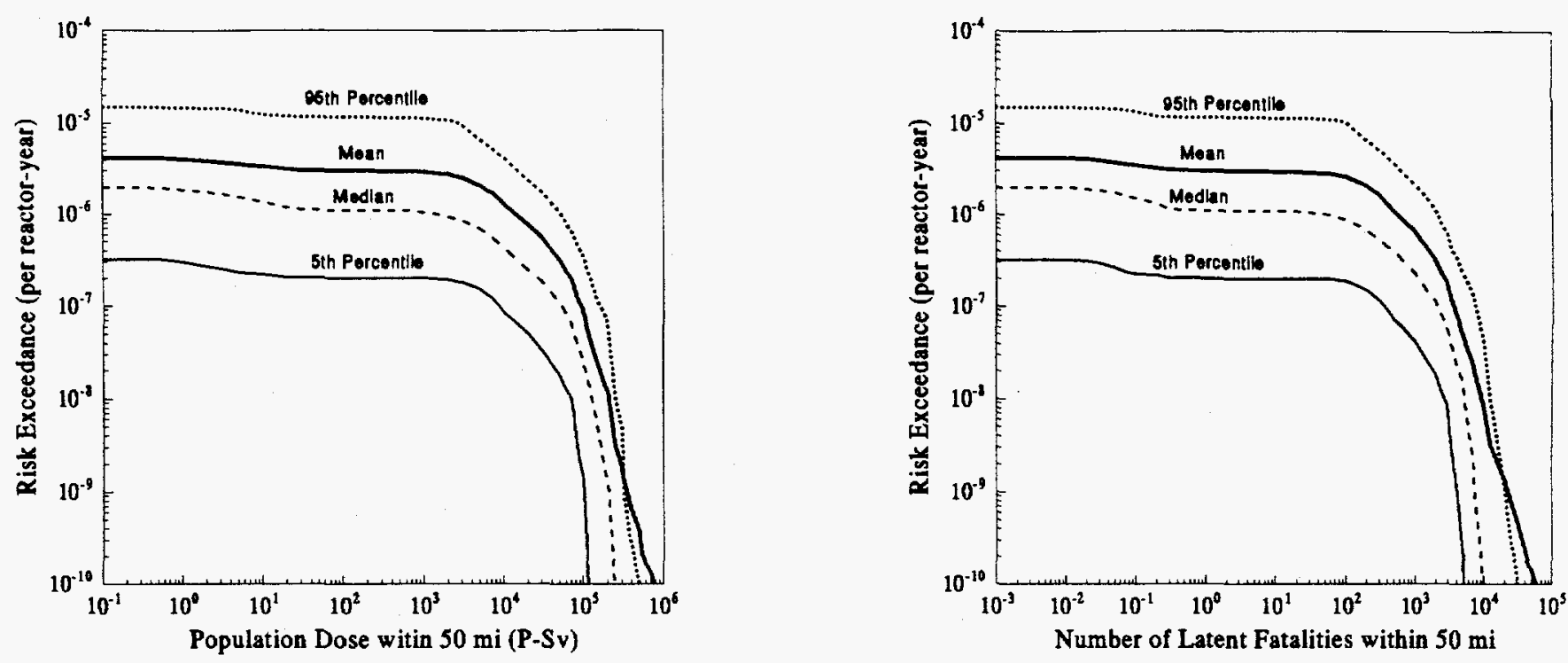

- Sth Percentile -. Median - Mean ..... 95th Percentile

- Sth Percentile -. Median - Mean ..... 95th Percentile
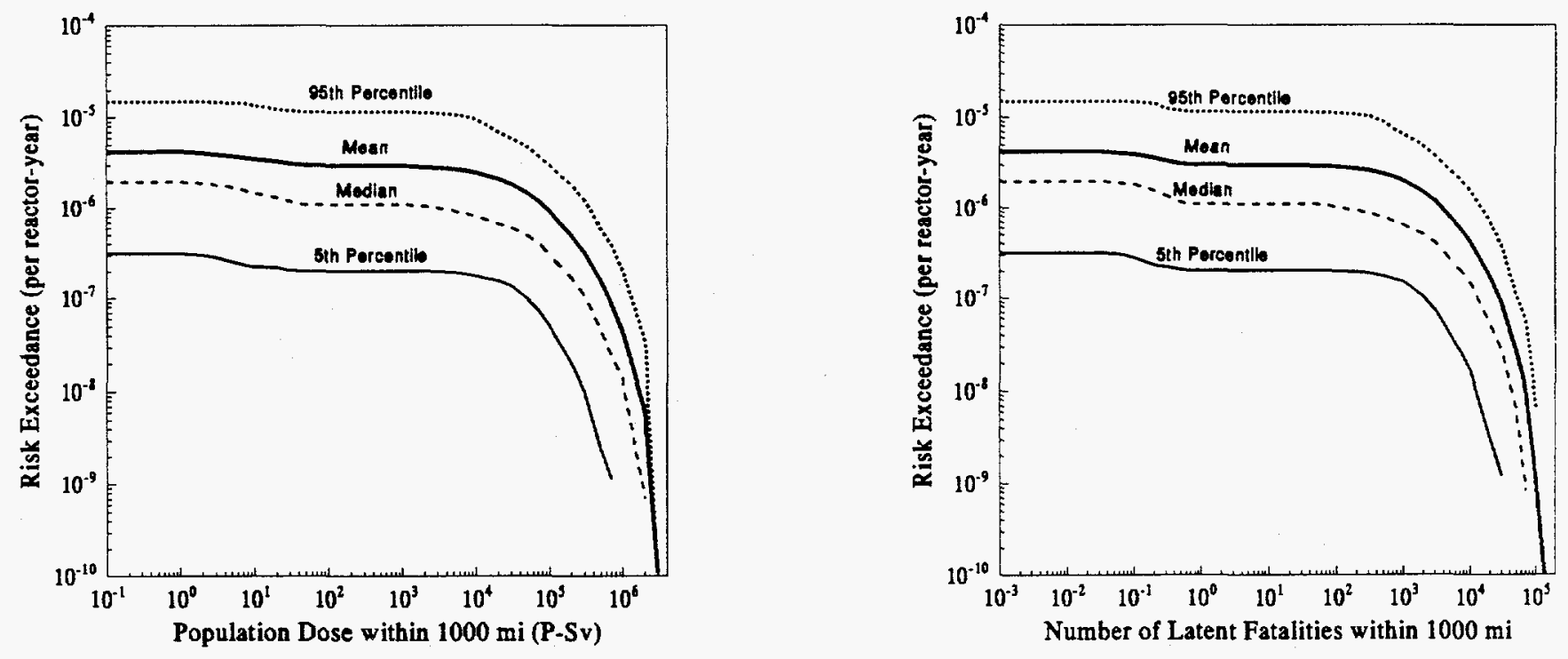

- 5th Percentile -. Median - Mean ..... 95th Percentile

— Sth Percentile -. Median - Mean ..... 95th Percentile

Figure 9.1 Results of the Risk Analysis for Internal Initiators 
9 Risk Calculations

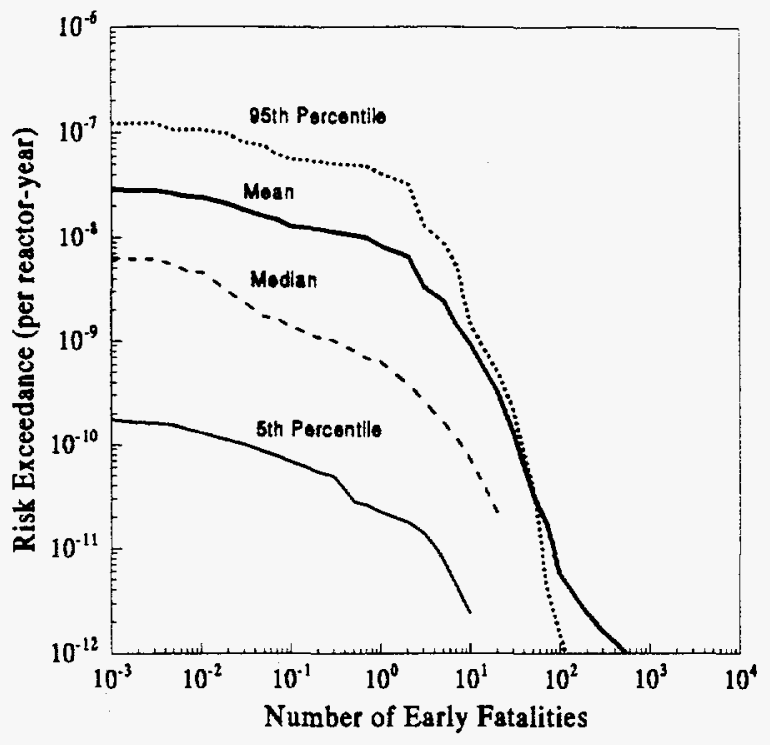

- 5th Percentile -- Median - Mean ..... 95th Pereentile

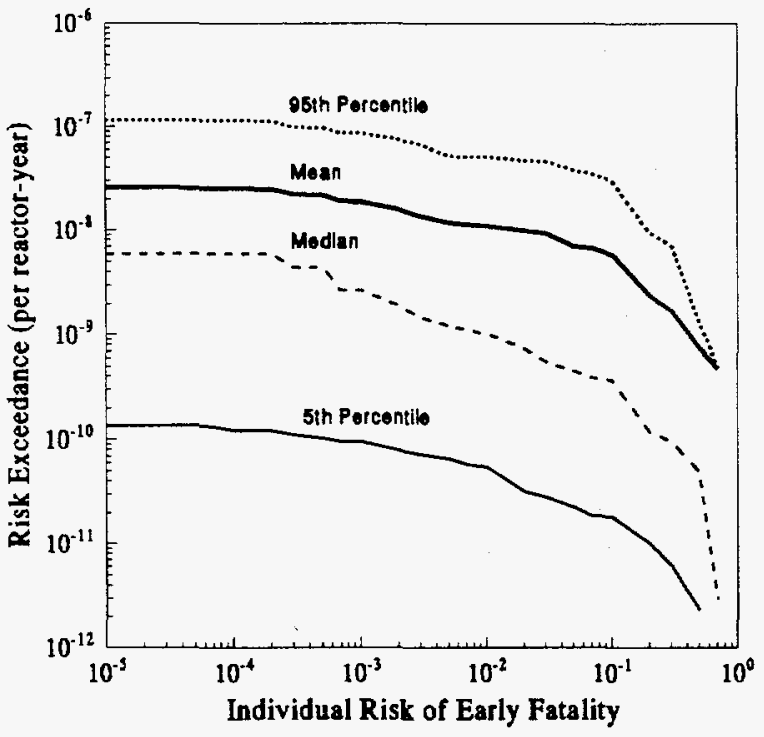

- 5th Percentile -- Median - Mesa .... 95th Percentile

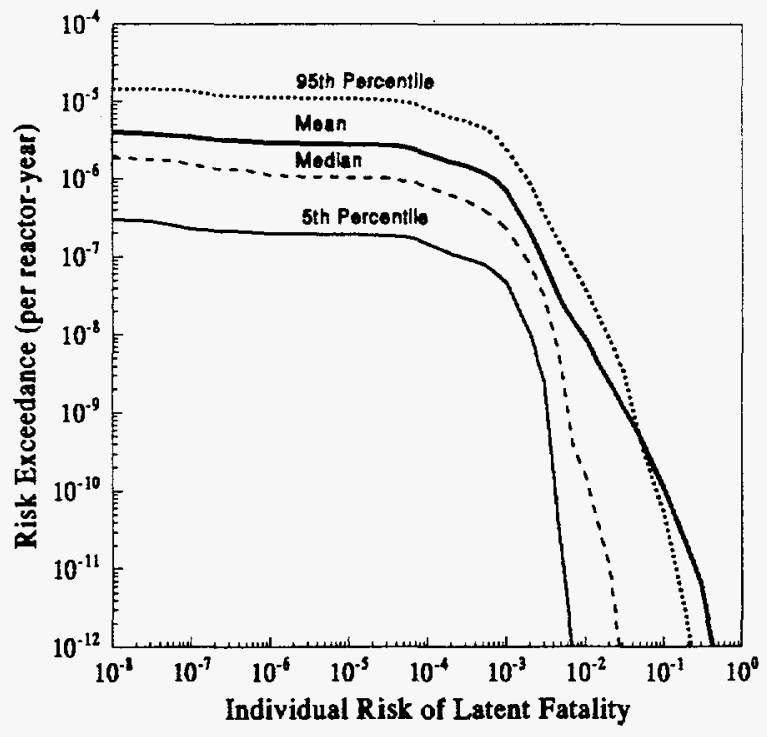

- Sth Percentile - - Median - Mean ..... 95th Percentile

Figure 9.1 (continued) 
Table 9.2 Distribution of Fractional Contribution to Risk for the Plant Damage States

\begin{tabular}{|c|c|c|c|c|}
\hline Fractional Contribution to Risk & PDS-1 & PDS-2 & PDS-3 & PDS-4 \\
\hline \multicolumn{5}{|l|}{ Early Fatalities } \\
\hline 5th Percentile & $7.86 \mathrm{E}-04$ & $7.74 \mathrm{E}-01$ & $3.29 \mathrm{E}-04$ & $1.89 \mathrm{E}-04$ \\
\hline Median & $1.43 \mathrm{E}-02$ & $9.54 \mathrm{E}-01$ & $4.86 \mathrm{E}-03$ & 3.47E-03 \\
\hline Mean & $4.16 \mathrm{E}-02$ & $9.30 \mathrm{E}-01$ & $1.46 \mathrm{E}-02$ & $1.37 \mathrm{E}-02$ \\
\hline 95th Percentile & $1.71 \mathrm{E}-01$ & 9.97E-01 & $6.21 \mathrm{E}-02$ & $7.70 \mathrm{E}-02$ \\
\hline Standard Deviation & $5.79 \mathrm{E}-02$ & $7.20 \mathrm{E}-02$ & $2.30 \mathrm{E}-02$ & 2.33E-02 \\
\hline \multicolumn{5}{|l|}{ Latent Fatalities, $50 \mathrm{mi}$} \\
\hline 5th Percentile & $1.63 \mathrm{E}-03$ & $7.17 \mathrm{E}-01$ & $1.55 \mathrm{E}-03$ & $1.16 \mathrm{E}-03$ \\
\hline Median & $3.29 \mathrm{E}-02$ & $9.22 \mathrm{E}-01$ & $1.82 \mathrm{E}-02$ & $9.73 \mathrm{E}-03$ \\
\hline Mean & $5.36 \mathrm{E}-02$ & $8.96 \mathrm{E}-01$ & $2.57 \mathrm{E}-02$ & $2.47 \mathrm{E}-02$ \\
\hline 95th Percentile & $1.97 \mathrm{E}-01$ & $9.87 \mathrm{E}-01$ & $8.99 \mathrm{E}-02$ & $1.02 \mathrm{E}-01$ \\
\hline Standard Deviation & $6.30 \mathrm{E}-02$ & $8.57 \mathrm{E}-02$ & $2.53 \mathrm{E}-02$ & $3.47 \mathrm{E}-02$ \\
\hline \multicolumn{5}{|l|}{ Latent Fatalities, $1000 \mathrm{mi}$} \\
\hline 5th Percentile & $1.24 \mathrm{E}-03$ & $7.26 \mathrm{E}-01$ & $1.48 \mathrm{E}-03$ & $7.69 \mathrm{E}-04$ \\
\hline Median & $2.44 \mathrm{E}-02$ & 9.32E-01 & $1.62 \mathrm{E}-02$ & $8.11 \mathrm{E}-03$ \\
\hline Mean & $4.99 \mathrm{E}-02$ & $9.06 \mathrm{E}-01$ & $2.24 \mathrm{E}-02$ & $2.17 \mathrm{E}-02$ \\
\hline 95th Percentile & $1.93 \mathrm{E}-01$ & $9.90 \mathrm{E}-01$ & $7.08 \mathrm{E}-02$ & $9.97 \mathrm{E}-02$ \\
\hline Standard Deviation & $6.18 \mathrm{E}-02$ & 8.11E-02 & $2.27 \mathrm{E}-02$ & $3.11 \mathrm{E}-02$ \\
\hline \multicolumn{5}{|l|}{ Population Dose, 50 mi } \\
\hline 5th Percentile & $1.64 \mathrm{E}-03$ & $7.19 \mathrm{E}-01$ & $1.59 \mathrm{E}-03$ & $1.17 \mathrm{E}-03$ \\
\hline Median & $3.29 \mathrm{E}-02$ & $9.21 \mathrm{E}-01$ & $1.83 \mathrm{E}-02$ & $9.78 \mathrm{E}-03$ \\
\hline Mean & $5.41 \mathrm{E}-02$ & $8.95 \mathrm{E}-01$ & $2.61 \mathrm{E}-02$ & $2.51 \mathrm{E}-02$ \\
\hline 95th Percentile & $1.97 \mathrm{E}-01$ & $9.87 \mathrm{E}-01$ & 9.14E-02 & $1.03 \mathrm{E}-01$ \\
\hline Standard Deviation & $6.34 \mathrm{E}-02$ & 8.63E-02 & $2.54 \mathrm{E}-02$ & $3.49 \mathrm{E}-02$ \\
\hline
\end{tabular}


9 Risk Calculations

Table 9.2 (continued)

\begin{tabular}{||l|c|c|c|c||}
\hline \hline Fractional Contribution to Risk & PDS-1 & PDS-2 & PDS-3 & PDS-4 \\
\hline \hline Population Dose, 1000 mi & $1.26 \mathrm{E}-03$ & $7.27 \mathrm{E}-01$ & $1.49 \mathrm{E}-03$ & $7.99 \mathrm{E}-04$ \\
\hline 5th Percentile & $2.48 \mathrm{E}-02$ & $9.33 \mathrm{E}-01$ & $1.65 \mathrm{E}-02$ & $7.96 \mathrm{E}-03$ \\
\hline Median & $4.99 \mathrm{E}-02$ & $9.06 \mathrm{E}-01$ & $2.24 \mathrm{E}-02$ & $2.17 \mathrm{E}-02$ \\
\hline Mean & $1.90 \mathrm{E}-01$ & $9.90 \mathrm{E}-01$ & $7.25 \mathrm{E}-02$ & $9.90 \mathrm{E}-02$ \\
\hline 95th Percentile & $6.17 \mathrm{E}-02$ & $8.10 \mathrm{E}-02$ & $2.26 \mathrm{E}-02$ & $3.11 \mathrm{E}-02$ \\
\hline Standard Deviation & & & & \\
\hline Individual Early Fatalities Risk, 1 mi & $7.82 \mathrm{E}-04$ & $7.78 \mathrm{E}-01$ & $3.29 \mathrm{E}-04$ & $2.17 \mathrm{E}-04$ \\
\hline 5th Percentile & $1.51 \mathrm{E}-02$ & $9.54 \mathrm{E}-01$ & $4.82 \mathrm{E}-03$ & $3.69 \mathrm{E}-03$ \\
\hline Median & $4.16 \mathrm{E}-02$ & $9.29 \mathrm{E}-01$ & $1.52 \mathrm{E}-02$ & $1.41 \mathrm{E}-02$ \\
\hline Mean & $1.75 \mathrm{E}-01$ & $9.97 \mathrm{E}-01$ & $6.68 \mathrm{E}-02$ & $8.15 \mathrm{E}-02$ \\
\hline 95th Percentile & $5.78 \mathrm{E}-02$ & $7.19 \mathrm{E}-02$ & $2.29 \mathrm{E}-02$ & $2.38 \mathrm{E}-02$ \\
\hline Standard Deviation & & & & \\
\hline Individual Latent Fatalities Risk, 10 mi & $2.02 \mathrm{E}-03$ & $6.80 \mathrm{E}-01$ & $1.76 \mathrm{E}-03$ & $1.56 \mathrm{E}-03$ \\
\hline 5th Percentile & $4.10 \mathrm{E}-02$ & $9.08 \mathrm{E}-01$ & $2.08 \mathrm{E}-02$ & $1.25 \mathrm{E}-02$ \\
\hline Median & $5.87 \mathrm{E}-02$ & $8.83 \mathrm{E}-01$ & $2.96 \mathrm{E}-02$ & $2.84 \mathrm{E}-02$ \\
\hline Mean & $2.08 \mathrm{E}-01$ & $9.85 \mathrm{E}-01$ & $8.60 \mathrm{E}-02$ & $1.23 \mathrm{E}-01$ \\
\hline 95th Percentile & $6.46 \mathrm{E}-02$ & $9.23 \mathrm{E}-02$ & $2.95 \mathrm{E}-02$ & $4.01 \mathrm{E}-02$ \\
\hline Standard Deviation & & & & \\
\hline \hline
\end{tabular}


Table 9.3 Distribution of Risk for the Plant Damage States

\begin{tabular}{|c|c|c|c|c|}
\hline Absolute Risk & PDS-1 & PDS-2 & PDS-3 & PDS-4 \\
\hline \multicolumn{5}{|l|}{ Early Fatalities } \\
\hline 5th Percentile & $8.76 \mathrm{E}-13$ & $1.25 \mathrm{E}-10$ & $1.55 \mathrm{E}-13$ & $1.74 \mathrm{E}-13$ \\
\hline Median & 4.19E-11 & $3.47 \mathrm{E}-09$ & $2.72 \mathrm{E}-11$ & $1.23 \mathrm{E}-11$ \\
\hline Mean & 2.34E-09 & 4.54E-08 & $5.29 \mathrm{E}-10$ & $6.87 \mathrm{E}-10$ \\
\hline 95th Percentile & $7.80 \mathrm{E}-09$ & 1.49E-07 & $1.93 \mathrm{E}-09$ & $2.71 \mathrm{E}-09$ \\
\hline Standard Deviation & $1.29 \mathrm{E}-08$ & $1.54 \mathrm{E}-07$ & 1.99E-09 & 3.68E-09 \\
\hline \multicolumn{5}{|c|}{ Latent Fatalities, $50 \mathrm{mi}$} \\
\hline 5th Percentile & $1.41 \mathrm{E}-06$ & $1.28 \mathrm{E}-04$ & 9.51E-07 & $4.50 \mathrm{E}-07$ \\
\hline Median & $2.83 \mathrm{E}-05$ & $7.66 \mathrm{E}-04$ & $2.01 \mathrm{E}-05$ & $1.01 \mathrm{E}-05$ \\
\hline Mean & $9.59 \mathrm{E}-05$ & $2.28 \mathrm{E}-03$ & $4.58 \mathrm{E}-05$ & 4.12E-05 \\
\hline 95th Percentile & $5.15 \mathrm{E}-04$ & $8.48 \mathrm{E}-03$ & $1.94 \mathrm{E}-04$ & $1.68 \mathrm{E}-04$ \\
\hline Standard Deviation & $1.64 \mathrm{E}-04$ & $3.56 \mathrm{E}-03$ & $6.95 \mathrm{E}-05$ & $7.44 \mathrm{E}-05$ \\
\hline \multicolumn{5}{|c|}{ Latent Fatalities, $1000 \mathrm{mi}$} \\
\hline 5th Percentile & $6.60 \mathrm{E}-06$ & $7.20 \mathrm{E}-04$ & 3.70E-06 & $1.70 \mathrm{E}-06$ \\
\hline Median & $1.30 \mathrm{E}-04$ & $5.10 \mathrm{E}-03$ & $1.10 \mathrm{E}-04$ & $6.30 \mathrm{E}-05$ \\
\hline Mean & $5.52 \mathrm{E}-04$ & $1.47 \mathrm{E}-02$ & $2.71 \mathrm{E}-04$ & 2.32E-04 \\
\hline 95th Percentile & $2.40 \mathrm{E}-03$ & $5.30 \mathrm{E}-02$ & $1.20 \mathrm{E}-03$ & $9.60 \mathrm{E}-04$ \\
\hline Standard Deviation & $1.01 \mathrm{E}-03$ & $2.48 \mathrm{E}-02$ & $4.59 \mathrm{E}-04$ & 4.97E-04 \\
\hline \multicolumn{5}{|c|}{ Population Dose, $50 \mathrm{mi}$} \\
\hline 5th Percentile & 3.65E-05 & $3.18 \mathrm{E}-03$ & $2.41 \mathrm{E}-05$ & $1.10 \mathrm{E}-05$ \\
\hline Median & $6.92 \mathrm{E}-04$ & $1.78 \mathrm{E}-02$ & $5.00 \mathrm{E}-04$ & $2.55 \mathrm{E}-04$ \\
\hline Mean & $2.24 \mathrm{E}-03$ & $5.36 \mathrm{E}-02$ & $1.10 \mathrm{E}-03$ & $9.80 \mathrm{E}-04$ \\
\hline 95th Percentile & $9.57 \mathrm{E}-03$ & $1.74 \mathrm{E}-01$ & $4.39 \mathrm{E}-03$ & 4.09E-03 \\
\hline Standard Deviation & $3.88 \mathrm{E}-03$ & $8.48 \mathrm{E}-02$ & $1.66 \mathrm{E}-03$ & $1.77 \mathrm{E}-03$ \\
\hline
\end{tabular}


9 Risk Calculations

Table 9.3 (continued)

\begin{tabular}{||l|c|c|c|c||}
\hline \hline Absolute Risk & PDS-1 & PDS-2 & PDS-3 & PDS-4 \\
\hline \hline Population Dose, 1000 mi & \multicolumn{5}{|l||}{} \\
\hline 5th Percentile & $1.50 \mathrm{E}-04$ & $1.70 \mathrm{E}-02$ & $8.90 \mathrm{E}-05$ & $4.10 \mathrm{E}-05$ \\
\hline Median & $3.10 \mathrm{E}-03$ & $1.20 \mathrm{E}-01$ & $2.50 \mathrm{E}-03$ & $1.50 \mathrm{E}-03$ \\
\hline Mean & $1.30 \mathrm{E}-02$ & $3.42 \mathrm{E}-01$ & $6.32 \mathrm{E}-03$ & $5.45 \mathrm{E}-03$ \\
\hline 95th Percentile & $5.80 \mathrm{E}-02$ & $1.20 \mathrm{E}+00$ & $2.70 \mathrm{E}-02$ & $2.30 \mathrm{E}-02$ \\
\hline Standard Deviation & $2.40 \mathrm{E}-02$ & $5.73 \mathrm{E}-01$ & $1.07 \mathrm{E}-02$ & $1.17 \mathrm{E}-02$ \\
\hline Individual Early Fatalities Risk, 1 mi* & & & \\
\hline 5th Percentile & $3.70 \mathrm{E}-14$ & $5.90 \mathrm{E}-12$ & $7.10 \mathrm{E}-15$ & $6.90 \mathrm{E}-15$ \\
\hline Median & $1.50 \mathrm{E}-12$ & $1.20 \mathrm{E}-10$ & $9.60 \mathrm{E}-13$ & $5.60 \mathrm{E}-13$ \\
\hline Mean & $7.00 \mathrm{E}-11$ & $1.64 \mathrm{E}-09$ & $1.94 \mathrm{E}-11$ & $2.08 \mathrm{E}-11$ \\
\hline 95th Percentile & $3.30 \mathrm{E}-10$ & $6.50 \mathrm{E}-09$ & $8.10 \mathrm{E}-11$ & $1.10 \mathrm{E}-10$ \\
\hline Standard Deviation & $2.91 \mathrm{E}-10$ & $5.25 \mathrm{E}-09$ & $7.14 \mathrm{E}-11$ & $8.71 \mathrm{E}-11$ \\
\hline Individual Latent Fatalities Risk, 10 mi* & & & & \\
\hline 5th Percentile & $2.00 \mathrm{E}-12$ & $1.20 \mathrm{E}-10$ & $1.10 \mathrm{E}-12$ & $6.20 \mathrm{E}-13$ \\
\hline Median & $2.70 \mathrm{E}-11$ & $6.40 \mathrm{E}-10$ & $1.90 \mathrm{E}-11$ & $1.00 \mathrm{E}-11$ \\
\hline Mean & $8.96 \mathrm{E}-11$ & $1.92 \mathrm{E}-09$ & $4.20 \mathrm{E}-11$ & $4.00 \mathrm{E}-11$ \\
\hline 95th Percentile & $4.60 \mathrm{E}-10$ & $6.90 \mathrm{E}-09$ & $1.70 \mathrm{E}-10$ & $1.70 \mathrm{E}-10$ \\
\hline Standard Deviation & $1.48 \mathrm{E}-10$ & $2.88 \mathrm{E}-09$ & $5.81 \mathrm{E}-11$ & $6.72 \mathrm{E}-11$ \\
\hline \hline
\end{tabular}

*NRC quantitative health objectives:

- Individual early fatality risk within one mile to be less than $5 \times 10^{-7}$ per reactor year.

- Individual latent cancer fatality risk within 10 miles to be less than $2 \times 10^{-6}$ per reactor year. 


\section{COMPARISON TO FULL POWER RESULTS}

This chapter compares the results of the risk estimates for accidents during mid-loop operation with the risk estimates $^{1}$ for accidents occurring at power. The mid-loop risk estimates are for three mid-loop POSs, namely POS 6 and POS 10 of a refueling outage and POS 6 of a drained maintenance outage. The risk results therefore do not represent the risk from all low power and shutdown operations. The risk estimates (because they are on a yearly basis) also reflect the rather short time that the plant is at mid-loop.

\subsection{Core Damage Frequency Analysis}

The results of the core damage frequency analysis are discussed in detail in Volume 2 of this report, which also includes a comparison with the full power study. In order to appreciate the accident progression analysis and risk estimates a description of the core damage frequency results is included in this chapter. Four statistical measures of the core damage frequency distribution (CDF) for accidents during mid-loop operation are compared with similar measures for accidents during power operation below:

\begin{tabular}{||l|c|c||}
\hline \hline & $\begin{array}{c}\text { Core Damage Frequency } \\
\text { for Mid-Loop Operation } \\
\text { (per reactor year) }\end{array}$ & $\begin{array}{c}\text { Core Damage Frequency } \\
\text { for Full-Power Operation } \\
\text { (per reactor year) }\end{array}$ \\
\hline \hline 95th Percentile & $1.9 \mathrm{E}-5$ & $1.0 \mathrm{E}-4$ \\
\hline Mean & $4.2 \mathrm{E}-6$ & $4.1 \mathrm{E}-5$ \\
\hline 50th Percentile & $2.0 \mathrm{E}-6$ & $2.5 \mathrm{E}-5$ \\
\hline 5th Percentile & $3.2 \mathrm{E}-7$ & $9.8 \mathrm{E}-6$ \\
\hline
\end{tabular}

The mean core damage frequency of accidents initiated by internal events during mid-loop operation is about an order of magnitude lower than the mean frequency of accidents during full power operation. In addition the mean and median frequencies of the two distributions were within a factor of approximately two. However, the tails of the distributions do overlap and therefore for some cases the mid-loop core damage frequency could be higher than the full power frequency.

The CDF analysis is coupled to the accident progression analysis through the plant damage states (PDS). Of particular interest is the characteristics of the PDS groups and their relative contribution to the core damage frequency estimates. The PDS characteristics are important because they strongly influence the subsequent accident progression. Table 10.1 displays the PDS contributors to the core damage frequency for both studies. Four statistical measures (namely the 5th percentile, median, mean and 9 th percentile) on the distributions of the various PDS groups are given in Table 10.1.

Accident sequences in which the operators did not correctly diagnose the situation or take proper actions were the largest contributor (approximately two-thirds of the total) to the mean core damage frequency for mid-loop 
operation. Accident sequences that lead to station blackout during mid-loop operation (loss of the $4 \mathrm{kV}$ Bus is similar to a station blackout) contribute about 10 percent to the mean CDF. Other accidents were identified that resulted in loss of core cooling after depletion of the refueling water storage tank and failure of recirculation. The leading cause of recirculation failure was found to be plugging of the suction from the sump. These accidents contribute about 20 percent to the mean core damage frequency.

Station Blackout accidents were the largest contributor (approximately two-thirds of the total) to the mean core damage frequency for accidents initiated by internal events during power operation. Other accidents initiated by loss-of-coolant accidents (LOCAs), transient events and anticipated transient without scram (ATWS) contributed about 25 percent to the mean CDF. Accidents that result in containment bypass (steam generator tube ruptures (SGTR) and interfacing systems LOCAs) contributed less than 10 percent to the mean CDF.

The plant damage states in Table 10.1 cannot be directly compared because the plant configuration during mid-loop operation is different than the configuration during full power operation. For example a Station Blackout during full power operation will have a different accident progression than a Station Blackout during mid-loop operation. An important difference is that the containment may not be isolated during mid-loop operation whereas the containment was found to be isolated for most of the accidents at full power. Differences in the status of containment integrity during mid-loop and full power operation have an important influence on the accident progression analysis and risk estimates. In the following sections differences in the plant configuration (and hence plant damage states) between mid-loop and low power are indicated.

\subsection{Accident Progression Analysis}

The plant damage states developed for the mid-loop and full power studies cannot be directly compared. An attempt was therefore made to summarize the results of the accident progression analyses performed for the two studies in such a way that differences in containment status could be ascertained for each of the plant damage states. Table 10.2 summarizes the probability of accident progression bins (APB) conditional on the various PDS groups for full power operation (NUREG/CR-4551, Volume 3) and for mid-loop operation (Chapter 6 of this report). The table has been constructed in such a way that APBs have the same meaning in both studies. For example accidents that "bypass" containment were identified in the full-power study but not in the mid-loop study, whereas "containment not isolated" was an important APB for accidents during mid-loop operation but not for full power.

The most significant difference in the results given in Table 10.2 relates to the probability of the containment not being isolated. In the full power study the probability for the containment not being isolated was very small because during power operation the Surry containment is maintained at a subatmospheric pressure and therefore containment leakage would be detected. However, the probability of the containment not being isolated was determined to be high for most of the plant damage states during mid-loop operation. In fact, the plant damage state that is the largest contributor to the mean core damage frequency (PDS 2 - Human Error) has a very high conditional probability for the containment being open. This is because it was determined in the accident progression analysis that if operator error due to failure to diagnose the accident led to core damage then the operators probably would not have taken measures to isolate containment.

Another difference between the results in Table 10.2 relates to accidents that bypass the containment. In the full power study accidents that bypass the containment contribute less than 10 percent to the mean CDF but, 
because they are high consequence events, they are large contributors to the risk estimates (as indicated in Section 10.5 below). However, in the mid-loop study accidents that bypass the containment (such as SGTRs or interfacing systems LOCAs) were not included because the configuration of the plant precludes such events.

The probability for early containment failure caused by such phenomena as hydrogen combustion, direct containment heating and steam explosions was found to be very low for all PDS groups in the full study. This is because the failure pressure of the containment was determined to be much higher than the design pressure and the loads predicted from the phenomena were generally lower than the failure pressures. The probability for early containment failure was also found to be small for accidents during mid-loop operation except for accidents involving station blackout and loss of the $4 \mathrm{kV}$ bus. For these accident sequences the mean conditional probability for early containment failure was determined to be between 0.1 and 0.2 . The cause of early containment failure was determined to be hydrogen combustion, which is a problem during mid-loop operation for two reasons. Firstly, if the operators are able to isolate containment during an accident in midloop operation there is a possibility that they may not be able to achieve full pressure retaining capability in the time available. The higher containment failure probability in the mid-loop study therefore reflects the lower pressure retaining capability of the containment relative to the capability expected during power operation. Secondly, for accidents involving station blackout it is unlikely that an ignition source would be available to ignite the hydrogen until power is recovered. This means that large quantities of unburned hydrogen could accumulate in containment. The higher early containment failure probability for station blackout accidents during mid-loop operation therefore also reflects the possibility that power will be restored after a large quantity of hydrogen has accumulated in containment.

The conditional probability of late containment failure, caused by the core debris penetrating the basemat or by overpressurizing the containment (due to the accumulation of steam and noncondensible gases) was determined to be between 0.01 and 0.1 for accidents during full power operation. Both of these failure mechanisms were eliminated for accidents during mid-loop operation based on deterministic calculations (described in Chapter 6). The calculations indicated that the decay heat levels for accidents during mid-loop operation were not sufficiently high to cause late containment failure by basemat penetration or containment overpressurization.

Finally, the mean conditional probability of the containment being intact (i.e., isolated, not bypassed, no excessive leakage, and no containment failure) was determined to be high (i.e., between 0.8 and 0.9 ) for all PDS groups in the full power except for the PDS group containing bypass accidents. As noted above, bypass accidents contribute less than 10 percent to the mean CDF in the full power study. The mean conditional probability of the containment being isolated varied over a wide range for accidents during mid-loop operation. The range varied from 0.05 (Human Error PDS) to about 0.9 for accidents involving loss of recirculation. However, as the Human Error PDS is the largest contributor to the mean CDF the probability of the containment being intact conditional on the mean CDF for all internal events during mid-loop operation was less than 0.3. This compares with a probability of the containment being intact conditional on the mean CDF for accidents during power operation of over 0.8. This difference in containment integrity during mid-loop and full power operation has an important influence on the risk estimates as indicated in Section 10.2.5.

\subsection{Results of the Source Term Analysis}

The source term model (SURSOR) used in the full power study was considered suitable for use in the midloop study with only minor modifications. This suitability was based on comparisons with calculations from 
a deterministic code, MELCOR, and the views expressed by an expert review panel drawn from staff at Sandia and Brookhaven National Laboratories. Therefore, as the same source term model was used in the two studies the source terms are similar for similar accident progression bins. Although the source term calculations are similar for the two studies the risk estimates for mid-loop operation are influenced by the changing radionuclide inventories for the various accidents because they can occur a long time after shutdown. In order to account for the changing radionuclide inventory the partitioning method used in the full power study to combine the source terms into a smaller number of representative source term groups had to be modified for the mid-loop study. Therefore, a direct comparison of the source term groups determined for the two studies would be difficult because of the changing inventory associated with accidents during mid-loop operation.

\subsection{Consequence Analysis}

The approach used to calculate offsite consequences was similar in both studies. The major difference was that the latest version of the MACCS code was used to evaluate the offsite consequence measures in the midloop study. The latest version of MACCS incorporates the BEIR V update to the latent cancer versus dose relationship, whereas the full power study used in an earlier version of MACCS, which did not include the latest BEIR V update. The latest BEIR V update gives a factor of approximately three times higher latent cancers for the same value of population dose.

\subsection{Risk Analysis}

Table 10.3 presents statistical measures of the distributions for seven consequence measures for accidents during mid-loop operation obtained from this study. Similar statistical measures for full power operation obtained from the NUREG-1150 study of Surry are also included in the table.

Table 10.3 indicates that the mean risk of offsite early health effects is over two orders of magnitude lower for accidents during mid-loop operation than for full power in spite of the lack of mitigative features. This is due to the natural decay of the radionuclide inventory (because the accidents occur a long time after shutdown) particularly the short-lived isotopes of iodine and tellurium, which are primarily associated with early health effects. The statistical measures for latent cancer fatalities (only 1000 miles was reported in Ref. 1) differ by a factor of approximately three, although the statistical measures for population dose (1000 miles) for mid-loop and full power operations are similar. This difference is largely explained by differences in the latent cancer versus dose relationship in the different versions of MACCS (refer to section 10.4) used in the two studies.

\subsection{References}

1. Breeding, R. J., et al., "Evaluation of Severe Accident Risks: Surry Unit 1," NUREG/CR-4551, Volume 3, Revision 1, Parts 1 and 2, 1990. 
Table 10.1 Comparison of the PDS Core Damage Frequencies (per reactor year) for Mid-Loop and Full-Power Operation (Internal Events Only)

\begin{tabular}{|c|c|c|c|c||}
\hline \multicolumn{5}{|c||}{ Full-Power Operation } \\
\hline PDS & 5th Percentile & Median & Mean & 95th Percentile \\
\hline \hline Station Blackout & & & & \\
\hline Short Term & $1.2 \mathrm{E}-7$ & $1.5 \mathrm{E}-6$ & $5.4 \mathrm{E}-6$ & $2.1 \mathrm{E}-5$ \\
\hline Long Term & $1.6 \mathrm{E}-6$ & $1.1 \mathrm{E}-5$ & $2.2 \mathrm{E}-5$ & $6.4 \mathrm{E}-5$ \\
\hline ATWS & $2.9 \mathrm{E}-8$ & $4.2 \mathrm{E}-7$ & $1.4 \mathrm{E}-6$ & $6.5 \mathrm{E}-6$ \\
\hline LOCAs & $1.2 \mathrm{E}-6$ & $3.9 \mathrm{E}-6$ & $6.1 \mathrm{E}-6$ & $2.0 \mathrm{E}-5$ \\
\hline Interfacing LOCA & $3.6 \mathrm{E}-11$ & $4.9 \mathrm{E}-8$ & $1.6 \mathrm{E}-6$ & $8.2 \mathrm{E}-6$ \\
\hline SGTR & $4.5 \mathrm{E}-7$ & $1.4 \mathrm{E}-6$ & $1.8 \mathrm{E}-6$ & $4.7 \mathrm{E}-6$ \\
\hline \hline Total & $9.8 \mathrm{E}-6$ & $2.5 \mathrm{E}-5$ & $4.1 \mathrm{E}-5$ & $1.0 \mathrm{E}-4$ \\
\hline
\end{tabular}

\begin{tabular}{||l|c|c|c|c||}
\hline \multicolumn{5}{|c||}{ Mid-Loop Operation } \\
\hline \multicolumn{1}{|c|}{ PDS } & 5th Percentile & Median & Mean & 95th Percentile \\
\hline Station Blackout & $1.9 \mathrm{E}-8$ & $1.2 \mathrm{E}-7$ & $4.0 \mathrm{E}-7$ & $1.7 \mathrm{E}-6$ \\
\hline Human Errors & $2.1 \mathrm{E}-7$ & $1.0 \mathrm{E}-6$ & $2.8 \mathrm{E}-6$ & $1.3 \mathrm{E}-5$ \\
\hline Loss of Recirculation & $5.3 \mathrm{E}-8$ & $4.1 \mathrm{E}-7$ & $7.8 \mathrm{E}-7$ & $3.3 \mathrm{E}-6$ \\
\hline Loss of 4 kV Bus & $8.9 \mathrm{E}-9$ & $8.9 \mathrm{E}-8$ & $2.2 \mathrm{E}-7$ & $1.3 \mathrm{E}-6$ \\
\hline \hline Total & $3.2 \mathrm{E}-7$ & $2.0 \mathrm{E}-6$ & $4.2 \mathrm{E}-6$ & $1.9 \mathrm{E}-5$ \\
\hline
\end{tabular}


Table 10.2 Comparison of the Mean Probabilities of APBs Conditional on PDS Groups for Mid-Loop and Full-Power Operation (Internal Events Only)

\begin{tabular}{|c|c|c|c|c|c|c|c|c|c|c|c|}
\hline \multirow{3}{*}{$\begin{array}{c}\text { Accident } \\
\text { Progression } \\
\text { Bin } \\
\text { Groups }\end{array}$} & \multicolumn{11}{|c|}{ Plant Damage State Groups $\dagger$} \\
\hline & \multicolumn{6}{|c|}{ Full-Power Operation* } & \multicolumn{5}{|c|}{ Mid-Loop Operation** } \\
\hline & $\begin{array}{c}\mathrm{SBO} \\
(2.8 \mathrm{E}-5)\end{array}$ & $\begin{array}{c}\text { ATWS } \\
(1.4 \mathrm{E}-6)\end{array}$ & $\begin{array}{c}\text { Transients } \\
(1.8 \mathrm{E}-6)\end{array}$ & $\begin{array}{l}\text { LOCAs } \\
(6.1 \mathrm{E}-6)\end{array}$ & $\begin{array}{l}\text { Bypass } \\
(3.4 \mathrm{E}-6)\end{array}$ & $\begin{array}{l}\text { All*** } \\
\text { (4.1E-5) }\end{array}$ & $\begin{array}{c}\text { SBO } \\
(4 E-7)\end{array}$ & $\begin{array}{c}\text { Human } \\
\text { Error } \\
(2.8 \mathrm{E}-6)\end{array}$ & $\begin{array}{c}\text { Loss of } \\
\text { Recirculation } \\
(7.8 \mathrm{E}-7)\end{array}$ & $\begin{array}{c}\text { Loss of } \\
4 \mathrm{kV} \mathrm{Bus} \\
(2.2 \mathrm{E}-7)\end{array}$ & $\begin{array}{l}\text { All**** } \\
(4.2 \mathrm{E}-6)\end{array}$ \\
\hline $\begin{array}{l}\text { Early } \\
\text { Containment } \\
\text { Failure }\end{array}$ & .008 & .003 & .001 & .006 & - & .007 & .17 & - & .03 & .11 & .03 \\
\hline $\begin{array}{l}\text { Late } \\
\text { Containment } \\
\text { Failure } \\
\end{array}$ & .079 & .046 & .013 & .055 & - & .059 & - & - & - & - & - \\
\hline $\begin{array}{l}\text { Containment } \\
\text { Bypass }\end{array}$ & .003 & .078 & .007 & - & 1.0 & .122 & - & - & - & - & - \\
\hline $\begin{array}{l}\text { Containment } \\
\text { Not Isolated }\end{array}$ & - & - & - & - & - & - & .28 & .95 & .10 & .28 & .69 \\
\hline $\begin{array}{l}\text { No VB, } \\
\text { No CF }\end{array}$ & .310 & .528 & .217 & .586 & - & .346 & .37 & .02 & - & .39 & .07 \\
\hline VB, No CF & .599 & .350 & .762 & .352 & - & .466 & .18 & .03 & .87 & .22 & .21 \\
\hline
\end{tabular}

* Reproduced from NUREG/CR-4551, Volume 3

** Reproduced from Table 6.6

*** The values given under the "All" column are frequency-weighted averages and not totals.

$\dagger$ Values given in parentheses are core damage frequency per reactor year for each plant damage state group. VB Vessel Breach

$\mathrm{CF}$ Containment Failure 
Table 10.3 Comparison of Distributions of Risks for Mid-Loop and Full-Power Operation (All Values per Reactor Year; Population Doses in P-Sv per Year)

\begin{tabular}{|c|c|c|c|c|c|c|c|c|c|c|}
\hline & \multicolumn{2}{|c|}{ 5th Percentile } & \multicolumn{2}{|c|}{ Median } & \multicolumn{2}{|c|}{ Mean } & \multicolumn{2}{|c|}{ 95th Percentile } & \multicolumn{2}{|c|}{$\begin{array}{l}\text { Standard } \\
\text { Deviation }\end{array}$} \\
\hline & $\begin{array}{l}\text { Mid- } \\
\text { Loop }\end{array}$ & $\begin{array}{c}\text { Full- } \\
\text { Power }\end{array}$ & $\begin{array}{l}\text { Mid- } \\
\text { Loop }\end{array}$ & $\begin{array}{l}\text { Full- } \\
\text { Power }\end{array}$ & $\begin{array}{l}\text { Mid- } \\
\text { Loop }\end{array}$ & $\begin{array}{l}\text { Full- } \\
\text { Power }\end{array}$ & $\begin{array}{l}\text { Mid- } \\
\text { Loop }\end{array}$ & $\begin{array}{c}\text { Full- } \\
\text { Power }\end{array}$ & $\begin{array}{l}\text { Mid- } \\
\text { Loop }\end{array}$ & $\begin{array}{l}\text { Full- } \\
\text { Power }\end{array}$ \\
\hline Early Fatalities & $1.26 \mathrm{E}-10$ & $7.60 \mathrm{E}-10$ & 3.57E-09 & 7.00E-08 & $4.90 \mathrm{E}-08$ & $2.00 \mathrm{E}-06$ & $1.59 \mathrm{E}-07$ & $5.40 \mathrm{E}-06$ & $1.69 \mathrm{E}-07$ & N.A. \\
\hline Latent Fatalities within $50 \mathrm{mi}$ & $1.55 \mathrm{E}-04$ & N.A. & $8.34 \mathrm{E}-04$ & N.A. & $2.46 \mathrm{E}-03$ & N.A. & $8.78 \mathrm{E}-03$ & N.A. & 3.68E-03 & N.A. \\
\hline Latent Fatalities within $1000 \mathrm{mi}$ & 7.97E-04 & 3.10E-04 & 5.35E-03 & $2.20 \mathrm{E}-03$ & 1.57E-02 & $5.20 \mathrm{E}-03$ & $5.50 \mathrm{E}-02$ & $1.90 \mathrm{E}-02$ & $2.52 \mathrm{E}-02$ & N.A. \\
\hline Population Dose within $50 \mathrm{mi}$ & 3.77E-03 & $5.90 \mathrm{E}-03$ & $1.98 \mathrm{E}-02$ & $2.70 \mathrm{E}-02$ & $5.79 \mathrm{E}-02$ & $5.80 \mathrm{E}-02$ & $1.89 \mathrm{E}-01$ & $2.50 \mathrm{E}-01$ & 8.77E-02 & N.A. \\
\hline Population Dose within $1000 \mathrm{mi}$ & $1.87 \mathrm{E}-02$ & $1.90 \mathrm{E}-02$ & $1.25 \mathrm{E}-01$ & 1.30E-01 & $3.66 \mathrm{E}-01$ & 3.10E-01 & $1.29 \mathrm{E}+00$ & $1.20 \mathrm{E}+00$ & $5.90 \mathrm{E}-01$ & N.A. \\
\hline Individual Early Fatalities Risk within $1 \mathrm{mi}$ & $6.00 \mathrm{E}-12$ & $1.40 \mathrm{E}-11$ & $1.27 \mathrm{E}-10$ & $8.70 \mathrm{E}-10$ & 1.74E-09 & $1.60 \mathrm{E}-08$ & $6.94 \mathrm{E}-09$ & $4.90 \mathrm{E}-08$ & $5.52 \mathrm{E}-09$ & N.A. \\
\hline Individual Latent Fatalities Risk within $10 \mathrm{mi}$ & $1.20 \mathrm{E}-10$ & $1.60 \mathrm{E}-10$ & $7.48 \mathrm{E}-10$ & $4.90 \mathrm{E}-10$ & 2.09E-09 & $1.70 \mathrm{E}-09$ & 7.10E-09 & $8.10 \mathrm{E}-09$ & 3.01E-09 & N.A. \\
\hline
\end{tabular}

N.A. - Not Available 


\section{OPEN ISSUES}

Several open issues were identified in the course of the study which potentially impact the risk of mid-loop operation and the uncertainty in the risk. A number of these issues relate to modeling of physical processes while others relate to lack of information. In some cases, if more information was made available then the uncertainty in the risk estimates could be reduced. In other cases significant additional analysis would be required to reduce uncertainty. The open issues have been grouped under four categories: (i) the status of procedures in place for dealing with accident conditions, (ii) the availability of systems for terminating the progress of an accident or mitigating its effects, (iii) environmental conditions in the plant which could impede recovery actions and (iv) recent changes in plant configuration during mid-loop operation.

\subsection{Status of Procedures}

An important issue surfaced by the study is the status of containment isolation during mid-loop operation and the adequacy of the procedures in place for achieving isolation if an accident occurs. This issue is discussed in more detail in Chapter 4. In the abridged study it was assumed that the containment could not be isolated in the time frame available before core damage and the start of the release of the core inventory. New procedures have been subsequently developed at Surry to address containment closure during mid-loop operation. However, questions still remain in the present study as to the adequacy of these procedures in ensuring the pressure retaining capability of the containment even if it is successfully isolated. This issue therefore remains an important contributor to the uncertainty associated with containment performance and determination of risk during mid-loop operation.

There are no procedures in place to ensure that the containment sump will be available as a source of water for recirculation cooling during an accident occurring in mid-loop operation. Plugging of the sump by temporarily stored materials required for performing plant maintenance during shutdown was found to be one of the contributors to core damage and risk due to failure of recirculation cooling.

\subsection{Systems Unavailability}

There is no requirement during mid-loop operation at Surry for the containment sprays to be available. Containment sprays are an important system during accident conditions for condensing steam and removing heat. Sprays are also potentially effective as a mitigation system for scrubbing fission products released as an aerosol and reducing the source term to the environment. Spray availability was therefore treated as an uncertainty parameter in the analysis; its potential availability during mid-loop operation was based on discussions with Surry plant personnel. However, if the sprays are available they would have to be manually actuated during mid-loop operation as automatic actuation is disabled at RCS temperature below $350^{\circ} \mathrm{F}$.

One open issue relates to the effect of spray activation after core damage when a large amount of radioactive aerosols and gases could be present in the containment atmosphere. If the containment is unisolated water droplets from the sprays could displace the atmosphere inside containment and cause the aerosols and gases to be released through the opening in the containment boundary at a faster rate than if the sprays had not been activated. This effect could exacerbate the release to the environment; however, it was not modeled in the present study. 


\subsection{Impact of Environmental Conditions on Recovery Actions}

The impact of environmental conditions in the plant after the start of bulk boiling on the potential for successfully performing recovery actions is another important issue. It may be difficult to carry out recovery actions, which cannot be carried out from the control room, after bulk boiling of the reactor coolant inventory begins. There are several actions during mid-loop operation that can only be performed by entering the containment, for example, restoring RHR and, for station blackout sequences, opening valves to feed the steam generator. The HRA considered the impact of environment as part of the quantification of recovery actions. At temperatures around $140-150^{\circ} \mathrm{F}$, the air is too hot for normal pulmonary function and selfbreathing respirators may be required for emergency personnel which would also significantly decrease the possibility of success of recovery actions. The uncertainty in the status of containment, referred to above, cuts across this issue. If the containment was isolated, it is unlikely that it would be re-opened to undertake a recovery action once it was recognized that core uncovery was imminent or had occurred as indicated by the radiation monitors. On the other hand, if the containment were unisolated or had no pressure holding capability, the high radiation levels in its immediate vicinity as shown by the onsite dose rates would also make recovery actions inside it unlikely. The impact of environment on the ability of operators to perform recovery actions remains an important issue which contributes to the overall uncertainty.

The impact of recovering cooling water early in the accident progression after core uncovery but before vessel breach is also an open issue. If the clad becomes embrittled on heat up it could fracture on quenching releasing the gap inventory. Water could then enter the ruptured fuel rods and leach out iodine (and other volatile fission products) from the fuel matrix. Depending on temperature and solubility limits, the iodine would be partitioned between the water in the vessel and the containment atmosphere. While this accident scenario is not likely to have any significant offsite consequences, it could have important onsite implications particularly for recovery actions. This type of release was not modeled in the study.

An issue related to the environmental conditions during accident progression which was also surfaced in the abridged study is related to the onsite dose predictions. Because containment performance is uncertain, the onsite "parking lot" dose rates are large. This finding highlights the importance of onsite evacuation schemes to limit the potential consequences to the exposed workers because there is a much larger population of onsite personnel performing maintenance duties, etc. during shutdown operation as compared with normal, full power operation.

\subsection{Changes in Plant Configuration During Mid-Loop Operation}

The impact of the ongoing risk study of mid-loop operation has had an impact on plant configuration and plant procedures during shutdown at Surry. The study has identified potential vulnerabilities over the last few years and the plant staff have responded, if they felt that a response was warranted, by making changes and improvements to plant configuration and procedures during shutdown (including mid-loop operation) to reduce these vulnerabilities. While these responses are encouraging and lead to improved plant safety, it has precluded an analysis based on a constant plant configuration and operations. In order to complete the study, some compromises had to be made therefore on how much new information could be incorporated within the time available. 


\section{SUMMARY AND CONCLUSIONS}

A systematic evaluation of risk has been performed for mid-loop operation at the Surry Unit 1 plant. The analysis includes accident frequency, accident progression, source terms, consequences, risk and a determination of the uncertainty in each of the component analyses and in the final risk measures.

The analysis takes into account the long time after shutdown that the accidents can occur and the impact of the consequent decay in power level and radionuclide inventory on the risk. The inclusion of this time factor in a risk analysis is a new development in PRA technology and represents a strength of the study from the methodological standpoint.

The results contained in the preceding Chapters of this report are based on the analysis of accident frequency during mid-loop operation (documented in Volume 2) where the accident sequences leading to core damage were binned into four plant damage state (PDS) groups: PDS 1 (station blackout events), PDS 2 (human errors, failure to diagnose or take proper actions on the part of the operators), PDS 3 (recirculation cooling failure) and PDS 4 (loss of $4 \mathrm{kV}$ bus). These PDS served as the entry point for the further analysis of accident progression, the determination of potential recovery actions, and the evaluation of source terms, consequences and risk.

The main finding of the study is that during mid-loop operation the risk of consequence measures related to long-term health effects, latent cancer fatalities and population dose, are high, comparable to those at full power, despite the much lower level of the decay heat and the radionuclide inventory. The reason for this is that there is a lack of mitigative features for a significant fraction of the accidents initiated during mid-loop operation so the releases to the environment are large and the radionuclide species which mostly contribute to long-term health effects (such as cesium) have long half-lives. PDS 2 (diagnostic and corrective action failures) makes the largest contribution to the risk. Another finding of the study is that the risk of early fatalities is low despite the unisolated containment due to the decay of the short-lived radionuclide species such as iodine and tellurium which contribute to early fatality risk. The risk estimates have a range of uncertainty extending over approximately two orders of magnitude from the 5 th to the 95 th percentile of the distribution. The conclusions drawn from this finding are discussed below.

\section{Containment Status}

The major factor driving the risk is the status of containment during mid-loop operation. As discussed in more detail in Chapters 4 and 11, there is a high probability that the containment is either unisolated or that it would not have full pressure retaining capability during mid-loop operation. This is particularly the case for PDS 2. If the operators fail to diagnose the accident it was judged unlikely that they would take action to isolate containment or could succeed in doing so within the available time frame. For PDS 2, it was determined that the conditional probability (conditional on core damage) of the containment being unisolated ranged from 0.67 (5th percentile) to 0.99 (95th percentile) with a mean of 0.89 . For other PDSs, the conditional probability of isolating the containment was judged to be higher. Overall, however, the conditional probability of the containment being unisolated ranged from 0.39 (5th percentile) to 0.88 ( 95 th percentile) with a mean of 0.67 . This factor played a significant role in influencing the risk estimates of mid-loop operation. 


\section{Summary and Conclusions}

During the course of the study, Surry plant personnel made available new procedures for containment closure during mid-loop operation. While this response is encouraging in recognizing the need to reduce the vulnerability of the plant during mid-loop operation, it was difficult to assess the adequacy of these procedures in ensuring the pressure retaining capability of the containment within the time frame encompassed by this study. This feature contributed significantly to the uncertainty in containment status and the estimate of risk.

\section{Availability of Containment Sprays}

There is no requirement at Surry for the containment sprays to be available during shutdown. Plant records show that the spray systems could be inoperable because of maintenance. Spray availability was modeled as an uncertainty parameter in the risk analysis. Since the sprays perform an important safety function in mitigating the effects of releases, spray unavailability contributed both to the risk and its uncertainty.

\section{Possibility of Core Damage Arrest}

The inclusion of the possibility of arresting the core degradation process before vessel failure is an important feature of this analysis as it was for the full power study. Termination of the accident in-vessel can significantly reduce some of the fission product releases and thus the risk. The potential for core recovery depends on the nature of the accident progression and is different for the various PDS Groups. For PDS Group 1 (SBO events) the conditional probability of core damage arrest (conditional on core damage) ranges from 0.45 (5th percentile) to 0.71 (95th percentile) with a mean of 0.55 . The dominant factor affecting the arrest of core damage for this PDS Group is recovery of offsite power. For PDS Group 4 (loss of $4 \mathrm{kV}$ bus) the conditional probability of arresting core damage ranges from 0.03 (5th percentile) to 0.86 (95th percentile) with a mean of 0.59 . Recovery of the $4 \mathrm{kV}$ bus is the major factor for this PDS. Accidents in PDS Group 2 are attributable to human error and the conditional probability of arresting core damage for this PDS Group ranges from 0.39 ( 5 th percentile) to 0.45 (95th percentile) with a mean of 0.42 . Recovery for PDS Group 2 depends on the operators making a correct diagnosis or taking proper action. Accidents in PDS Group 3 are initiated by recirculation failure due to sump plugging and recovery of the recirculation system and arresting further degradation of the core was assumed to be not possible after core damage occurs. Overall, the conditional probability of core damage arrest ranged from 0.23 (5th percentile) to 0.44 (95th percentile) with a mean of 0.35 .

\section{Comparison with Full Power Study}

The results of the present study are compared with the results of the full power study in Chapter 10 . The comparison has shown that the mean core damage frequency for accidents during mid-loop operation is about an order of magnitude lower than the mean frequency of accidents caused by internal events at full power. In NUREG-1150, the 50 mile population dose ranged from about 5E-3 P-Sv/year (5th percentile) to 3E-1 PSv/year (95th percentile) with a mean of $6 \mathrm{E}-2 \mathrm{P}-\mathrm{Sv} /$ year. For mid-loop operation, the corresponding range is from 4E-3 P-Sv/year (5th percentile) to $2 \mathrm{E}-1 \mathrm{P}$-Sv/year (95th percentile) with a mean of 6E-2 P-Sv/year. What this finding implies is that the lower decay heat and lower radionuclide inventory of the mid-loop operating state, compared with full power, is offset by the likelihood of containment being unisolated. Finally, the mean risk of early health effects is over two orders of magnitude lower for accidents during mid-loop operation than for accidents during full power operation. This is due to the natural decay of those 
radionuclide species which have the greatest impact on early fatality risk because accidents during mid-loop operation occur a long time after shutdown.

\section{Comparison With the Safety Goals}

Comparison of the results of this study against the NRC safety goals is done for the two quantitative health objectives identified in the Commission's policy statement of August 1986. These objectives deal with individual early fatality and latent cancer fatality risks within 1 mile and 10 miles of the site, respectively. The numerical value of these objectives are given in Table 9.3. The 95th percentile of the distribution for individual latent cancer fatality risk presented in Chapter 9 (refer to Table 9.1) falls more than an order of magnitude below the objective. The 95 th percentile of the distribution for individual early fatality risk (refer to Table 9.1) falls over two orders of magnitude below the corresponding health objective. The health objectives, however, apply to the total risk of the Surry plant. The risk estimates of this study are for accidents initiated by internal events during mid-loop operation and therefore reflect only a fraction of the total risk at Surry. 


\section{DISTRIBUTION LIST}

Kiyoharu Abe

Dept. of Reactor Safety Research

Nuclear Safety Research Center

Tokai Research Establishment

JAERI

Tokai-mura, Naga-gun

Ibaraki-ken,

JAPAN

Sarbes Acharya

Department of Energy

NS-1/FORS

Washington, DC 20585

Dr. Ulvi Adalioglu

Cekmece Nukleer Arastraima ve

Egitim Merekezi

P.K. 1

Havaalani/ISTANBUL

TURKEY

Dr. Eng. Kiyoto Aizawa

Senior Engineer

Reactor Eng. Dev. Department

PNC

9-13, Chome, Akasaka

Minato-K, Tokyo

JAPAN

Harry Alter

Manager Applied Tech

Nuclear Systems Tech

NE-46

US DOE

Washington, DC 20585
R.M. Andrews

Nuclear Installations Insp.

St. Peters House

Balliol Raod, Bootle

Merseyside L20 31Z

UNITED KINGDOM

George Apostolakis

UCLA

Boelter Hall, Room 5532

Los Angeles, CA 90024-1597

Director of Reactor Engineering

Argonne National Laboratory

9700 S Cass Ave

Bldg 208

Argonne, IL 60439

Ephraim Asculai

Division of Nuclear Safety

Wagramestrasse, 5

P.O. Box 100

A-1400 Wien

AUSTRIA

Vladimar Asmolov

Head, Nuclear Safety Department

I. V. Kurchatov Institute of Atomic Enegry

Moscow, 123181

RUSSIA 
J. de Assuncao

Cabinete de Proteccao è

Seguranca Nuclear

Ministerio da Indusstria

Ave. de Republica 45-6

1000 Lisbon

PORTUGAL

H.P. Balfanz, Head

Institute of Probabilistic

Safety Analysis

TUV Nord

Grosse Bahnstrasse 31

D-22525 Hamburg 54

GERMANY

Pat Baranowsky

USNRC-AEOD/TPAB

MS: T-4A9

Robert A. Bari, Deputy Chairman

Dept of Nuclear Energy

Bldg 197C

Brookhaven National Laboratory

Upton, NY 11973

Librarian

Technical Information Section

Battelle Pacific Northwest Lab

P. O. Box 999

Richland, WA 99352

Dr. John Baum

Dept of Nuclear Energy

Radiological Sciences Div

Bldg $703 \mathrm{M}$

Brookhaven National Laboratory

Upton, NY 11973
Eric Beckjord

USNRC-RES/DO

MS: T-10F12

Robert Bernero

USNRC-NMSS/DO

MS: T-8A23

Andrea Besi

Institute for Systems Engineering and Informatics

CEC Joint Research Centre

CP N 1

1-21020 Ispra (Varese)

ITALY

John Bickel

Scientech, Inc.

12760 High Bluff Drive

Suite 310

San Diego, CA 92140

Vicki Bier

Dept. of Industrial Engineering

University of Wisconsin-Madison

1513 University Avenue, Room 389

Wisconsin, WI 53706

Scott Bigelow

S-CUBED

2501 Yale SE, Suite 300

Albuquerque, NM 87106 
Prof. Dr. Dr.-Ing. E. H. Adolf Birkhofer Gesellschaft für Anlagen und

Reaktorsicherheit (GRS) mbH

Forschungsgelände

D-8046 Garching

Federal Republic of Germany

David Black

American Electric Power

1 Riverside Plaza

Columbus, OH 43215

Harold Blackman

Idaho National Engineering Lab.

EG\&G MS: 3850

P.O. Box 1625

Idaho Falls, ID 83415-3850

Dennis Bley

Buttonwood Consulting

17291 Buttonwood St.

Fountain Valley, CA 92708

Roger Blond

Booz-Allen \& Hamilton

4330 East West Highway

Bethesda, MD 20814

M. P. Bohn

Division 6449

Sandia National Laboratories

Albuquerque, NM 87185

Dr. Mario Bonaca

Manager, Reactor Engineering

Northeast Utilities

P.O. Box 270

Hartford, Conn. 06141
Robert B. Borsum

Nuclear Power Division

B \& W Nuclear Tech

1700 Rockville Pike

Suite 525

Rockville, MD 20852

Stephen Boult

Electrowatt Engineering Services

(UK) Ltd.

Grandford House

16 Carfax, Horsham

West. Sussex RH12 IUP

ENGLAND

Gary Boyd

Safety \& Reliability Optimization

Services

9724 Kingston Pike, Suite 102

Knoxville, TN 37922

Brookhaven National Laboratory (11)

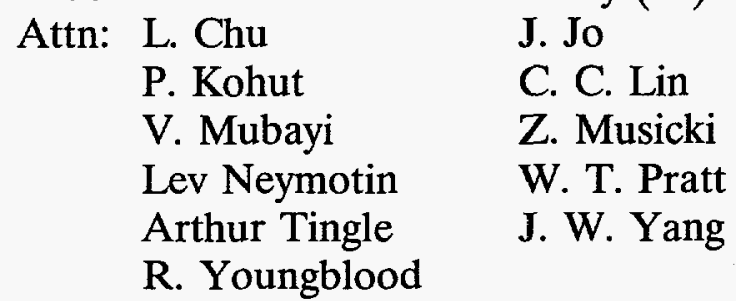

Building 130

P.O. Box 5000

Upton, NY 11973-5000

Brookhaven National Laboratory (15)

ATTENTION: B. Kponou

Building 130

P.O. Box 5000

Upton, NY 11973-5000 
David M. Brown

Paul C. Rizzo Associates, Inc. 300 Oxford Drive Monroeville, PA 15146-2347

Tom D. Brown

Sandia National Laboratories

Dept. 6413

P.O. Box 5800

Albuquerque, NM 87185

Robert J. Budnitz

Future Resources Associates, Inc. 2039 Shattuck Avenue, Suite 402 Berkeley, CA 94704

Gary Burdick

USNRC-RES/SAIB

MS: T-10F13

Arthur Buslik USNRC-RES/PRAB

MS: T-9F31

Edward Butcher USNRC-NRR/SPSB

MS: O-10E4

Technical Library

B\&W Nuclear Service Co

P. O. Box 10935

Lynchburg, VA 24506
Stefaan Caeymaex

Safety \& Systems Section

Nuclear Generation Dept.

TRACTEBEL

Avenue Ariane 7

B-1200 Bruxelles

BELGIUM

Leonard Callan, Administrator

U.S. Nuclear Regulatory Commission

Harris Tower and Pavilion

611 Ryan Plaza Drive, Suite 400

Arlington, TX 76011-8064

\section{J. Calvo}

Division of PSA \& Human Factors

Consejo de Seguridad Nuclear

Calle Justo Dorado, 11

28040 Madrid

SPAIN

A. L. Camp

Division 6412

MS: 0748

Sandia National Laboratories

Albuquerque, NM 87185-0748

John Forbes Campbell

HM Superintending Inspector

Health \& Safety Executive

St. Peter's House

Balliol Road

Bootle L20 31Z

UNITED KINGDOM 
Leonel Canelas

New University of Lisbon

Quinta de Torre

2825 Monte de Caparica

PORTUGAL

Harold Careway

General Electric Co., M/C 754

175 Curtner Ave.

San Jose, CA 95129

D. D. Carlson

Division 6411

Sandia National Laboratories

Albuquerque, NM 87185

Jose E. De Carlos

CSN International Coordinator

Consejo de Seguridad Nuclear

Calle Justo Dorado 11

28040 Madrid

SPAIN

Annick Carnino

International Atomic Energy Agency

Wagramerstrasse 5, P.O. Box 100

A-1400 Vienna

AUSTRIA

S. Chakraborty

Swiss Federal Nuclear Safety

Inspectorate

Hauptabteilung für die Sicherheit

der Kernanlagen

CH-5232 Villigen-HSK

SWITZERLAND
Erulappa Chelliah

USNRC-RES/PRAB

MS: T-9F31

Mike Cheok

NUS

910 Clopper Road

Gaithersburg, MD 20878

Nilesh Chokshi

USNRC-RES/SSEB

MS: T-10L1

Peter Cooper

SRD/AEA Technology

Wigshaw Lane

Culcheth

Cheshire WA3 4NE

England

Susan E. Cooper

Science Applications Int'l. Corp.

11251 Roger Bacon Drive

Reston, VA 22090

Michael Corradini

University of Wisconsin

1500 Johnson Drive

Madison, WI 53706

E.R. Corran

ANSTO Reasearch Establishment

Lucas Heights Reserch Labs.

Private Mail Bag 1

Manai, NSW 2234

AUSTRALIA 
Massimo Cozzone

A.N.P.A.

Via V. Brancati, 48

I-00144 Rome

ITALY

George Crane

1570 E. Hobble Creek Dr.

Springville, Utah 84663

Mark Cunningham

USNRC-RES/PRAB

MS: T-9F31

S. Daggupaty

Environment Canada

4905 Dufferin Street

Downsview

Ontario, M3H ST4

CANADA

Louise Dahlerup

Inspectorate of Nuclear Inst.

Danish Civil Defense \&

Emergency Planning Agency

16, Datavej

DK-3460 Birkerod

DENMARK

John Darby

SEA, Inc.

6100 Uptown Blvd. NE

Albuquerque, NM 87110

Gerald Davidson

Fauske and Associates, Inc.

16 W 070 West 83rd Street

Burr Ridge, IL 60521
Peter Davis

PRD Consulting

P.O. Box 2046

Sheridan, WY 82801

P. De Gelder

Secretary, BELGIAN NUCLEAR

SOCIETY (BNS)

A V Nuclear

Avenue du Roi 157

B-1060 Brussels

BELGIUM

Lennart Devell

Studsvik Nuclear

Studsvik Energiteknik AB

S-611 82 Nykoping

SWEDEN

J. Devooght

Service de la Metrologie Nucl

University Libre de Bruxelles

Faculte des Sciees Appliqu.

50 Avenue F-D Roosevelt

Bruxelles 5

BELGIUM

G. Diederick

Commonwealth Edison Co.

LaSalle County Station

RR1, Box 220

2601 North 21st Rd.

Marsielles, IL 61341

Chuck Dobbe

Idaho National Engineering Lab.

EG\&G MS: 3840

P.O. Box 1625

Idaho Falls, ID 83415 
Mary Drouin

USNRC-RESISAIB

MS: T-10F13

Dr. Romney Duffey, Chairman

Department of Advanced Technology

Brookhaven National Laboratory

P.O. Box 5000

Upton, New York 11973-5000

Duke Power Co. (2)

Attn: Duncan Brewer

Steve Deskevich

422 South Church Street

Charlotte, NC 28242

Bill Eakin

Northeast Utilities

Box 270

Hartford, CT 06141

Stewart D. Ebneter

USNRC

101 Marietta St., Suite 2900

Atlanta, GA 30323-0199

Adel A. El-Bassioni

USNRC-NRR/PRAB

MS: O-10E4

ENEA/DISP (2)

Attn: Alvaro Valeri Alfredo Bottino

Via Vitaliano Brancati, 48

00144 Roma EUR

ITALY
Walter P. Engel

PRAG MGR Analysis \& Reg Matter

NE-60

CRYCITY

US DOE

Washington, DC 20585

John Flack

USNRC-RES/SAIB

MS: T-10F13

Karl Fleming

Pickard, Lowe \& Garrick

2260 University Drive

Newport Beach, CA 92660

Terry Foppe

Safety Analysis Engineering

Rocky Flats Plant

Energy Systems Group

Rockwell International Corp

P.O. Box 464

Golden, CO 80401

R H. Gauger

Manager-Reliability Engr

A/E Div

Holmes \& Narver Inc.

R Roanne Circle

Irvine, CA 92714

Robert Gobel

Clark University

Center for Technology, Environment and Development

950 Main St.

Worcester, MA 01610-1477 
Paul Govaerts

Studiecentrum voor Kernenergie

(SCK/CEN)

Boeretang, 200

B-2400 Mol

BELGIUM

Mr. Gubler

International Atomic Energy Agency

NENS/SAD BO842

Wagramerstrasse 5, P.O. Box 100

A-1140 Vienna

AUSTRIA

Paul M. Haas, President

Concord Associates, Inc.

725 Pellissippi Parkway

Suite 101, Box 6

Knoxville, TN 37933

F. T. Harper

Division 6413

MS: 0748

Sandia National Laboratories

Albuquerque, NM 87185-0748

Dr. U. Hauptmanns

Gesellschaft Für Anlagen und

Reaktorsicherheit (GRS) $\mathrm{mgH}$

Schwertnergasse 1

D-5000 Köln 1

GERMANY

Sharif Heger

UNM Chemical and Nuclear

Engineering Department

Farris Engineering, Room 209

Albuquerque, NM 87131
Jon C. Helton

Dept. of Mathematics

Arizona State University

Tempa, AZ 85287

Dr. P. M. Herttrich

Gesellschaft für Anlagen und

Reaktorsicherheit (GRS) mbH

Schwertnergasse 1

5000 Köln 1

GERMANY

Dr. D.J. Higson

Radiological Safety Bureau

Australian Nuclear Science \&

Technology Organisation

P.O. Box 153

Roseberry, NSW 2018

AUSTRALIA

Dr. Mitsumasa Hirano

Deputy General Manager

Institute of Nuclear Safety

NUPEC

3-6-2, Toranomon, Minato-ku

Tokyo 108

JAPAN

Dr. S. Hirschberg

Paul Scherrer Institute

Vurenlingen and Villigen

CH-5232 Villigen PSI

SWITZERLAND

Steven Hodge

Oak Ridge National Laboratories

P. O. Box Y

Oak Ridge, TN 37831 
Gary Holahan

USNRC-AEOD/OSP

MS: T-4A9

N.J. Holloway

A72.1

Atomic Weapons Establishment

Ademaston

Reading RG7 4PR

UNITED KINGDOM

Griff Holmes

Westinghouse Electric Co.

Energy Center East

Bldg. 371

P.O. Box 355

Pittsburgh, PA 15230

William Hopkins

Bechtel Power Corporation

15740 Shady Grove Road

Gaithersburg, MD 20877

Dean Houston

USNRC-ACRS

MS: P-315

Der-Yu Hsia

Institute of Nuclear Energy Research

Lung-Tan 325

TAIWAN

Alejandro Huerta-Bahena

National Commission on Nuclear

Safety and Safeguards (CNSNS)

Insurgentes Sur N. 1776

C. P. 04230 Mexico, D. F.

MEXICO
Peter Humphreys

US Atomic Energy Authority

Wigshaw Lane, Culcheth

Warrington, Cheshire

UNITED KINGDOM, WA3 4NE

W. Huntington

Commonwealth Edison Co.

LaSalle County Station

RR1, Box 220

2601 North 21st Rd.

Marsielles, IL 61341

J.S. Hyslop

USNRC-RES/PRAB

MS: T-9F31

Idaho National Engineering Lab. (2)

Attn: Doug Brownson

Darrel Knudson

EG\&G MS: 3840

P.O. Box 1625

Idaho Falls, ID 83415

Idaho National Engineering Lab. (2)

Attn: Art Rood

Mike Abbott

EG\&G MS: 2110

P.O. Box 1625

Idaho Falls, ID 83415

Hanspeter Isaak

Abteilung Strahlenschutz

Hauptabteilung für die Sicherheit

der Kernanlagen (HSK)

CH-5303 Wurenlingen

SWITZERLAND 
Brian Ives

UNC Nuclear Industries

P. O. Box 490

Richland, WA 99352

Kamiar Jamili

DP-62/FTN

Department of Energy

Washington, D.C. 20585

Robert Jones

USNRC-NRR/DSSA

MS: O-8E1

Edward Jordan

USNRC-AEOD/DO

MS: T-4D18

Dr. H. Kalfsbeek

DG/XII/D/1

Commission of the European

Communities

Rue de la Loi, 200

B-1049 Brussels

BELGIUM

Yoshio Kano

General Mngr. \& Sr. Engineer

Systems Analysis Section

O-arai Engineer. Centr, PNC

Higashi-Ibaraki-gun

Ibaraki-Ken, 133-13

JAPAN

William Kastenberg

UCLA

Boelter Hall, Room 5532

Los Angeles, CA 90024
Barry Kaufer

OECD/NEA

"Le Seine St. Germain" 12

Boulevard des Iles

92130 Issy-les-Moulineaux

FRANCE

Paul Kayser

Division de la Radioprotection

Avenue des Archiducs, 1

L-1135 Luxembourg-Belair

LUXEMBOURG

Ken Keith

TVA

W 20 D 201

400 West Surmnit Hill

Knoxville, TN 37092

G. Neale Kelly

Commission of the European

Communities

Joint Research Centre

Rue de la Loi 200

B-1049 Brussels

BELGIUM

John Kelly

Sandia National Laboratories

P. O. Box 5800

MS 0742

Albuquerque, NM 87185

Knolls Atomic Power Laboratory (2)

Attn: Ken McDonough

Dominic Sciaudone

Box 1072

Schenectady, NY 12301 
Dr. K. Koberlein

Gesellschaft für

Reaktorsicherheit mbH

Forschungsgelände

D-8046 Garching

GERMANY

Alan Kolaczkowski

Science Applications International

Corporation

2109 Air Park Rd. S. E.

Albuquerque, NM 87106

Jim Kolanowski

Commonwealth Edison Co.

35 1st National West

Chicago, IL 60690

John G. Kollas

Institute of Nuclear Technology and

Radiation Protection

N.R.C.P.S. "Demokritos"

P.O. Box 60228

GR-153 10 Aghia Paraskevi

Attiki

GREECE

S. Kondo

Department of Nuclear Engineering

Facility of Engineering

University of Tokyo

3-1, Hongo 7, Bunkyo-ku

Tokyo

JAPAN
D. Lamy

CEN/SCK

Dept. Scientific Irradiation

Experiment \& Study BR2

Boeretang, 200

B-2400 Mol

BELGIUM

Dr. J.M. Lanore

CEA/IPSN/DAS

Centre d'Etudes Nucléaires de

Fontenay-aux-Roses

B.P. $\mathrm{n}^{\mathrm{o}} 6$

92265 Fontenay-aux-Roses CEDEX

FRANCE

Jose A. Lantaron

Consejo de Seguridad Nuclear

Sub. Analisis y Evaluaciones

Calle Justo Dorado, 11

28040 Madrid

SPAIN

Josette Larchier-Boulanger

Electricte de France

Direction des Etudes Et Recherches

30, Rue de Conde

75006 Paris

FRANCE

H. Larsen

Head of Department

Riso National Laboratory

P.O. Box 49

DK-4000 Roskilde

DENMARK 
Lawrence Livermore Nat'l Lab. (4)

Attn: George Greenly

Marvin Dickerson

Rolf Lange

Sandra Brereton

Livermore, CA 94550

Shengdar Lee

Yankee Atomic Electric Company 580 Main St.

Boston, MA 17407

B.T.F. Liwaang

Dept. of Plant Safety Assessment

Swedish Nuclear Power Inspec.

P.O. Box 27106

S-10252 Stockholm

SWEDEN

Peter Lohnberg

Expresswork International, Inc.

1740 Technology Drive

San Jose, CA 95110

Steven M. Long

USNRC-NRR/SPSB

MS: O-10E4

D. Eugenio Gil Lopez

Consejo de Seguridad Nuclear

Calle Justo Dorado, 11

28040 Madrid

SPAIN

Los Alamos National Laboratory (2)

Attn: Kent Sasser

N-6, K-557

Los Alamos, NM 87545
Christiana H. Lui

USNRC-RES/PRAB

MS: T-9F31

John Luke

Florida Power \& Light

P.O. Box 14000

Juno Beach, FL 33408

Daniel Manesse

ISPN

Boite Postale $n^{\circ} 6$

92265 Fontenay-aux-Roses CEDEX

FRANCE

Fred Mann

Westinghouse Hanford Co.

WIA-53

P.O. Box 1970

Richland, WA 99352

Nadia Soido Falcao Martins

Comissao Nacional de Energia Nuclear

R General Severianao 90 S/408-1

Rio de Janeiro

BRAZIL

Harry F. Martz

Analysis and Assessment Division

Los Alamos National Laboratory

Los Alamos, NM 87545

Herbert Massin

Commonwealth Edison Co.

35 1st National West

Chicago, IL 60690 
Hideo Matsuzuru

Tokai Research Establishment

Tokai-mur

Maka-gun

Ibaraki-ken, 319-11

JAPAN

Jim Mayberry

Ebasco Services

60 Chubb Ave.

Lyndhurst, NJ 07071

Andrew S. McClymont

IT-Delian Corporation

1340 Saratoga-Sunnyvale Rd.

Suite 206

San Jose, CA 95129

Michael McKay

Los Alamos National Laboratory

A-1, MS F600 Services

P.O. Box 1663

Los Alamos, NM87545

Zen Mendoza

SAIC

5150 El Camino Real

Suite C3 1

Los Altos, CA 94022

Dr. J. Mertens

Division of Risk Analysis \&

Reactor Technology

Institute of Safety Research

Research Centre Julich (KFA)

D-52425 Julich

GERMANY
Jim Meyer

Scientech

11821 Parklawn Dr.

Suite 100

Rockville, MD 20852

Joe Minarick

Science Applications Int'l Corp.

301 Laboratory Road

P.O. Box 2501

Oak Ridge, TN 37830

Jose I. Calvo Molins, Head

Division of P.S.A. and Human Factors

Consejo de Seguridad Nuclear

Calle Justo Dorado, 11

28040 Madrid

SPAIN

Ken Muramatsu

Risk Analysis Laboratory

Japan Atomic Energy Research Institute

Tokai-mura, Naka-gun

Ibaraki-ken, 319-11, Tokyo

JAPAN

Joseph A. Murphy

Division of Safety Issue Resolution

U.S. Nuclear Regulatory Commission MS: T-10E50

Washington, DC 20555

Kenneth G. Murphy, Jr.

US Department of Energy

19901 Germantown Rd.

Germantown, MD 20545 
Shankaran Nair

Central Electricity

Generating Board

Berkeley Nuclear Laboratories

Berkeley

Gloucestrshire CL13 9PB

UNITED KINGDOM

Ray Ng

NEI

1776 Eye St. N

Suite 300

Washington, DC 20006-2496

G. Niederauer

Los Alamos National Laboratory

P. O. Box 1663

MSK 575

Los Alamos, NM 87545

Oak Ridge National Laboratory (2)

Attn: Steve Fisher

Sherrel Greene

MS-8057

P.O. Box 2009

Oak Ridge, TN 37831

Ken O'Brien

University of Wisconsin

Nuclear Engineering Dept.

153 Engineering Research Blvd.

Madison, WI 53706

Theresa Oh

INEL Tech Library

EG\&G MS: 2300

P. O. Box 1625

Idaho Falls, ID 83415-2300
N. R. Ortiz, Director

Nuclear Energy Technology

Division 6400

Sandia National Laboratories

Albuquerque, NM 87185

Robert Ostmeyer

U.S. Department of Energy

Rocky Flats Area Office

P. O. Box 928

Golden, CO 80402

Robert Palla

USNRC-NRR/SPSB

MS: O-10E4

Gareth Parry

NUS Corporation

910 Clopper Rd.

Gaithersburg, MD 20878

Vern Peterson

Building T886B

EG\&G Rocky Flats

P.O. Box 464

Golden, CO 80402

G. Petrangeli

ENEA Nuclear Energy ALT Disp

Via V. Brancati, 48

00144 Rome

ITALY 
Ing. Jose Antonio Becerra Perez

Comision Nacional De Seguridad

Nuclear Y Salvaguardias

Insurgentes Sur 1806

01030 Mexico, D. F.

MEXICO

Urho Pulkkinen

Technical Research Centre of

Finland

Laboratory of Electrical \&

Automation Engineeering

Otakaari 7B, 02150 Espoo 15

FINLAND

Blake Putney

Science Applications

International Corporation

5150 El Camino Real, Suite C31

Los Altos, Ca 94022

Dr. V. M. Raina

Project Manager-Risk Assessment

Ontario Hydro H11 G1

700 University Ave.

Toronto, Ontario M5G 1X6

CANADA

William Raisin

NEI

1726 M. St. NW

Suite 904

Washington, DC 20036

Ann Ramey-Smith

USNRC-RES/PRAB

MS: T-9F31
Dale Rasmuson

USNRC-AEOD/TPAB

MS: T-4A9

John Ridgely

USNRC-RES/SAIB

MS: T-10F13

Richard Robinson (2)

USNRC-RES/PRAB

MS: T-9F31

M. Roch

Manager of Design, Nuclear

Department

TRACTEBEL

Avenue Ariane 7

B-1200 Bruxelles

BELGIUM

A.E. Rogers

General Electric Co

175 Curtner Ave

MC-489

San Jose, CA 95125

Judy Rollstin

GRAM Inc

8500 Menual Blvd. NE

Albuquerque, NM 87112

Marc Rothschild

Halliburton NUS

1303 S. Central Ave.

Suite 202

Kent, WA 98032 
Christopher Ryder

USNRC-RES/PRAB

MS: T-9F31

Takashi Sato, Deputy Manager

Nuclear Safety Engineering Section

Reactor Design Engineering Dept.

Nuclear Energy Group, Toshiba Corp.

Isogo Engineering Center

8, Shinsugita-cho, Isogo-ku,

Yokohama 235, JAPAN

Martin Sattison

Idaho National Engineering Lab.

P. O. Box 1625

Idaho Falls, ID 83415

Dr. U. Schmocker

Hauptabteilung für die

Sicherheit der Kernanlagen

CH-5232 Villigen HSK

SWITZERLAND

A.J. Seebregts

ECN Nuclear Energy

Westerduinweg, 3

Postbus 1

NL-1755 Petten ZG

THE NETHERLANDS

Dr. S. Serra

Ente Naxionale per I'Energia

Electtrica (ENEL)

via G.B. Martini 3

I-00198 Rome

ITALY
H. Shapiro

Licensing \& Risk Branch

Atomic Energy of Canada Ltd.

Sheridan Park Research Comm.

Mississauga, Ontario L5K 1B2

CANADA

Nathan O. Siu

Center for Reliability and Risk

Assessment

Idaho National Engineering Lab.

EG\&G MS: 3850

P.O. Box 1625

Idaho Falls, ID 83415-3855

E. Soederman

ES-Konsult AB

Energy and Safety

P.O. Box 3096

S-16103 Bromma

SWEDEN

Desmond Stack

Los Alamos National Laboratory

Group Q-6, Mail Stop K556

Los Alamos, NM 87545

Jao Van de Steen

KEMA Laboratories

Utrechtseweg, 310

Postbus 9035

NL 800 ET Arnhem

THE NETHERLANDS

Eli Stern

Israel AEC Licensing Div.

P.O. Box 7061

Tel-Aviv 61070

ISRAEL 
Dr. Egil Stokke

Advisory Group

OECD Halden Reactor Project

P.O. Box 173

N-1751 Halden

NORWAY

Stone \& Webster Engineering Corp

Technical Information Center

A. Hosford

245 Summer Street

245/01

Boston, MA 02210

Dennis Strenge

Pacific Northwest Laboratory

RTO/ 125

P.O. Box 999

Richland, WA 99352

Technadyne Engineer. Consultants (3)

Attn: David Chanin

Jeffery Foster

Walt Murfin

Suite A225

8500 Menual Blvd. N

Albuquerque, NM 87112

Ashok Thadani

USNRC-NRR/ADT

MS: O-12G18

T. G. Theofanous

University of California, S. B.

Department of Chemical and Nuclear Engineering

Santa Barbara, CA 93106
Catherine Thompson

USNRC-RES/SAIB

MS: T-10F13

Soren Thykier-Nielsen

Riso National Laboratory

Postbox 49

DK4000 Roskile

DENMARK

R. Toossi

Physical Research, Inc.

25500 Hawthorn Blvd.

Torrance, CA 90505

Ennio Traine

ENEL

Via Vialiano, 48

00144 Rome

ITALY

Ulf Tveten

Environmental Physics Section

Institutt for Energiteknikk

Postboks 40

N-2007 Kjeller

NORWAY

US Department of Energy

Energy Library

Room G 034/GTN

AD-622.1

Washington, DC 20585 
US Department of Energy

NS-50 (GTN)

NS-10.1

S-161

Washington, DC 20585

U.S. Environmental

Protection Agency (2)

Attn: Allen Richardson

Joe Logsdon

Office of Radiation Programs

Environmental Analysis Division

Washington, DC 20460

Harold VanderMolen

USNRC-RES/PRAB

MS: T-9F31

Dr. A. Valeri

A.N.P.A.

Via Vitaliano Brancati, 48

I-00144 Rome

ITALY

Magiel F. Versteeg

Ministry of Social Affairs and Employment

P.O. Box 90804

2509 LV Den Haag

THE NETHERLANDS

Martin Virgilio

USNRC-NRR/DSSA

MS: O-8E2
R. Virolainen, (Chairman PWG5)

Systems Integ. Off. (STUK)

P.O. Box 268

Kumpulanite 7

SF-60101 Helsinki

FINLAND

Seppo Vuori

Technical Research Centre of Finland

Nuclear Engineering Laboratory

Lonnrotinkatu 37

P.O. Box 169

Sf-00181 Helsinki 18

FINLAND

Dr. Ian B. Wall

81 Irving Avenue

Atherton, CA 94027

Edward Warman

Stone \& Webster Engineering Corp.

P.O. Box 2325

Boston, MA 02107

J.E. Werner

Reactor Research \& Techn Division

US DOE Idaho Operations

MS: 1219

850 Energy Drive

Idaho Falls, ID 83401-1563

Dr. Wolfgang Werner

Safety Assessment Consulting $\mathrm{GmbH}$

Veilchenweg 8

D 83254 Breitbrunn

GERMANY 
Westinghouse Electric Corp

Technical Library

P. O. Box 355

East 209

Pittsburgh, PA 15230

Westinghouse Electric Corp

NTD

Central File Nuclear Safety

P. O. Box 355

408 1-A

Pittsburgh, PA 15230

Westinghouse Electric Company (3)

Attn: John Lacovin

Burt Morris

Griff Holmes

Energy Center East, Bldg. 371

P.O. Box 355

Pittsburgh, PA 15230

Westinghouse Savannah River Co. (2)

Attn: Kevin O'Kula

Jackie East

Safety Technology Section

1991 S. Centennial Ave., Bldg. 1

Aiken, SC 29803

Donnie Whitehead

Department 6412, MS: 0747

Sandia National Laboratories

P.O. Box 5800

Albuquerque, NM 87185-0747
Keith Woodard

PLG, Inc.

7315 Wisconsin Ave.

Suite 620 East

Bethesda, MD 20814-3209

John Wreathall

John Wreathall \& Co.

4157 MacDuff Way

Dubin, $\mathrm{OH} 43017$

M. K. Yeung

University of Hong Kong

Mechanical Engineering Dept.

Polfulam

HONG KONG

Carlo Zaffiro

A.N.P.A.

Directorate for Nuclear

Via Vitaliano Brancate, 48

I-00144 Rome

ITALY

Dr. X. Zikidis

Greek Atomic Energy Comm.

N.R.C.P.S. "Demokritos"

GR-153 10 Agia Paraskevi

Attiki

GREECE 


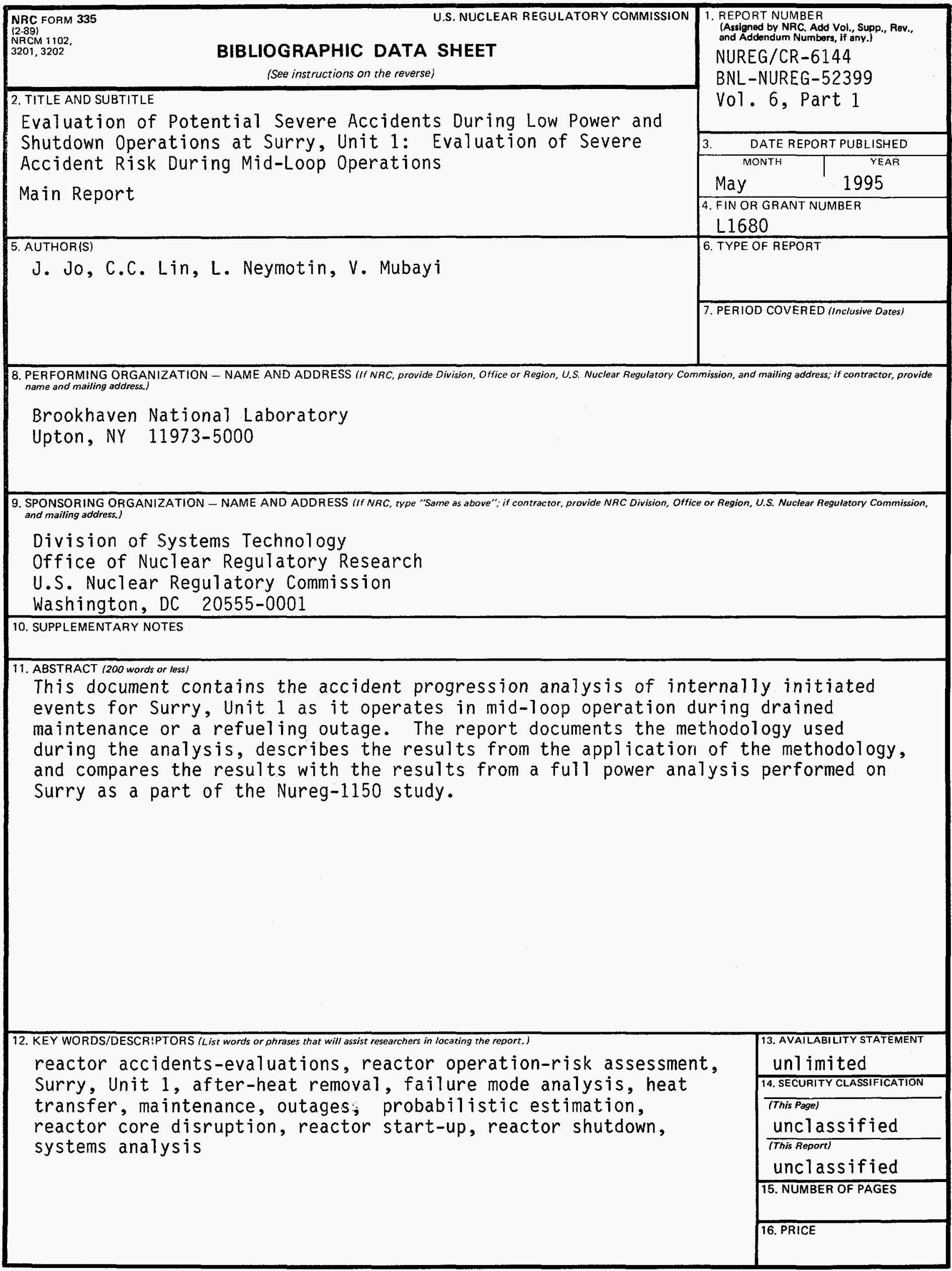

